\title{
Exploring Factors Influencing Heart Failure Readmission
}

Mee Young Sowa

Ruckersville, Virginia

BSN, University of Virginia, 2009

MSN, University of Virginia, 2012

A Capstone Presented to the Graduate Faculty of the University of Virginia in Candidacy for the Degree of

Doctor of Nursing Practice

\author{
School of Nursing \\ University of Virginia \\ August 12, 2015
}

Arlene Keeling, PhD, RN, FAAN

Signature of Chair

$\underline{\text { Catherine Kane, PhD, RN, FAAN }}$

Signature of Member

$\underline{\text { Juanita Reigle, MSN, ACNP-BC }}$

Signature of Member

Craig Thomas, MSN, ACNP-BC

Signature of Member 


\begin{abstract}
Heart Failure (HF) readmission is complicated and influenced by multiple factors. Few studies have directly investigated patients' perspectives regarding reasons for HF readmission. The purpose of this descriptive qualitative study was to examine the experiences of persons who were readmitted to a mid-Atlantic medical center for all causes within 30 days of discharge from the initial hospitalization with HF. Nine HF patients over 50 years of age were recruited to complete a semi-structured interview (HSR \#17345). The participants described the reasons they believe they were readmitted and they shared their insight into how they believe they could have prevented readmission. A review of the medical record was performed to collect demographic, clinical, diagnostic, and post discharge activity. The interview utilized five open-ended questions on etiology, self-care, and decision-making on seeking care, education/treatment, and input for prevention. Several themes emerged: inevitable or unavoidable readmission due to the severity of the condition; optimal self-care adherence; symptom monitoring and taking action with family and provider's support; heart failure readmission decision appreciated as a shared result of wellcoordinated transitional care; appreciation for evidence based programs; and patient satisfaction regarding self-care teaching. The readmission trend in the current study reflected the challenges from the patients' severity of condition and population characteristics that are faced by an academic teaching hospital. The nine participants voiced satisfaction, which exemplified the high quality of inpatient care (teaching, optimization of treatment, and discharge planning) and seamless transitional care from collective evidence based interventions, although their readmissions were not prevented. The findings of this study can assist clinicians by including patients' perspectives in evidence based interventional strategies for reducing HF readmission. Keywords: readmissions, heart failure, qualitative research, patient perspectives, transitional care
\end{abstract}




\section{Acknowledgements}

I would like to acknowledge the members of my Capstone committee for their guidance and mentorship. Professor Arlene Keeling, my advisor and committee chair, believed in me, encouraged me, and guided me through my Master's and Doctor of Nursing Practice programs. She continues to support me with my pursuit of my professional career goals. Dr. Catherine Kane provided me with invaluable guidance for developing my Capstone proposal. Professor Juanita Reigle and Mr. Craig Thomas were always available for me and guided my clinical practica and this Capstone project. Dr. Myra Clark provided invaluable assistance with revising the interview questions and theoretical framework. All of these individuals are my role models for my professional career. Special thanks to all faculty members, staff and classmates at the University of Virginia, and all my acquaintances and students for their encouragement and support during my journey. A very special recognition to the patients who agreed to participate in this study, conducting the interviews despite their ailments, in order to provide valuable input for the benefit of future patients. And, a special thank you to my relatives and family members, William, Elle, and Leo for their supporting and believing in me. I was truly blessed to have all of you next to me on my path. I dedicate this Capstone to my deceased parents who never had an opportunity for a higher education. 


\section{Table of Contents}

$\begin{array}{ll}\text { Section I: Introduction } & 5\end{array}$

Section II: Review of Literature $\quad 9$

$\begin{array}{ll}\text { Section III: Methods } & 26\end{array}$

$\begin{array}{ll}\text { Section IV: Findings } & 33\end{array}$

$\begin{array}{ll}\text { Section V: Discussion } & 45\end{array}$

$\begin{array}{ll}\text { References } & 67\end{array}$

$\begin{array}{ll}\text { Appendix A: Figures } & 83\end{array}$

Appendix B: Description of Literature $\quad 86$

$\begin{array}{ll}\text { Appendix C: Patient Interview Questions } & 114\end{array}$

Appendix D: Chart Review Guide 115

Appendix E: Informed Consent Patient Participants 118

Appendix F: Institutional Review Board Approvals $\quad 124$

Appendix G: Table: Demographic Characteristics 128

Appendix H: Instructions for Authors, Heart \& Lung 129

Appendix I: Draft Manuscript 143 


\section{Exploring Factors Influencing Heart Failure Readmission}

\section{Section I: Introduction}

\section{Overview of the Problem}

Heart failure (HF) is a clinical syndrome characterized by the impaired cardiac pump function either with a problem of left ventricular filling or ejection. The prevalence of HF continues to increase, making this disease a major public health problem. Currently, HF affects 6.5 million people in the United States. With the aging of the U.S. population, the impact of HF will continue to expand (Heidenreich et al., 2013). Heidenreich and colleagues estimated that by 2030 more than 8 million people ( 1 in 33) will be diagnosed with HF. In addition, the total annual direct medical cost for HF will increase from $\$ 21$ billion today to $\$ 53$ billion by 2030 .

The term hospitalization for HF is defined as a new onset or worsening signs and symptoms of HF requiring urgent therapy and resultant hospitalization (Gheorghiade, Vaduganathan, Fonarow, \& Bonow, 2013). Among Medicare beneficiaries, readmission for all causes within 30 days following HF hospitalization approaches about 25\% (Hersh, Masoudi, \& Allen, 2013). As of October 2012, Centers for Medicare and Medicaid Services (CMS) began reducing Medicare payments to hospitals with excessive HF readmissions. CMS also began providing incentives for hospitals to develop innovative approaches to reduce HF readmissions (Kansagara et al., 2011; Tao, Ellenbecker, Chen, Zhan, \& Dalton, 2012). Thus, HF is the leading cause of rehospitalization. HF hospitalization has become a focal point for quality improvement (Boutwell et al., 2011; Bradley et al., 2012; Jack et al., 2009), and reducing readmission is a key policy initiative embedded in the Patient Protection and Affordable Care Act (Stephens et al., 2013). 
HF readmission is costly and challenging: avoiding HF patients' readmissions has been a major goal of health care systems, due to the significant burden on both patients and payers. However, the causes of HF readmission are not well-understood (Retrum et al., 2013). In order to prevent avoidable HF rehospitalization, the factors that contribute to this phenomenon must be identified, so that effective prevention strategies can be developed. Most hospitals have quality improvement teams and implement evidence based practices to reduce preventable readmissions for patients with HF (Bradley et al., 2012).

A goal of Health People 2020 is to reduce hospitalizations for older adults with HF (Healthy People, 2011). Elective admissions are not counted as readmissions by CMS. However, unplanned hospital admissions (UHA) are a problem for health systems, as UHA are costly. In order to reduce the burden on health care and administer efficient resource utilization, clinicians must manage UHA effectively. However, Collins et al. (2013) suggest that most HF patients are hospitalized without a clear need for time-sensitive therapies or procedures. The majority of patients are not in need of acute intervention beyond congestion management. Many HF hospitalizations are driven by gaps in the process of care rather than worsening pathophysiology or a marker of high risk. Every organization must develop a process to determine whether each rehospitalization for HF patients reflects a limited capacity of the patient, provider, or health care system, in order to find opportunities for improvement.

HF readmission is increasingly being used as a quality metric and outcome measure in HF research (Gheorghiade et al., 2013). However, despite recent public attention given to reducing HF readmission, HF readmission is still an understudied phenomenon. There is a gap in research and practice. That is, most HF risk prediction models based on the results of quantitative studies perform poorly (Hersh et al.; Kansagara et al., 2011). The research evidence 
on interventional strategies in reducing HF readmission is still weak (Hansen, Young, Hinami, Leung, \& Williams, 2011). In order to assess the HF readmission phenomenon more fully, researchers and clinicians must collaborate and include the patients' viewpoint in the evaluation of why the patient was readmitted to the hospital.

\section{The Purpose of this Study}

HF readmission is complicated and influenced by multiple factors. Therefore, the primary purpose of this Capstone project was to increase knowledge of the reasons for HF readmission from the patient's perspective. This project aimed to describe trends and patterns of HF readmissions and gain insight for reducing HF readmission.

\section{Research Question}

The following questions directed this process:

1. What factors are identified by HF patients (and their caregivers) that contribute to readmission following inpatient treatment for HF?

2. What barriers and potential causes for readmission can be identified in the patients' medical records?

To answer these questions, a qualitative study based on in-depth patient interviews and medical record review was conducted at this mid-Atlantic tertiary care medical center.

\section{Conceptual Model}

Conceptual frameworks not only provide a structure for the planning and delivery of interventions, but can also guide the research. In order to understand the phenomenon of HF readmission, this study attempted to integrate several theoretical frameworks (see Figure A1, Appendix A) that could describe the phenomenon of HF readmission, by incorporating several constructs that emerged from the literature review. Thirty day readmission is defined as an 
admission for all causes (e.g., myocardial infarction, heart failure, and pneumonia) within 30 days of discharge from the index hospitalization into inpatient units at this mid-Atlantic medical center for persons over 50 years old with a primary discharge diagnosis of heart failure.

Donabedian's model (Donabedian, 1968) captures three major concepts: structure (the context in which care is delivered), process (the transactions between patients and providers throughout the delivery of healthcare), and outcome (effects of healthcare on the health status of the patients). This conceptual model provides a basic framework for examining the HF readmission phenomenon in terms of quality of care given to patients with HF, where patients navigate the health care system in time and environment.

The Health Belief Model (HBM) is congruent with HF self-care adherence, the most emphasized concept in HF educational interventions to prevent HF readmission. In HBM, HF self-care adherence (or decision-making in seeking care or delay seeking care) depends on the patient's perceived benefits (or barriers) for behavioral change or 'cues to action' given from the social network including caregivers.

Heart failure is chronic in nature; thus, the HF Illness Trajectory Model (adapted from the Corbin and Strauss chronic illness trajectory model, Corbin, 1998) is useful in addressing the downward trajectory of heart failure in a time and environmental context in which patients and healthcare providers interact and make decisions to manage the course of the disease (e.g., treatment goal adjustment).

Finally, the Explanatory Model (McSweeney \& Allan, 1997: adapted from Kleinman, 1978) was added to reword the interview questions developed by the investigator. This model allows clinicians to consider the patients' socio-cultural perspectives in clinical encounters (e.g., interview about illness experience, self-care adherence, and decision-making process for service 
utilization behavior). These four theoretical models guided the interview, chart review, and analysis (see Figure A1, Appendix A).

The conceptual framework proposed by this study may provide insight into patients' responses (from interview data) to self-care management (e.g., barriers to adherence, and seeking or delayed seeking care in response to symptom recognition and need) and decision-making of resource utilization (i.e., keeping follow-up appointments, Emergency Department visit, or hospitalization). The qualitative analysis of the patients' chart reviews may not only provide better knowledge on the patients' characteristics grounded from literature review (e.g., risk factors by Gruneir et al., 2011 and by Anderson, 2013), but also provide some insights into providers' perspectives on reasons for readmission and how to improve the quality of care in terms of the clinician's adherence to CMS recommendation for improving discharge coordination and education for HF patients and their caregivers (Holland, Mistiaen, \& Bowles, 2011; Jack et al., 2009; Kirk, Prasad, \& Aldelhafiz, 2006; Mulder, Tzeng, \& Vecchioni, 2012).

\section{Section II: Review of the Literature}

\section{The Problem and Researching for a Solution}

Quantitative research on HF is abundant with efforts to reduce HF readmission; however, most of the research focuses on interventional strategies to improve self-care adherence as part of a HF disease management program (e.g., effectiveness of telemonitoring intervention) or to improve discharge coordination and transitional care (Hansen et al., 2011; Riegel et al., 2009). Another trend in HF research reflects recent quality improvement initiatives to contain health care cost. Many researchers developed HF readmission risk prediction tools by utilizing administrative or clinical data (Kansagara et al., 2011). Predicting hospital readmission risk is important to identify which patient would benefit most from resource-intensive interventions or 
care transition interventions. Several prediction models for HF readmission have been validated and published, but the state of risk prediction in HF readmission still remains crude and within the domain of clinical researchers (Hersh et al., 2013). These validated statistical models have been primarily used to compare hospital outcomes or to evaluate patients' needs for advanced treatment options (Kansagara et al., 2011). However, thus far, the findings from these quantitative studies have not provided any answers to the questions of why readmissions occur, or what can be done for individual patients to avoid HF readmission. Researchers and health care providers should integrate patient perspectives into this inquiry of HF readmission. Therefore, the purpose of this literature review was to examine current research focusing on HF readmission and to identify the impact of gaps in current knowledge about factors influencing HF readmission.

\section{The Literature Search}

An integrative review was conducted using MEDLINE, CINAHL, Google Scholar, and ancestry search. It included qualitative and non-experimental quantitative studies (Whittemore \& Knafl, 2005) in order to gather current evidence on factors influencing HF readmission. The timeframe for the database search strategy was January 2000 through November 2013. Studies written in foreign languages (i.e., non-English) were excluded for this review. A series of literature searches were conducted using a combination of 'heart failure' or 'congestive heart failure' and another key search term (see Figure A2, Appendix A). The final number of articles that met the criteria for the literature review was 31 (19 qualitative, 6 mixed methods, and 6 quantitative studies). Final inclusion criteria for the qualitative articles included the rigor of the study (i.e., authors' effort to explain methods for sampling, collecting, analyzing, and interpreting data to enhance the credibility of the study), or having the theoretical framework or 
interview guide. The quantitative studies were selected based on the practicability of the instruments (e.g., simplicity of prediction tools or survey questions) for bedside clinicians to utilize to assess or to intervene patients' needs to reduce HF readmission.

\section{Critique}

Across studies, the variables under investigation (e.g., HF readmission or self-care adherence) were not clearly defined, and it was assumed that readers would understand them as part of the research questions. In the six studies utilizing a mixed method, the variables of interest were defined, and the validity and reliability of instruments used for the quantitative part were reported. As inclusion criteria, the persons with HF or other heart condition were specified; however, only 13 out of 31 studies defined HF by using any clinical definition, such as the New York Heart Association classification to describe the study participants. For the qualitative interview schedule, no validity or reliability statistics were reported.

Overall, the strengths of the qualitative studies analyzed in the current review included: using purposive sampling, using multiple data collection setting, having a good sample size, substantial efforts in articulating the significance of the research problem, and utilizing theoretical frameworks and mixed methods in order to provide meaning to the findings of the studies. However, several studies had limitations in literature coverage, in reporting on how to develop interview guides, and on efforts to enhance the credibility of qualitative data.

In summary, from this literature synthesis, few studies (Annema, Luttik, Jaarsma, 2009; Hekmatpou, Mohammadi, Ahmadi, \& Arefi, 2009; 2010; Hodges, 2009; Kirk et al., 2006; Retrum et al., 2013) directly investigate patient perspectives regarding reasons for HF readmission. In the rest of the studies, the factors influencing HF readmission were indirectly 
conceptualized by addressing HF self-care adherence, decision-making in seeking care, and the need for post-discharge transitional care.

\section{Themes Identified}

Several themes related to factors influencing HF readmission have emerged in the literature: HF readmission as a multifactorial phenomenon with special attention to context; the need to listen to patients and their caregivers; and, the need to have a theoretical framework and simple tools to understand this phenomenon. The recurrent theme identified in the current review was that self-care decision-making does not happen in isolation, but happens in the patients' environmental context (i.e., personal, sociocultural, spiritual, and geographical context). Assessing patients in their environmental context to identify barriers for self-care adherence must precede any interventional strategies to reduce HF readmission.

HF readmission influenced by multiple factors. HF readmission is multifaceted and complicated. The consistent themes revealed from the current review is that HF readmission must be understood as a process outcome contributed to by multiple factors (e.g., patients, providers, and health system). HF readmissions occur in the environment where patients live and interact - their socio-cultural context. Identifying and focusing on this context will promote adherence to HF self-care regimen and reduce HF readmission.

Two studies (Annema et al., 2009; Retrum et al., 2013) addressed the causes of the HF readmission directly. Retrum et al. (2013) systematically examined patient perspectives about reasons for HF readmission. As the authors noted, this study was the first systematic qualitative inquiry on a patient's perspective of HF readmission. They conducted semi-structured interviews of 28 patients readmitted within 6 months of index heart failure admission. The researchers found that patient experiences were complex and heterogeneous and the causes for HF admission 
were multifactorial; therefore, the causes were not easily categorized as preventable or not preventable. The reasons for HF readmission identified from this study include distressing symptoms, unavoidable progression of chronic disease, influence of psychological or social environmental factors (e.g., adequate support versus unavailable resources), imperfect self-care adherence, and health system factors (e.g., suboptimal health care delivery, premature discharge, and lack of ambulatory follow-up care). The authors suggest the need for systemic, multifaceted intervention integrated with patient input.

In a mixed method study conducted in the United States, Annema et al. (2009) asked participants (i.e., patients, caregivers, nurses, and cardiologists) to state the reasons or opinions about readmission and whether the readmission could have been prevented. The participants agreed that not all admission could have been prevented when considering the role of comorbidity as underlying reason for readmission. Patients reported enhancing adherence and seeking help earlier as important interventions to prevent readmission. Participants also stated comorbidity, nonadherence, and nonoptimal medication as contributing factors for readmission besides the most cited reason, worsening heart failure. HF readmission is a multidimensional phenomenon, which not only reflects the worsening pathophysiology, the unavoidable decompensated state needing acute medical intervention, but also signifies the typical ecological view of humans interacting within the embedded context. That is, patients' personal beliefs and values interact with other systems (caregivers, clinicians, community, and health systems), and HF patients make decisions on HF self-care adherence and service utilization (i.e., rehospitalization). The key suggestion from the qualitative studies reviewed includes the need to improve clinicians' sensitivity toward HF readmission and discharge, and the need to improve 
post-discharge education and support - and the culture of health systems in general - in order to reduce HF readmission.

Qualitative researchers have studied the factors contributing to symptom recognition and interpretation in patients with heart failure (Clark et al., 2009; Jurgens, Hoke, Byrnes, \& Riegel, 2009; Patel, Shafazand, Schaufelberger, \& Ekman, 2007; Riegel et al., 2010; Rogers et al., 2002). The researchers found that decision-making in seeking care is a multifactorial process in which personal (cognitive and emotional), and socio-cultural context (faith, belief, value, and culture) contribute. The findings from qualitative studies are consistent in showing multiple factors contribute to HF patients' delay seeking care. Many HF patients fail to recognize worsening symptoms and interpretation due to aging and morbidity; therefore, there is a need to include not only educating HF patients about HF symptoms recognition and interpretation in order to get a timely assistance, but also caregivers for this education in order to possibly compensate for the patients' delayed cognitive response in worsening HF symptoms.

The importance of listening. Health care providers must listen to patients and caregivers and assist them with transitional care paying special attention to the post-discharge environment. The majority of the studies in this current review included caregivers and clinicians to validate findings from HF patients. However, a major omission within the studies in this current review is the lack of discussion about HF readmission from the patient's experience and about the meaning of living with HF. For example, the findings by Granger et al.'s study (2009) identified that the patients' self-care adherence is "work" that needs informational and instrumental support from multiple caregivers, including informal caregivers and health care providers (p. 310). A consistent finding from this current review is that the informal caregivers of HF patients play major roles in decision-making, regarding information management, self-care adherence, and 
seeking care from providers or hospitalization (Annema et al., 2009; Dickson, McCarthy, Howe, Schipper, \& Katz, 2013; Freydberg, Strain, Tsuyuki, McAlister, \& Clark, 2010; Granger et al., 2009; Jurgens et al., 2009; Patel et al., 2007; Piamjariyakul et al., 2012; Riegel et al., 2010; Sanford, Townsend-Rocchicciolli, Horigan, \& Hall, 2011; van der Wal, Jaarsma, Moser, van Gilst, \& van Veldhuisen, 2010). According to Sanford et al. (2011), the decision-making process by caregivers of family members with HF is influenced by situations, people, relationships and the environment. The authors describe the decision-making process as a nonlinear one consisting of several phases: actualization of the challenge, issues, or problem; seeking input, information, or support; reflecting on the decision; making a decision choice; evaluating the decision; and validating the decision (p. 55). There is a need to integrate perspectives from patients and caregivers to reduce HF readmission. The needs of caregivers should be included in the discharge-coordinated effort to assist patients' transitions into their community environments in order to reduce HF readmission. HF readmissions occur in an environment where patients live and interact with their socio-cultural context. Identifying socio-cultural values in order to promote adherence to HF self-care regimen and prompt seeking care at the community can result in avoiding unnecessary hospitalization (Dickson et al., 2013; Freydberg et al., 2010; Sanford et al., 2011; Stephens et al., 2013). Conceptualizing HF self-care decision-making as a process with patients and caregivers as major players may be a necessary step toward patient-centered decision-making, the ultimate goal of health care reform. A consensus seems to exist among researchers (Riegel et al., 2010; Rogers et al., 2002) regarding the need to teach HF patients to report to their caregivers or to educate caregivers to initiate monitoring of their patients' deteriorating state or symptoms. 
In summary, the findings from qualitative studies are consistent in showing multiple factors contribute to HF patients' delaying seeking care. Many HF patients fail to recognize worsening symptoms and interpretation due to aging and morbidity. Therefore, there is a need to educate HF patients about HF symptoms recognition and interpretation, in order to get timely assistance, and including caregivers for this education in order to compensate for the patients' possible delayed cognitive response. HF readmission may not be just an outcome measure; it may require understanding it as a process measure. Causes of HF readmission can be conceptualized by multiple factors (e.g., patient, caregivers, providers, and health system) embedded in the patient's socio-cultural environmental context where patients are living and interacting after being discharged from the hospital.

The importance of a theoretical framework. Conceptual frameworks are helpful in guiding the research. In this current review, only eight studies explicitly reported using theoretical frameworks. However, only in three studies (Granger et al, 2009; Patel et al., 2007; van der Wal et al, 2009), did theories actually guide the process of qualitative study. That is, the theoretical frameworks guided the study methods (e.g., design and unit of analysis) and interpretation of results. Given that few qualitative studies directly addressed HF readmission, there is a need to integrate concepts from existing studies to guide future research projects or innovative intervention targeting HF readmission. Based on factors or themes influencing HF readmission, as were identified from the previous sections, three models could be beneficial to conceptualize the research process targeting HF readmission: Donabedian's Medical Process Model, Health Belief Model, and HF Illness Trajectory Model.

The importance of having simplified instruments. The current review can provide some insight and valuable tools for future research and innovative practice to reduce HF 
readmission. The findings of the review revealed that few researchers (Boyd et al., 2004; Clark et al., 2009; Scotto, 2005; van der Wal, Jaarsma, Moser, van Gilst, van Veldhuisen, 2010) conducted phenomenological studies to explore the experience of HF patients living with this chronic condition. Additionally, only two qualitative studies (Annema, et al., 2009; Retrum et al., 2013) focused on listening to the patient's perspective by asking the reasons for readmission directly. Furthermore, there is a need for simple interview guides and HF risk prediction tools for the clinicians at bedside to listen to patients and caregivers and assist them with transitional care giving special attention to the post-discharge environment. The two primary quantitative studies chosen in this review have simple and practical tools for clinicians to utilize for individualized care of patients. Gruneir et al (2011) utilized the LACE (Length of stay, Acuity, Charlson-comorbid score, Emergency department visits) index (previously published by van Walraven et al., 2010) in their analysis of 26,045 patients' administrative data. They found that high-risk patients (LACE $\geq 10$ ) were readmitted with twice the frequency as other patients, stayed longer and had higher mortality during readmission. LACE index consists of four components: length of hospital stay, acuity on admission, comorbidity, and emergency department visits. It is empirically derived and validated. The scores range from 0 to 19: higher scores indicate greater risk for 30-day readmission or death. This tool has a potential to be utilized as a readmission review tool due to its significant simplicity. Anderson's study (2013) also shed light on how bedside clinicians can contribute to reducing HF readmission by utilizing administrative data. This descriptive study explored the clinical and diagnostic indicators in individuals $(N=134)$ who did and did not experience a heart failure hospitalization within 60 days of the index stay. The findings indicated that nursing-sensitive factors, dyspnea, crackles, and assistance with activities of daily living (ADL) at the time of discharge were more predictive of 60-day heart failure 
readmissions than were gender, age, ethnicity, left ventricular function, serum sodium, blood pressure, blood urea nitrogen, creatinine, BNP, and cardiac medications. This study is important because nurses can contribute to clinical decision-making and reducing HF readmission by enhancing clinical assessment and evaluating patients' discharge readiness (Anderson, 2014).

The current review provides clinicians with suggestions to improve communication with patients to reduce HF readmission. Several quantitative studies emphasize the need to improve discharge coordination (Kirk et al., 2006; Mulder et al., 2012; Jack et al., 2009). In Kirk et al.'s study, about one third of the patients and caregivers expressed that readmission could be avoidable if the patients stayed longer in the hospital during the first admission or had greater support in the community after discharge. The authors suggested that patients' readiness for discharge should be discussed before leaving the hospital. A qualitative improvement project utilized the electronic medical record to assess whether the Institute for Healthcare Improvement's recommendations to prevent rehospitalization was implemented (Mulder et al., 2012). The four key areas included enhanced admission assessment for post hospital needs, effective teaching and enhanced learning, real time patient and family-centered handover communication, and post hospital care follow-up. The project Re-Engineered Discharge (RED) developed by Jack et al. (2009) focused on redesigning the hospital discharge process. Jack and colleagues used 11 mutually reinforcing components to improve the discharge process. They found that participants in the discharge intervention group had a lower rate of hospital utilization than those receiving usual care: the RED intervention decreased hospital utilization by about $30 \%$. The questions used for their trial can be adopted as interview guides if any organization wants to replicate this study in order to improve the quality of patient education and continuity of care (Jack et al., 2009). 
Lastly, current literature review suggests that the unit of analysis should be the patient, but caregiver perspective will be informative in describing this complicated phenomenon of HF readmission. Clinicians can develop their own interview guides to listen to HF patients and families (or informal caregivers) depending on their research questions, theoretical framework, and time constraints. Clinicians may require a simplified tool or may choose to adopt the existing interview guide such as Retrum et al.'s (2013) or tools from the STate Action on Avoidable Rehospitalizations (STAAR) Initiative project (STAAR Worksheet, n. d.). Using existing documentary sources has the advantages of abundance and availability (Green \& Thorogood, 2009). If clinicians' notes can uncover the reasons for HF readmission, medical record review can also be utilized to validate information from patients and caregivers, and to gain a holistic picture of HF readmission. In the majority of the studies reviewed, a detailed retrospective chart review was used to describe the characteristics of the participants and to identify information that could be compared with the findings from the patient interview (e.g., outpatient and emergency visits between hospitalizations and any clinicians' remarks about reasons for readmission, etc.).

\section{Discussion}

There is a gap in our knowledge and understanding of HF readmission. Few qualitative studies directly explored patients' perspectives on HF readmission. No simple HF risk prediction model is available for clinicians to apply in their clinical decision-making in order to understand and reduce HF readmission. This review attempted to elicit some indirect answers by conceptualizing several concepts to understand the HF readmission phenomenon (see Figure A1, Appendix A). Themes that have been identified by researchers in this review include HF readmission as a multifactorial phenomenon with special attention to context, a need to listen to 
patients and their caregivers, and a need to have a theoretical framework and simple tools to understand this phenomenon.

Current review reveals multiple factors influence HF self-care adherence, symptom monitoring, and seeking help in terms of health care utilization (e.g., contacting primary care clinicians versus emergency department visit). However, this is an area where critical gaps exist in terms of knowledge and understanding of the HF readmission phenomenon. The researchers of the studies reviewed consistently suggested involving the caregiver as a key player for patientcentered care decision-making in order to improve transitional care and reduce HF readmission (Piamjariyakul et al., 2012; Sanford et al., 2011). Both qualitative and quantitative studies agreed the need to improve the discharge coordination process in terms of promoting self-care education for patients and caregivers and enhancing communication among providers so patients can seek an appropriate level of care in the community before HF symptoms worsen.

Another theme derived from the qualitative studies reviewed is the impact of sociocultural environmental context on HF readmission. The impact of social context on HF readmission is identified by systematic reviews of many quantitative studies (Hersh et al., 2013; Kansagara et al., 2011; Linda Calvillo-King et al., 2013). These studies agreed that clinicians must address the social determinants of health influencing patients after discharge. Kansagara et al. (2011) note, in their review of 30 studies of risk prediction models, that illness severity, mental health and substance use, overall health and function, socioeconomic status, social support, access to care, health literacy, numeracy, and self-management skills were less commonly utilized as social determinants. Hersh et al. (2013) proposed a new conceptual model for HF readmission that integrates patient, provider, health system, and environment factors. 
Hersh and colleagues assert that HF readmission must be conceptualized as a sociobiological process rather than a discrete physiologic occurrence.

The recurrent theme identified in the current review is that self-care decision-making does not happen in isolation but happens in the context (Freydberg et al., 2010; Retrum et al., 2013). Assessing patients in their socio-cultural context to identify barriers for self-care adherence must precede any interventional strategies to reduce HF readmission. Conceptualizing HF self-care decision-making as a process with patients and caregivers as major players may be a necessary step toward patient-centered decision-making.

There is a need to include patient and caregiver-centered perspectives to mobilize the most effective intervention and generate the best outcomes for both patients and caregivers. There is a concern that the current systems of care have not adequately emphasized patient priorities and shared decision-making for end of life care (Heidenreich et al. (2013).

Researchers and health care providers must integrate patient perspectives when exploring reasons for HF readmission. Patient-centeredness depends on the clinician's willingness to listen to patients, explore the meaning of the illness experience, and identify their needs (Rogers, Kennedy, Nelson, \& Robinson, 2005). Especially, when clinicians interview patients or caregivers about reasons for admission during hospitalization (i.e., an emotional and stressful time), clinicians need to be more empathetic and attentive with a caring attitude. Listening to patients in a nonjudgmental and accepting manner may allow clinicians to obtain valuable information about patients' conditions and assist patients with their needs. Many nursing theorists and researchers assert that a caring presence and listening are the basic interventional strategies for holistic nursing care (Browning \& Waite, 2010; Covington, 2003; Lekander, Lehmann, \& Lindquist; 1993; Shipley, 2010). These authors agreed that listening is a critical 
component of all aspects of nursing care, but it is less utilized by nurses for meaningful interaction with patients because of nurses' time constraints. In a concept analysis on listening, Shipley (2010) views listening as one of the less studied concepts in nursing research, and suggests to incorporate the concept of listening in nursing research and practice, and to develop and validate tools to evaluate the effectiveness of listening from both the nurses' and patients' perspective. Fredriksson (1999) synthesized the qualitative studies on presence, touch, and listening in a caring conversation: the author also found that listening was the weakest theme in the review, indicating a gap in caring and nursing research. Browning and Waite (2010) explain how the simple act of listening can be utilized in improving patient-clinician relationships by providing anecdotal examples from their "JUST Listening Project".

In order to understand the complex phenomenon of HF readmission, researchers need to integrate available knowledge (e.g., much studied concepts and variables in other theories) in a theoretical framework and validate with both qualitative and quantitative studies. Current review holds that adding social determinants as predictors for a HF prediction model or applying a mixed method may enhance the predictability of the model and validity of findings and improve our understanding of the HF readmission phenomenon.

Researchers and clinicians can contribute to our understanding of this HF readmission phenomenon by adapting available tools and apply these to their clinical decision-making for their patients. However, there is a need for clinicians to test these tools working with their own population, because every organization differs in terms of the characteristics of the patients (Gannuscio, 2012). As the findings from Anderson's study (2014) suggested, nurses can play a major role in inpatient-centered care by enhancing their nursing assessment skills (e.g., assess needs on admission, improve teaching, patient-centered handover communication, check 
readiness at discharge, and arrange follow-up after discharge). The importance of the nurse's role as a patient advocate in the discharge process is also consistent with findings from the current review (Jack et al.; Mulder et al., 2012). This was also suggested by several state initiative projects conducted in the United States to reduce HF readmission such as the RED and STAAR projects (Jack et al., 2009; STAAR Initiative, 2011). A nurse's basic skill for assessment starts from listening to the patient. However, in the current hospital environment, clinicians lose sensitivity for the admission and discharge process for HF patients, as Hekmatpou et al. theorized in their studies with the grounded theory techniques $(2009 ; 2010)$. The authors also suggest establishing discharge education in order to reduce HF readmission. The last key suggestion in this review, highlighted by Holland et al.'s study (2012) is the use of a standardized assessment tool to identify and address the continuing care needs for HF patients. Nurses can advocate for HF patients in their compassionate and attentive listening, the basic and essential caring skills needed for any clinical encounters.

In summary, this integrative review on the factors influencing heart failure readmission demonstrates five points as follows:

1. HF readmission must be understood as a process outcome contributed to by multiple factors (e.g., patients, providers, and health system).

2. HF readmissions occur from an environment where patients live and interact with their socio-cultural context; this context needs to be understood to promote HF patients' selfcare regimen.

3. Caregivers must be included in the process of shared decision-making to target patientcentered care (from HF diagnosis to inpatient care, transitional care) and to reduce readmission. 
4. Health care providers must listen to patients and caregivers and assist them with transitional care giving special attention to the post-discharge environment.

5. The Donabedian's Medical Process, Health Belief, and HF Trajectory models may provide insight into patient and family responses to self-care management (e.g., regimen adherence versus non-adherence and seeking or delayed seeking care) and decisionmaking of resource utilization (i.e., keeping follow-up appointments, ED visit, or hospitalization).

Further study details can be found in Appendix B.

\section{Nursing Implications}

HF management is challenging and HF readmission is costly. Few previous studies have focused on the experiences of HF patients who must make everyday decisions on self-care adherence, seeking treatment, and service utilization (e.g., emergency department visit or readmission). Researchers and health care providers must integrate patient perspectives when exploring HF readmission. Patient-centeredness depends on the clinician's willingness to listen to patients, explore the meaning of the illness experience, and identify their needs (Rogers et al., 2005). Listening to patients and caregivers must become a prerequisite for enhancing patientcentered care. Nurses are in the best position to listen to patients' accounts of HF readmission and empower patients and their caregivers with appropriate resources in order to make the right decisions during the trajectory of illness experience.

\section{Conclusion}

$\mathrm{HF}$ is costly and challenging. Current literature review supports that there is significant lack of qualitative studies that directly explored patients' perspectives on HF readmission. The needs of HF patients and caregivers should be included in a discharge-coordinated effort to assist 
patients' transitions into their community environments in order to reduce HF readmission. The insights and knowledge gathered from this literature review will serve as an important step toward a patient-centered approach. Clinicians should include patient and caregiver perspectives in evidence based interventional strategies to reduce HF readmission.

\section{Gaps in the Literature to Date}

HF readmission is complicated and influenced by multiple factors. The causes of HF readmission are not well understood and many gaps exist. Therefore, the purpose of this literature review was to examine current research focusing on HF readmission and to identify the impact of gaps in current knowledge about factors influencing HF readmission. The current literature review supports that there is a significant lack of qualitative studies that directly explore patients' perspectives on HF readmission. Few studies (Annema et al., 2009; Hekmatpou et al., 2009 \& 2010; Hodges, 2009; Kirk et al., 2006; Retrum et al., 2013) directly investigated patient perspectives about reasons for HF readmission. No study utilized the phenomenological paradigm to describe the lived experience of being readmitted to the hospital with heart failure. In order to understand the phenomenon of HF readmission, the current review attempted to integrate several theoretical frameworks (see Figure A1, Appendix A) that could describe HF readmission indirectly, by incorporating the themes that emerged from this review (i.e., HF selfcare adherence, decision-making in seeking care, and need for post-discharge transitional care). The coverage of current literature synthesis is limited; however, the findings from the current literature review can provide researchers or clinicians with some insights on themes identified on HF readmission, research design, unit of analysis, interview guide, and theoretical frameworks, which can guide future research and interventions to reduce HF readmission.

\section{The Purpose of the Present Study}


$\mathrm{HF}$ readmission is complicated and influenced by multiple factors. The causes of $\mathrm{HF}$ readmission are not well understood. There is a significant lack of qualitative studies that directly explore patients' perspectives on HF readmission. Therefore, the primary purpose of the present study was to increase knowledge of the reasons for HF readmission from the patient's perspective. The project aimed to describe trends and patterns of HF readmission and gain insight for reducing it. This qualitative study examined the experience of persons who were readmitted to this mid-Atlantic medical center with heart failure within 30 days of discharge from the index hospitalization.

\section{Research Question}

The following questions were addressed in this project:

1. What factors are identified by HF patients (and their caregivers) that contribute to readmission following inpatient treatment for HF?

2. What barriers and potential causes for readmission can be identified in the patients' medical records?

\section{Section III: Methods}

Most hospitals have quality improvement teams and implement evidence based practices to reduce preventable readmissions for patients with HF (Bradley et al., 2012). This mid-Atlantic medical center has adopted a multidisciplinary HF disease management (DM) program to reduce HF readmission. This medical center has been accredited with HF disease specific care certification and has been translating scientific evidence into clinical practice for HF patients at high risks. The Heart Center at this mid-Atlantic medical center has quality improvement teams devoted to reducing preventable readmissions for patients with HF. According to the Centers for Medicare and Medicaid Services (CMS) website, persons with heart failure (HF) are readmitted 
to hospitals within 30 days at a rate of 19.6 percent (Jenks, Williams, \& Coleman, 2009).

Although, the 30-day HF readmission rate at this mid-Atlantic medical center was lower (17\% at inpatient units during study period) than the national average, it is necessary to inquire patients' perspectives on the reasons for rehospitalization and identify information which can lead to improvement.

\section{Research Design}

A major omission within studies in the current review was the lack of discussion about factors on HF readmission from the patient's experience and meaning of living with HF. Therefore, a qualitative descriptive design with phenomenological framework was selected to identify the reasons for HF readmissions. Researchers use phenomenology to understand the essence of a phenomenon and what it means to those experiencing it (Creswell, 2012 \& 2013). Patients were interviewed with a semi-structured interview guide, which consists of open-ended questions. Using open-ended questions was necessary, because the attainment of patientcenteredness depends on the clinician's willingness to listen to the patient, explore the meaning of the illness experience, and identify their needs (Rogers, Kennedy, Nelson, \& Robinson, 2005). This method was effective not only to capture the patient's perspectives, but it could also ensure that the focus is always on what matters most to patients (Lee, 2011). A detailed retrospective chart review (See Figure A 3, Appendix A)was conducted for each patient in the study to describe the characteristics of the participants and to identify information that could be compared with the findings from the patient interview (e.g., outpatient and emergency visits between hospitalizations and any clinicians' remarks about reasons for readmission, care-coordination activities, etc.).

\section{Setting}


The study setting was a mid-Atlantic medical center, an academic teaching hospital. In 2014, the facility had 28,274 admissions and 58,544 emergency room visits. The average daily inpatient census of this facility was 446 and the average length of stay was 5.75 . The study site included 5 inpatient units ( 3 Cardiology and 2 Medical Surgical units) to capture data of patients with heart failure who are readmitted within 30 days of discharge from the index hospitalization. An index stay is defined as the first hospitalization with a discharge diagnosis for heart failure occurring in the study period. Readmission was defined as an admission into inpatient units for all causes at the mid-Atlantic medical center with a primary discharge diagnosis of heart failure.

\section{Description of Sample, Inclusion and Exclusion Criteria:}

A purposive, convenience sample was recruited from the target population of patients who were readmitted to inpatient units for all causes at the mid-Atlantic medical center within 30 days of discharge from the index hospitalization during the study period (Spring-Summer 2014).

The nature of phenomenological inquiries suggests a small sample size of 10 or fewer from which rich data are collected (Polit \& Beck, 2008; Sandelowski, 1995). Data saturation was reached from 9 participant's view of the heart failure readmission in this study. The patients' perspectives were clear and revealed patterns. No new themes were generated from interviews (Sandelowski, 1995; Corbin \& Strauss, 2014).

During the recruitment period (Spring-Summer 2014), the investigator identified the potential subjects by accessing the computerized data of daily inpatients readmission to the midAtlantic medical center (operated by Home Health Continuum Services). Patient participants who met the following criteria were recruited for the study:

\section{Inclusion criteria}


- Adult men and women over 50 years old with a discharge diagnosis of heart failure during index hospitalization.

- Readmitted to inpatient units for all causes at the mid-Atlantic medical center within 30 days of discharge from the index hospitalization during the study period (Spring-Summer 2014)

- Willing and able to give informed consent

\section{Exclusion criteria}

- Planned readmission

- Dementia documented in the medical chart or screened positive for delirium in EPIC nursing assessment sheet

- Non-English speaker

- Patients readmitted from nursing homes

- Known pregnancy

- Patients with left ventricular assist device (LVAD), post heart transplant, trauma

\section{Measures}

The interview protocol was developed based on the literature review and it consisted of five open-ended questions (see Appendix C). The chart review guide was adapted from the chart review guide in the STAAR initiative: many items were added based on the results of the literature review and conceptual models produced by the investigator (see Appendix D).

\section{Procedures}

The data collection period was from May through August 2014. Eligible patients were approached, and after receiving informed consent of the patient (see Appendix E), a mutually agreeable time was set for the interviews. The interview was conducted in the patient's room at a 
time chosen by the patient (e.g., when the unit is quiet or when having no patient care interruption). The consenting participants were asked to complete a structured 30 minute interview, after patient's clinical stability was checked by the patient's nurse or investigator before proceeding with the interview. Only on one occasion were caregivers (wife and daughter) present during the interview per the patient's request. The interview questions explored etiology and symptoms, decision-making for seeking care, self-care, education, treatment and the patient's opinion for preventing readmission. The duration of the interview ranged from 15 to 33 minutes.

The interview was audiotaped with a MP3 player. Field notes were taken during the interview or immediately after the interview in order to capture body language and facial expressions that were used to compare with transcriptions and support the interpretation during analysis. The medical record was reviewed to collect the demographic, diagnostic, pre and post discharge activities (see Appendix D). The chart review guide served as worksheets to collect data needed for the investigator to reflect any missed opportunities for readmission: medical records for both index and readmission periods were reviewed. (see Figure A3, Appendix A). The investigator read the notes by providers and wrote a reflected summary as an analytic memo for analysis. The individual patient's case was reviewed by phases (e.g., index, discharge, and follow-up periods) to analyze any missed opportunities to prevent readmission: the idea of reviewing by cases and phases was adopted from Feigenbaum et al.'s study (2012).

Triangulation of methods (validating data from patient with those from medical record review) was used to ensure validity and reliability. Content validity was established by consulting with committee members who were experts in advanced heart failure practice.

\section{Role of Researcher and Data credibility}


In a qualitative study, the researcher is the instrument of qualitative inquiry. Qualitative data do not contribute to rigorous statistical analysis. Therefore, the process of bracketing was ensued to examine personal biases and preconceived ideas about the phenomenon studied (Scotto, 2005). The principal investigator is a certified HF nurse who understands this study population well, and the principal investigator delivered an in-depth interview in order to increase its credibility. The principal investigator is well experienced in qualitative interviews and has been formerly trained with knowledge and skill for qualitative research and analysis from two doctorate level qualitative research classes at a mid-Atlantic university.

For the consistency of the study, all interviews were conducted by the principal investigator. During the analysis, key constituents and structure were discussed and validated with clinical and academic mentors of the principal investigator.

\section{Data Analysis}

The unit of analysis for the chart review was the patient. The interview was transcribed by the principle investigator. Data collection began after the first interview and guided the future interviews. Transcripts were read line-by-line and coded to identify trends and patterns of the patient's perception and experience of HF readmission. Themes were identified and the categories were placed into the themes, and new concepts were identified from the data. The data analysis techniques used in this study were the thematic content analysis method (Green \& Thorogood, 2011) and coding methods suggested by Saldana (2013). After the first round of descriptive coding, the theoretical coding informed by the conceptual framework proposed in the current study was performed to affirm categories and themes found from the initial descriptive coding. Then, in order to increase the analytic rigor, additional coding methods (e.g., value and versus coding as described in Saldana, 2013) were utilized. The investigator tried to capture the 
meaning, different perspective of the data, and process of the multifactorial phenomenon under investigation by answering the research questions proposed by this study. As the analysis progressed, experts in heart failure served to confirm the identification of themes.

Trustworthiness of the data was ensured by maintaining a coding manual (field notes and analytic memo).

\section{Protection of Human Subjects}

The study protocol was submitted and reviewed for the protection of human subjects by the Health Sciences Research Board. The initial study was approved (HSR \# 17345). Approval was requested and received to extend the study period to a later date (see Appendix F). The study protocol was followed and no adverse effects occurred.

\section{Limitations}

First, this study was conducted in a single mid-Atlantic medical center; therefore, the result of this study cannot be generalized to other hospitals. Second, the sample size of 9 was too small in terms of grounding theory of unknown phenomenon. Third, this study was limited due to its retrospective nature in data collection. Therefore, there is a possibility of recall bias when asking patients a series of questions about their reasons for coming back to the hospital, and events before hospitalization (e.g., primary care clinician visit) and self-care behavior (e.g., taking medicine and typical meals). Fourth, the interview and chart review guides were developed based on the investigator's literature review (including the STAAR initiative project), and there is no reported validity and reliability. Another challenge was ensuring participants were well enough to participate in the interview in the acute care setting. The chart audit from administrative data also posed a limitation in this study in terms of the researcher's lack of 
control. Lastly, the researcher was also an interviewer for this study, so researcher's bias was possible.

\section{Products of the Capstone}

The formal products of this Capstone include:

1. The result of the qualitative analysis

2. A manuscript summarizing the Capstone suitable for publication in Heart \& Lung: The Journal of Acute and Critical Care, the official publication of The American Association of Heart Failure Nurses (AAHFN). (see Appendix I).

\section{Section IV: Findings}

The following research questions were addressed in this project:

1. What factors are identified by patients that contribute to readmission following inpatient treatment (i.e., index HF hospitalization) for HF?

2. What barriers and potential causes for readmission can be identified in the patients' medical records?

These questions were pursued through in-depth, semi-structured interviews and medical record reviews guided by the theoretical model proposed by this researcher (see Figure A1, Appendix A). The interview questions explored etiology and symptoms, decision-making for seeking care, self-care, education and treatment and patient's opinion for preventing readmission. The duration of interview ranged from 15 to 33 minutes.

A total of 9 patients were interviewed. All of the participants met the criteria of the institutional review board approval: they were readmitted for all causes in 30 days of discharge from the mid-Atlantic medical center following an index admission for heart failure. There were 4 females, 5 males; and 3 subjects were African Americans, 6 were Caucasian. One was an 
immigrant from an African country. Days to readmission varied from 1 to 24 days. Four patients were readmitted less than 7 days of discharge. Patients' ages ranged from 55 to 79 years with a mean age of 69.1. The LACE score ranged from 9 to 13 with a mean score of 10.7. Demographics of the participants can be found in Table 1 (see Appendix G).

Data saturation was reached from 9 participant's views of their heart failure readmission in this study. The patients' perspectives were clear and revealed patterns and no new themes were generated from interviews (Corbin \& Strauss, 2014).

Triangulation of themes was achieved between patients' perceptions (from interview analysis) and providers' perception (from medical record review). Several themes emerged from the preliminary analysis: inevitable or unavoidable readmission due to worsening of the disease process; optimal symptom monitoring and taking action with family and provider's support; heart failure readmission decision appreciated as a shared resulting from well-coordinated transitional care; appreciation on evidence based programs; patient satisfaction regarding selfcare teaching; but, room for improvement (patient's desire to stay a little longer during index admission and learn more about the disease process, be more sensitive with addressing end of life care issues, include family members in the decision making process).

Readmission at the mid-Atlantic medical center exemplified the high quality of inpatient care and seamless transitional care and discharge planning; the readmission trend reflects the patient population it serves.

Inevitable or Unavoidable Readmission due to Worsening of the Disease Process or Other Condition: "I had to come back for symptom relief and further treatment".

Most participants stated that the rehospitalization was inevitable or unavoidable due to the urgency of the symptoms aroused from the disease process of the heart failure or other 
chronic morbid condition or recurrent condition from the index hospitalization. The most common symptoms cited by participants were palpitations, shortness of breath, and edema. Two participants (Patient 5 and Patient 6) experienced chest pain from myocardial infarction, and loss of urine control from recurrent infection, respectively. Participants cited multiple factors as reasons for unplanned readmission.

When the participants were asked, "Why do you think you had to come back to the hospital?" a 73 year old, female, Caucasian participant shared her story of urgency of the symptoms and unexpected need to return to hospital for symptom relief:

I think I just had to come back... I have, uh, fibrillation, my heart was fibrillating. I was dizzy and short of breath... I called my doctor and she told me to come in... (quote from Patient 1).

Another female participant who was also admitted with palpitation answered to the question, "What do you think could have prevented you from coming back to the hospital?" There just wasn't, yes...it was unforeseeable that my heart would start racing... There was no way in the world to prevent... (quote from Patient 2).

A 55 year old female, African American participant answered the following to the previous question asked:

...This time I had...it felt like...um...real sharp pains in my chest, and I just knew I was having a heart attack... (quote from Patient 5)

This patient had three vessel disease, and the provider's note revealed that this patient was counseled about the risk of returning home without having surgery. However, the patient's request was granted and she had to come back to hospital the next day. This patient honestly spoke about her belief caused the readmission: 
....they wanted me to have the surgery that Friday, but I believe that I had to go home, because my kids didn't know where my life insurance policies and stuff were at. So, I felt I need to go home and get that in order. But, I knew I was coming back... (quote from Patient 5)

\section{Patient Satisfaction Regarding Education: "Coaching was good".}

Most participants expressed satisfaction with the education provided to them and their family members by the health care providers during their index stays.

Patient 2 expressed her satisfaction regarding the providers' explanation when medication was changed or administered to her:

...they changed my medicine, uh, some they gave up, and some they dropped off. And, they tell me all the time, what so, every morning, they explain what they're giving me. So, that makes me feel good (quote from Patient 2).

This participant also commented the providers' explanation as follows:

They are wonderful at explaining things to me. What's happening, what could happen, what they're going to do, and hopefully that it will work...They're pretty sure of everything (quote from Patient 2).

One patient named her physician and reported to the interviewer that his team was already in her room on that morning telling her about the discharge date:

They explained it and what should happen, and that I should be alright (quote from Patient 2).

Another participant expressed a similar comment about the providers' education: All you have to do is just ask questions, and you will answer them (quote from Patient 1). 
Another male respondent, who spoke rudimentary English, answered to the interview question, "Is our education support, or doctor's or nurse's way to explain to you, enough?"

Yeah, it's enough. I understand them. I understand them... They are good (quote from Patient 9).

Optimal symptom monitoring: Doing their best in self-care management even with limited resources. "I am doing my best at home in self-care management".

In the current study, all participants except one (Patient 5) reported adhering to daily monitoring of self-care regimens recommended by providers: their routine include daily monitoring of weight, blood pressure, oxygen saturation (by some patients), and swelling of ankles or legs, and they reported abnormal values or symptoms to their providers. Patient 5, morbidly obese, admitted that she could not afford a scale or automatic blood pressure machine. However, this patient had a basic knowledge of HF self-care:

I mean, you know, it was just basic, you know, to keep doing. You know, leave the salt alone, and not drink a whole lot of water. And, basically, you know, just try to get a little exercise, but don't push it. But, try to do a little something (quote from Patient 5)

The majority of the participants reported that they live on limited income; however, they relayed that they were doing their best in their HF self-care. All participants confirmed their priority in purchasing prescribed medications. The family members or patients themselves loaded medication into their pill box.

The following is the story shared by a female participant who lives alone and usually ends up eating TV dinners, because she had limited physical ability to move around in order to prepare food for herself: 
....because I can't stand up long enough to cook, so I will have something in my refrigerator that I can put in a microwave... I only get $\$ 52$ worth of food stamps a month. And, it's hard for me to buy the things that I know I need to eat. So, I have to buy what I can afford to buy... You know, like I said, it takes...I get a disability; it takes everything that I have to run my household. So, I don't...it don't leave me much to try to put what the $\$ 52$ can get things. So, I have to do what I can do. I mean, I have to buy what my money can afford to buy (quote from Patient 5).

However, a 79 year old, Caucasian male participant, who also lived alone, told his story of tapping into his neighbors' help for meal planning as follows:

I've got my neighbor across the street who I go with; she comes in two or three times a day with me. And, I've got a neighbor behind me who's a year and a half older than I am, who comes in the morning for breakfast, comes fix lunch and for my dinners and all, so... Oh, I've got a wonderful community... (quote from patient 8 ).

A 73 year old male, an immigrant from an African country, shared his story, with his limited spoken English, how he tried to adhere to salt restriction, and activity regimen even though he has been living with the pain in legs from arthritis:

The nurse said I shouldn't touch salt, at all... So my sister doesn't put salt on anything... I go walking around. In the morning. Every morning... (quote from patient 9)

\section{Optimal Seeking Help with Family and Provider's Support: "They continue to monitor}

\section{when I was back home"}

In the current study, all of the participants not only monitored symptoms daily, but they also sought timely help when the symptoms became unmanageable at home: all of them tapped 
into family and providers' support to get consultation and took the actions recommended by the health care providers.

One 79 year old Caucasian female patient, who felt palpitation, reported the following: Wednesday, they discharged me. And then, Thursday, I had to come back, because my heart started racing... my family brought me. Well, uh, my daughter took me to the heart doctor there.... I was there for a little while. They did some blood work, and sent me on over here... (quote from patient 2).

Another female patient (Patient 1, 73 year old Caucasian) stated the following: My heart was fibrillating. I called my doctor. She told me to come in...Then she sent me from her office over to E.R (quote from Patient 1).

All participants except two (Patients 5 and 6) contacted their physician's office and followed the guidance whether to go to their physician's office or hospital. These two patients consulted with family members who were present when they experienced severe chest pain or symptoms of severe hypothermia. Patient 5 reported she had to act fast because she knew she was having a heart attack from her childhood memory of her mother having a heart attack. According to the other female participant (Patient 6), her daughter who is a registered nurse, prompted her to call an ambulance because the symptoms were extremely unusual.

Three participants lived alone; however, all participants were either with a family member or neighbor-friend at the time of symptom recognition and sought help from their health care providers.

Satisfaction and Appreciation toward Support by Providers, Well-Coordinated Transitional Care, and Evidence Based Programs: "They helped. We did it together. I Survived. We appreciate it". 
The majority of the participants were offered 'Hospital to Home' (H2H), 'Heart Health at Home' (3H), and 'Care Coordination Continuum' (C3) services, the evidence based HF programs. All participants expressed satisfaction and appreciation toward the provider for coordinating and assisting with the patients' readmission process in order to treat the patients' conditions and provide them with symptom relief. Participants identified the continued coaching and monitoring of self-care management by their community as effective for taking action for rehospitalization.

A 79 year old Caucasian male reported how the home continuum nurse monitored his vital signs (including oxygen saturation) and coordinated the readmission:

She was following me every hour on the hour to watch my...vitals...and oxygen, because she was worried... oxygen kept dropping lower and lower. And, we knew something was wrong... she said if it dropped to a certain level, call 911 and get transported... (quote from patient 8).

A 60 year old female Caucasian participant was served by the $3 \mathrm{H}$ program. She expressed her appreciation toward the coordinated care:

I had been for blood tests that morning. And, then, by the time I hadn't been home two hours, they were calling me. Something was way off, and I had to come... The home health aide was at the house when they called and told me I had to come back to the hospital. She stayed with me. She helped me pack my bag to come. She was just so helpful. She wouldn't leave me... I feel like I get blessed to have these people in my life, you know?... (quote from Patient 7).

\section{Appreciation for evidence based programs and providers' support.}

One male participant, who emigrated from an African country 30 years ago answered to a question, "Do you think this program (C3 telemonitoring home health) was helpful for you?" 
... Yeah. Every morning, I weigh. Then they communicate with me. A very good idea... (quote from Patient 9)

Another female participant expressed an appreciative feeling:

They call me about every day...If the doctor would not call me, then it was the nurse who called me. I had somebody call me every day... (quote from Patient 1).

\section{Room for Improvement: "For future patients, I would suggest..."}

Participants pointed out four areas for improvement:

- Desire to stay a little longer during index admission.

- Learn more about the disease process.

- Include family members in the decision making process.

- Be more sensitive with addressing end of life care issues.

\section{Patient's desire to stay a little longer during index admission for researching into treatment option, and facilitating learning process.}

In the current study, three participants stated that they could have stayed longer in the hospital during the index stay. They opined that providers could further research into other treatment options before discharging them to home. They also confirmed that they could learn more about the disease process if they could have stayed longer during the index hospitalization.

Participant 2, a 79 year old female patient who was discharged one day after the stent placement, answered the following to the investigator's question, "How prepared did you feel returning home when you left the hospital the last time?"

I thought I would have liked to have stayed one more day until Thursday...And my doctor has said that there were a lot of coughs and flus and things on the floor. And he said, "I'd 
hate to see you catch something." You know... Uh, with all this heart stuff going on. So, he sent me home (quote from Patient 2).

Patient 3, a 78 year old male replied with a similar answer to the question, "What do you think could have prevented you from coming back to the hospital?"

The doctor sent me home too early. If they had not sent me home too early... I would not have had to come back.... (quote from Patient 3).

A 68 year old male answered the following to the same previous question:

On the discharge date, well, I was optimistic; I felt pretty good... I was cautiously optimistic that we were moving in the right direction.... You need a better coordination between the surgical team, your cardiac team, your discharge team: it just gets a little disjointed...They needed to get a better handle on my, um, you know, with congestive heart failure, you have fluid problems, and, I have liver issues, and with that you have liver problems. They just didn't get a proper handle on what was going on before they sent me home (quote from Patient 4).

Patient 8 , a 79 year old Caucasian male patient, certainly repeated the same desire: If they kept me longer, and done a little bit deeper research into what my problems were... (quote from Patient 8).

\section{Desire to learn more about the disease process.}

Most participants in the current study were satisfied with education offered by health care providers. However, two participants stated that they could benefit if more detailed explanation about their disease process was given during their index stay. For example, Patient 3, a 78 year old African American male patient who came to the hospital with recurrent fluid overload, expressed his desire to learn: 
What causes that fluid to continue building up like that (quote from Patient 3)?

Include family members in the decision making process and be more sensitive with addressing end of life care issues.

Patient 1, a 73 year old Caucasian female patient, was interviewed on the discharge date. This patient suggested to include her daughter in the teaching:

When they explain it to her, you know, she will explain to me (quote from Patient 1). Another 60 year old female patient agreed with the former one:

I would suggest they try to make sure the family is with me. That someone in my family is with me when they want to talk about teaching or disease process (quote from Patient 7).

The investigator interviewed this patient in the cardiac intensive unit and witnessed her feeling about being referred to palliative care:

They sent the palliative care people in here, and I wasn't ready for that, too...They said that my daughter had asked me, and I don't...but she had not asked me...It was a big surprise. It was a shock to me. They came in. Well, first of all, she put on an isolation gown, and I thought, well, I'm not in isolation...And then she came in and said who she was. And, I'm like, “Palliative care?” I knew what that meant, you know (quote from Patient 7).

\section{Findings from Chart Review}

The Electronic Health Record review has not provided the investigator with any explicit evidence suggesting that health care providers missed any opportunities in terms of preventing readmission. 
The chart review guide served as worksheets to collect data needed for the investigator to reflect any missed opportunities for readmission. The investigator read the notes by providers and tabulated missed opportunities by phase and cases and a reflected summary was written (chart review method was adopted by Feigenbaum, 2012). During data analysis, the summary was revisited by the investigator to assess whether the readmission for each case was preventable.

The chart review revealed that the mean value of the LACE for the participants was 10.7 . Three participants had heart failure with preserved ejection fraction (HFpEF). Four patients were readmitted with recurrent conditions (2 recurrent fluid overload, infection, pleural effusion). Bacteremia was noted as a main reason for readmission for Patient 9, a 73 year old African American male who has no medical insurance. The interdisciplinary team attempted to assist him to have dental service in order to correct the probable main cause of his cardiac condition (endocarditis) since the index admission. However, during the readmission period, the social worker was still in the process of locating a reduced rate dental clinic in the patient's community.

In the current study, all participants were served by the interdisciplinary discharge team to facilitate transitional care. Most patients were supported by evidence based interventions $(\mathrm{H} 2 \mathrm{H}, 3 \mathrm{H}, \mathrm{C} 3$, home physical therapy, etc.) to reduce readmission. On average, the participants received at least two of the interventions. Some of the participants were also seen by the heart failure navigator and (or) by the in-patient heart failure nurse practitioner during the index stay. There was no documented evidence of using a health literacy screening tool or teach back during the study period (May to August, 2014). 
Only one patient's discharge summary reported that the patient had bilateral crackles and a slight pitting lower extremity edema $(+1)$ on the discharge day. Otherwise, clinicians' notes did not report any acute distress on the discharge date.

\section{Section V: Discussion}

The purpose of this study was to explore the patient's perspective on the reasons for a 30 day readmission to a mid-Atlantic medical center. The current study is unique as it is the first qualitative study to examine the readmission phenomenon using both interview and chart review at an academic teaching hospital. Several themes emerged from the analysis: inevitable or unavoidable readmission due to worsening of the disease process; optimal symptom monitoring and taking action with family and provider's support; heart failure readmission perceived as positive as a result of well-coordinated transitional care; appreciation on support from the evidence based programs; patient satisfaction regarding self-care teaching; but, room for improvement (be more sensitive with addressing end of life care issues; include family members in the decision making process; and the patient's desire to stay a little longer during index admission to learn more about the disease process). The results of this study provided both patients' and providers' reflections on whether the readmission was preventable and suggested future preventative strategies.

\section{Severity of Condition as Reasons for Readmission}

Participants in this study reported that the severity of the condition, either from worsening of heart failure or other multiple comorbidities, was the primary reason for readmission. The providers' perspectives were reflected by analyzing the providers' medical records. Both patients and providers perceived that the readmission was inevitable or unavoidable due to worsening of their health status (either new or chronic disease condition). 
In the current study, among nine participants who were rehospitalized, four patients reported worsening symptoms of heart failure as primary reasons for readmission. Three participants' symptoms were originated from cardiac conditions: two had arrhythmia and one experienced an Implantable Cardioverter Defibrillator shock. One female patient stated that recurrent urinary infection was the reason for readmission. Only one patient experienced a new symptom of acute myocardial infarction that led her to readmission. That is, eight out of nine patients' cases were cardiac related readmission. All of them relayed that hospital readmission was inevitable due to the severity of their condition. They all reported that worsening of their health status (or condition) with a need for symptom management was a primary reason for rehospitalization. This finding is consistent with the findings of previous studies (Annema et al., 2009; Patel et al., 2007; Retrum et al., 2013). In the current study, almost half of the patients also implicated other comorbidities as directly or indirectly related to their readmission. This finding was also expected with the finding of others (Annema et al. 2009; Islam, O’Connell, \& Lakhan, 2012; Retrum et al., 2013). The 2006 Kirk et al. also reported that most patients, caregivers and clinicians believed that the readmission was unavoidable by reflecting the chronicity of illness.

The chart review revealed that the mean value of the LACE for the participants was 10.7, signifying that the participants were all high risk for readmission in terms of acuity and significant co-morbid conditions aside from the primary diagnosis of heart failure. LACE index is validated as being a useful tool to predict hospital readmission and mortality rate (Gruneir et al., 2011; Snyderman, Salzman, Mills, Hersh, \&Parks, 2014; van Walraven, Wong, \& Forster, 2012).

Feigenbaum et al. (2012) conducted chart review of 537 readmission cases and identified that $57 \%$ of potentially preventable readmissions occurred during index hospitalization. The 
factors in their 'Care during index stay' category include suboptimal management of chronic condition, unrecognized worsening condition, suboptimal coordination of care, patient discharged too soon, and surgical/procedural complication, etc. Using their suggested categories, the investigator performed the reflective inquiries: "As providers, was there anything we could have addressed during index admission, or do the providers have to conclude the admission was inevitable?" Several participants' cases who were rehospitalized with recurrent problem were revisited and reflected with this question.

The investigator could not find any evidence for suboptimal treatment during index stay. However, in each case, providers could have researched into other treatment options as several participants suggested in the interview.

In a teaching hospital, there is a little control over treatment decision during index stay and on discharge, although evidence based practice guidelines are used for specific disease treatment. The resident doctors are trained to follow the teaching protocol under the discretion of the attending physician. It is difficult to optimize treatment in a short period of stay in an acute care hospital setting, especially when patients have multiple comorbidities; multiple teams are involved in treating a specific patient.

For example, in the case of Patient 4, who had to come back for recurrent pleural effusion, the innovative treatment (e. g., ultrafiltration) was available as an option at this midAtlantic medical center, but he had not received it. A review on pharmacologic treatment for heart failure patients revealed that the early detection of congested HF patients for ultrafiltration treatment might improve decongestion and reduce readmission (Shchekochikhin, Ammary, Lindenfeld, \& Schrier, 2013). In the current study, at the community level, after the patient was discharged, transitional care was optimally managed by nurse practitioners, and other supportive 
services $(\mathrm{C} 3$ and $3 \mathrm{H})$. For the cases of diuretic use, community transitional pharmacy involvement may be necessary to address the issue of over versus under diuresis. One case study (Fera, Anderson, Kanel, and Ramusivich, 2014) conducted in a community hospital reported that integrating pharmacist services into the care transition process was effective in reducing 30 day acute care readmission and improving patient satisfaction.

Urgent readmission to the hospital is commonly used to measure hospital quality of care (van Walraven, Jennings, \& Forster, 2012). However, most of the urgent readmission is unavoidable. According to Walraven et al.'s meta-analysis of hospital readmissions (2012), less than one in four readmissions were deemed avoidable. Berenson and Shih (2012) report in their Commonwealth Fund analysis, safety-net hospitals are 30\% more likely to have 30-day hospital readmission rates above the national average, compared with other hospitals. Herrin et al. (2015) examined the readmission rate of 4,073 hospitals between July 2007 to June 2010 and found that community factors as measured by county characteristics explain $58 \%$ of variation in hospital readmission rates. The case of Patient 9, whose underlying cause for repeated hospitalization could be from lack of dental treatment, exemplifies the issue of the population characteristics that an academic teaching (or safety net hospital) serves. According to Joynt \& Jha (2012), one of the most important drivers of readmissions is poverty.

The readmission trend in the current study reflects the challenges from patients' severity of condition (both acute and chronic) and population characteristics that an academic teaching hospital typically serves (or safety net hospital).

\section{Optimal Self-Care Management}


In the current study, patients reported optimal self-care adherence, symptom monitoring, and taking action with family and provider's support. Medical record review also confirmed this finding.

Despite the abundance of literature reporting patients' non- adherence as reasons for readmission (Annema et al., 2009; Heo, Lennie, Mose \& Okoli, 2009; Patel et al., 2007), in the current study, the participants' symptom were optimally monitored by self or with a group effort (self, family, and providers) and non-adherence to any medication or diet and fluid restriction was not reported. Only one female patient who was readmitted with a myocardial infarction reported not checking daily weight because she could not afford a scale. The provider's note also reported that she had a history of non-adherence to diabetic self-care regimen. This woman's self-care knowledge was exceptional, though she admitted to eating TV dinners occasionally for convenience. She could benefit from dietician counseling, for example, on how to pick up healthy food if she wants to get food from the food pantry. Two participants reported eating occasional hot dogs (Patient 3) or a ham sandwich (Patient 1). In both cases, family members prepared meals for these dependent patients. Therefore, definitely, there is a need to include family members, and to tailor teaching on diet choices (e.g., choice of hot dogs, and amount of ham). According to a qualitative study on dietary adherence by Heo et al. (2009), those factors identified as affecting adherence included knowledge, social pressure and encouragement from others, and social situations. In the current study, the majority of the participants reported doing their best to adhere to dietary restriction, though some of them admitted the social, functional, or financial situations limited them to have less of an ideal food selection. Our participants' knowledge and adherence was optimal, because the majority of the participants had family support and, furthermore, they were encouraged to follow dietary recommendation by health 
coaches (i.e., HF navigator, home health aide and tele- nurse) from inpatient to transition to home. Every patient's situation is unique: nurses may need to be trained how to ask and what to teach, possibly using the case scenario and simulation technique.

In the current study, all the participants utilized a pill box to adhere to medication regimens. Even some of them admitted that although they had to live on limited financial resources, they all had access to medication. No adverse drug events were reported as reasons for nonadherence, though all of them were on polypharmacy.

Fluid restriction is an important topic to address for HF patients as part of self-care teaching. In the current study, one patient admitted that she may have consumed a little over the limit. Most patients reported knowing the limit and adhering to fluid restriction with support of family members.

Symptom recognition is the hallmark of self-care management in persons with heart failure (Riegel et al., 2012). Delay in seeking care is cited as reasons for rehospitalization or mortality for heart failure patients (Annema et al., 2009; Friedman \& Quinn, 2008; Jurgens et al., 2009). The systemic review conducted by Clark et al. (2012) suggests that the help-seeking decision in people with heart failure can be facilitated by good involvement and frank communication between patients, caregivers, and health professionals. In the current study, for all the participants, there was urgent need for readmission for symptom relief and no one delayed seeking help from the medical providers. This finding is very important in terms of effectiveness of evidence based practice interventions offered for the participants. Jurgens et al. (2009) reported contrary results with this study's findings; participants in the Jurgens et al. study delayed seeking help with many reasons. The reasons that led participants to poor symptom recognition included social (e.g., prior negative hospital experiences, and financial concerns), 
cognitive, and emotional (e.g. anxiety) factors, etc. The majority of participants in the 2009 Jurgens et al. study did not report symptoms to caregivers; only $25 \%$ of the sample $(n=77)$ contacted family members. The Patel et al. 2007 study reported similar findings: 57\% of the participants delayed seeking care earlier since they could neither recognize worsening symptoms nor were they certain they needed care. Patel et al. suggest including caregivers in educating symptom recognition and response.

In the current study and in all 9 participants' cases, family members or home health aides were present or patients contacted family members when the symptom arose and got worse, and the patient and family members took actions. Most participants believed that by following the clinicians' recommendations on self-care adherence, they can prevent coming back to the hospital. One participant (Patient 6) asserted that she had a strong trust for her doctor's expertise at this mid-Atlantic medical center by stating:

I passed several hospitals and came here; they know what they are doing (quote from Patient 6).

The findings in the current study support that participants demonstrated optimal self-care behavior (recognizing the early symptoms of impending decompensation and taking timely action for seeking help) in order to reduce hospital readmission. Symptom monitoring is challenging especially when patients have to differentiate HF symptoms from those signaling other conditions (Jurgens, Lee, Reitano, \& Riegel, 2013). It is necessary for the clinicians to cover broad aspects of symptom recognition beyond HF disease-specific symptoms when they teach patients and caregivers about symptom monitoring at home.

\section{Optimal Self-Care Coaching}


In the current study, most of the participants were supported by $\mathrm{H} 2 \mathrm{H}, 3 \mathrm{H}$, and $\mathrm{C} 3$. Patients conveyed that they were satisfied with teaching provided in the hospital by nurses and doctors. They also reported that self-care teaching continued in their own homes, enhanced by home health and telemonitoring services. They voiced: "They felt they were served and secured by being continuously coached on how to monitor symptoms and take actions".

The two distinct programs ( $3 \mathrm{H}$ and $\mathrm{C} 3$ ) that the current study participants exposed have remote technology application. These two programs utilized the concept of transitional coaches (either home health aide and/or a C3 nurse). They served patients as a private coach to assist patients with self-care management at home. They continue to address the self-care aspects of heart failure: by assessing and reassessing the patient in terms of knowledge about the diagnosed condition, coaching (motivational interviewing, encouraging), reinforcing the need to monitor vital signs, weight, and how to interpret and seek care in a timely manner. The $\mathrm{C} 3$ nurse also served as a private case manager: analyzing the patient's transferred data by telemonitoring systems and providing snap shots of patient data for the primary care physician, and arranging immediate visits to a local clinic, as necessary. The home health aide in the $3 \mathrm{H}$ team performed a similar function by being a mediator between the patient at home and the nurse practitioner in the office.

In a review (McGreal, Hogan, Walsh-Irwin, Maggio, Jurgens, 2014) of heart failure selfcare interventions to reduce rehospitalization, HF education was the core of all intervention. The educational intervention included instrumental support (weight scales, pill boxes, and measuring cups), a telemonitoring system with weight and blood pressure capability, and monitoring and reinforcement of education with follow-up telephone calls. Another systematic review on transitional care interventions targeting chronically ill adults (Naylor et al., 2011) reported many 
of the successful interventions share similar features: assigning a nurse as the clinical manager or leader of care and including in-person visits to discharged patients.

The investigator believes the reasons for our participants to perceive satisfaction from these transitional care programs may not be just from instrumental support (e.g., close monitoring of weight or vital sign via telemonitoring or home health aide visit). The source of satisfaction must have come from the psychological support they received through the continued interaction with C3 nurses or home visit nurse aides who were assigned to them. The current interview data confirmed that participants not only felt continuously monitored and coached what to do and how to do, but they felt safe because the coaches were present either physically or on the phone. The enhanced self-confidence, satisfaction with relationship based caring or presence, and self-esteem from being part of the communication and decision making process, were evident in their reports. The investigator summarizes the patients' overall experience as such, "Somebody is out there watching over me. My doctor is calling me every day. The nurses are teaching me what to observe, how to do, and when to contact them and they brought me back here to fix my heart. I believe in my doctors. They are good and I am on good programs. They will help me to get better." The patient called the nurse practitioner as her doctor and did not differentiate a nurse aide from a registered nurse, but the patient did not seem frustrated, although she was rehospitalized. The patients were empowered with self-care knowledge, selfcare confidence, learning about their condition with clinical feedback, and absolutely believing in their providers' ability to help them. The continued communication process between clinicians and patients that guided patients to learn about skills in HF self-care management (e.g., detecting a change in health status and how to respond to worsening symptoms) must be perceived as the source of patient satisfaction by improving self-care confidence. An important finding from this 
study is that the continuous monitoring and self-care coaching were key successful strategies, which were identified by the 2013 Jurgens et al. study.

Fairbrother et al. (2013) explored the views of patients with HF on a telemonitoring service. The participants in their study felt reassurance arising from what was perceived as continuous practitioner surveillance. Social support contributes to success in managing chronic illness. Riegel and Dickson (2008) proposed in their situation-specific theory of HF self-care, that social support improves self-care confidence and thereby improves patients' abilities to perform self-care. Dansky et al.'s (2008) study tested this situation-specific theory of HF selfcare and found that the use of telehealth facilitated patients' confidence in self-care. Subsequently, the patient's ability to adhere to a self-care regimen was enhanced in the intervention group compared to the control group (home visits only). The Health Belief Model seems to be applicable to explain how the support from health care providers serves as 'cues to action' to participants (van der Wal et al., 2010). 'Cues to action' is defined as strategies to activate readiness and is a very appealing concept to explain how clinicians can use appropriate reminder systems to assist patients' self-care adherence. However, 'cues to action' has never been systematically studied (Champion \& Skinner, 2008). As part of the HF disease management program, structured tailored message intervention became more popular. Sethares and Elliott (2004) examined the effect of a tailored message intervention by evaluating health beliefs of HF patients regarding perceived benefits and barriers to HF self-care. They identified the Health Belief Model as the organizing framework. In their study, the tailored message intervention focused on clients' decreasing barriers to self-care and increasing perceived benefits of action (e.g., adherence to taking medication or sodium restricted diet and self-monitoring for signs of fluid overload). The goal of the tailored message intervention was to improve the readiness of the 
HF patients to perform self-care behaviors, which may lead to improve outcomes (i.e., quality of life or readmission rate). Seto et al. (2012) conducted a qualitative study of 22 heart failure patients on the use of mobile phone based telemonitoring. Patients felt more empowered and less anxious since the physiologic data were reported to the patients frequently to help them make decisions (e.g., restrict salt and fluid, take more diuretic) with real time clinical feedback from clinicians. No empirical study was conducted to test the concept of the Health Behavior Model and the above mentioned patient outcomes. The Health Belief Model may be useful to explain the perceived satisfaction found in the current study. Clinician's direct interaction (e.g., face to face or communication by phone) or indirect interaction (e.g., through telemonitoring) served as 'cue to action' and the continued coaching process (assessment, training. reinforcement, and reevaluation) improved the patient's self-efficacy and confidence in one's ability to take action (Champion \& Skinner, 2008).

In our current study, the use of remote monitoring technology was embedded into the intervention package offered to participants as part of HF disease management to reduce HF readmission. However, thus far, there is no conclusive evidence on the effect of telemonitoring on the outcomes of interest (e.g., reducing HF readmission rate), since most interventions used in clinical trials lacked power to generate statistically significant results. There were some qualitative and clinically-relevant findings that were very promising in improving self-care behavior and self-care confidence (Artinian et al. 2003, and Dansky et al., 2008). But, the structured telephone support is still a main stream mode of intervention, and nurses play an important role in this interventional mode. Technology may not replace the nurse's role in the whole intervention process (e.g., creating, guiding, assessing, evaluating, and modifying based on process outcomes). But, technology reduces the geographical barriers for communication. 
The perceived satisfaction by patients on the educational component in the current study needs to be further researched. Knowledge alone is not sufficient to improve outcomes. The participants felt they were served, supported, and continuously coached by the same health coaches who must have developed a relationship and communicated effectively with a caring attitude.

\section{Patient-Centered Outcomes: Satisfaction on Evidence based Supportive Programs}

Participants in this study reported satisfaction and appreciation regarding support by providers, well-coordinated transitional care, and evidence based programs. This finding suggests from the patients' perspectives that not all readmission seems to be perceived as bad. They did not report any frustration, although some of them reported they were scared when their symptom got worse. Their satisfaction seemed to reflect their experience on the overall care they received: the providers were with them, or on the phone, and directed them what to do. They felt that they were served and allowed to make a decision with family and providers as a team. Some of the participants conveyed their absolute belief in their providers' ability in finding a solution to their health problem that had led them to readmission. In the current study, the participants may have perceived that their readmission event was an extension of self-care management programs, that is, a result of well-coordinated transitional care. They found themselves in the hospital for improvement of their health status and, therefore, in that sense, the participants viewed heart failure readmission as an opportunity for restoration of their health status and further researching into treatment options. From the patient's perspective, the readmission does not suggest poor quality of care. In the current study, their goal of survival was achieved.

In the current study, most patients were supported by post-discharge evidenced based interventions $(\mathrm{H} 2 \mathrm{H}, 3 \mathrm{H}, \mathrm{C} 3$, home physical therapy, etc.) to reduce readmission beside the 
inpatient multidisciplinary care coordination during index stay. On average, the participants were on at least two of the post-discharge interventions. It was not surprising that this extraordinary transitional support was cited by participants as a source of satisfaction and appreciation.

The speculation that the readmission trend in the current study could be the result of wellcoordinated transitional care may be perplexing to the health care system and providers.

However, this is consistent with previous findings where frequent monitoring of symptoms or access to the providers is associated with a higher admission rate (Goldman et al., 2014;

Gorodeski, Starling \& Blackstone, 2010; Herrin et al., 2015; Joynt \& Jha, 2012; Kangovi et al., 2012).

Gorodeski and colleagues (2014) assert that there is a potential association between readmission and mortality and that a higher admission rate may be the result of low mortality rates and good access to hospital care (i.e., a consequence of a successful transitional care). Several other literature (Goldman et al. 2014; Herrin et al. 2015; \& Joynt \& Jha, 2012) also reported similar findings.

Readmission from any cause is perceived as an adverse event; however, readmission can be used as an opportunity for both patients and providers for researching into shared decision making for maximizing therapies and further researching into treatment options. During readmission, patients can not only recuperate their clinical condition but also establish shared care communication and reciprocity (Sebern and Woda, 2012). Therefore, in the current study from the patient's perspective, survival of the sickest person (i.e., high risk for readmission) supported by evidenced based intervention is a positive patient centered outcome. Goal of readmission reduction imposed by CMS may need to be reconsidered. The meaning of 30 day readmission needs to reflect both patients' and providers' perspectives. Reassessment of the 
patient care goal needs to be pursued as a continuous process. Desai and Stevenson (2012) envisioned redesigning models of HF care. In their proposed model, they believe that the optimal strategy for heart failure could vary depending on the care setting, patient capacity for selfmanagement or severity of disease, and patient centered outcomes. The patients' goals include reduction of mortality, hospitalization, improving function, quality of life or death. The conceptual framework proposed for the current study can address their suggestion. With continuing assessment of the patient's changing needs in their own trajectory of disease, healthcare providers can plan a smooth transition of care in the patient's community. This transition centers on well-coordinated communication amongst the patient, family, and team of providers.

\section{Effectiveness of Collective interventions}

The participants in the current study were on several collective interventions. The transitional care interventions arranged by care coordination during the participants' index stay include home-visiting programs, telemonitoring, and outpatient clinic-based care managed by nurse practitioners. Most participants reported positive outcomes on the programs in terms of patient satisfaction and health restoration. The coaching and optimization of therapies in the outpatient setting through the transitional care programs may highlight the most important aspects why the interventions were perceived as effective by the participants. Another explanation for the sources for the participants' satisfaction may be the interpersonal transformation among patients and providers who had been involved in coaching (mainly by the $\mathrm{C} 3$ nurse and home health aide in $3 \mathrm{H}$ ) and continued adjustment of therapies by nurse practitioners or primary care physicians. It was a collective intervention approach, consisting of home visiting, telemonitoring, and outpatient clinic-based care interventions. 
However, there arises a concern whether all interventions must be offered to every patient. It is premature to discuss the effectiveness of collective interventions in the current study, because no study was conducted using the exact combination (e.g., $\mathrm{C} 3$ combined with $3 \mathrm{H}$ ) of interventions as it was in the current study. So far, the evidence shows mixed effect. For the current participants who were high risk for readmission, providing several interventions seemed reasonable. McGreal et al. (2014)'s systematic review found that interventions that augment selfconfidence or self-efficacy to achieve optimal self-care management were useful to reduce clinical events and symptom burden for patients with HF. The interventions offered for participants in the current study were unique because the technology embedded in the programs reduced not only geographical but also time barriers. The nurse practitioners were able to optimize patient therapies timely based on the changes in the patient's status reported by the mediators, the front line coaches, the HHAs and $\mathrm{C} 3$ nurses.

The systematic review on intervention to reduce 30-day rehospitalization by Hansen and colleagues (2011) found that no single intervention implemented alone was associated with reduced risk for 30-day rehospitalization. The 2013 Bradley et al. study supports Hansen et al.'s findings: hospitals that implemented more strategies had significantly lower 30-day readmission rates. Practice recommendations on reducing hospital readmission (Snyderman et al., 2014) also reported collective interventions, such as alternating home visits and follow-up telephone calls may be more effective in reducing readmission than individual interventions.

However, more is not always better; not all patients should be offered all the interventions utilized in the current study. According to Albert et al. (2015), providing more services may not be the answer to decreasing rehospitalization rates in HF. The type of service, service delivery depth and breath, ongoing communication during the service delivery period, 
and quality monitoring for best practices may be more important than simply increasing available services options.

Collective interventions were utilized in the current study and little is known which specific intervention is more effective (Albert \& Trupp, 2014). Continuous monitoring and coaching on self-care management thorough transitional care programs were perceived positive for the participants in the current study. There is a need to tailor interventions: tailoring intervention to meet the needs of every patient is challenging. Every patient's goal differs. Depending on outcomes of interest (reducing symptom burden, improving quality of life, morbidity, mortality, and hospitalization) suggested by Mc Greal and colleagues (2014), clinicians and patients must make a shared decision on choice and dose of intervention.

\section{Room for Improvement}

Three participants reported that they could have stayed a little longer during index admission. They expressed their opinion that the readmission could be avoidable if the patients stayed longer in the hospital during the first admission.

Similarly to the findings of the current study, Kirk et al. (2006) found about one third of the patients and caregivers expressed that readmission could be avoidable if the patients stayed longer in the hospital during the first admission or had greater support in the community after discharge.

However, in the current study, no one felt that they were not ready for discharge. In most cases, a physical therapist evaluated the patient's functional status to ensure the patient's safety at home. Three patients were discharged with home physical therapy. The participants believed that the extra days may have enabled them to learn more about their condition and providers could further research into other treatment options. Three participants in the current study 
identified the need for more detailed and tailored learning to understand their disease process. The patients' desire to learn about the disease process may differ in terms of their characteristics, role in their self-care, and comorbid conditions. Clinicians may have to provide patients with both specific and generic contents of symptom monitoring and action plan in order to cover all underlying health problems (e.g. symptoms of myocardial infarction, infection, how normal differs from abnormal), so that they can be well-prepared for future health crises (Slatyer, 2013). Williams (2013) and Scott, Shohag, \& Ahmed (2014) also suggest the comprehensive patient centered approaches may be more effective to reduce readmission than standard disease focused intervention.

One male participant, reporting that his liver and kidney were failing beside his heart, complained that teaching and care-coordination were not perfect and disjointed. He suggested to have a better coordination between disciplines. His case signifies the need for tailoring interventions: every patient differs in terms of need and support, and where they are in the phase of disease. His comorbid conditions are challenging for health care providers to research into further treatment options. However, the patient's voice needs to be heard and his need for searching answers to his problems must be addressed to provide effective patient centered care.

The chart review revealed only one patient had bilateral crackles on the discharge note. There was no evidence that patients were unstable for discharge, and the patients confirmed that they felt ready for discharge.

The final discussion point raised by a 60 year old female participant focuses on promoting provider sensitivity in initiating the end of life care talk with patients. This patient survived in the cardiac intensive care unit after refusing the code status change to 'Do not resuscitate (DNR) or Do not intubate (DNI)' in the step-down unit: she became emotional when 
she recalled the experience of meeting the palliative care team without having any notification of the consultation. This patient addressed that the health care providers must demonstrate empathy and cultural competence in this sensitive topic, and suggested to include family members in initiating the talk.

Advance care planning is the process of discussing and recording patient preferences regarding goals of care for patients who may lose capacity or communication ability in the future (Brinkman-Stoppelenburg, Rietjens, \& van 2014). Advance care planning could potentially reduce hospitalizations and improve end of life care but health care providers require training on how to initiate the talk with patients and families or refer to palliative consultation. It may be vital that health care providers have some holistic training on end of life care and mindfulness practice before they meet with the patients and families during their highly emotive time, the end of life. Interprofessional education with some innovative teaching methods (e.g., role play and simulation) may be necessary for medical and nursing professionals to facilitate their comfort level. Clinicians across settings may need to collaborate in order to initiate, and continue to discuss the end of life care to their patients and families.

\section{Final Suggestion}

The findings of this study support the need for continuing research on effective interventions to integrate efforts on the clinician, hospital, and system level to improve patient outcomes (Gheorghiade et al., 2013). New innovative models of care, such as adding the new pharmacy transitional coach or specialty consultation in the community, may be promising in order to optimize pharmacological intervention and facilitate the patient's navigating between specialties in the community and avoiding unnecessary rehospitalization (Fera et al., 2014). The investigator's final comment is that, during the study period (May to August 2014), the roles of 
inpatient HF nurse practitioner and HF navigator were not substantially visible. The chart review has not noted any specific evidence that in patient units were using the Teach Back method, one of The Joint Commission's recommendations to improve patients' self-care teaching (White, Garbez, Carroll, Brinker, \& Howie-Esquivel, 2013).

\section{Summary}

Patients voiced satisfaction and appreciation about the care they received during index, community, and rehospitalization. Exacerbation of HF or chronic illness was the main reasons for readmission. Readmission trends at this mid-Atlantic medical center in the current study exemplified the high quality of inpatient care (teaching, optimization of treatment, and discharge planning) and seamless transitional care. The findings of this qualitative study suggest that the root causes for readmission (e.g., poverty or uninsured status) may be solved only at the health system level. The mid-Atlantic medical center was successful in improving patient experience.

\section{Strengths and Weaknesses of the Design}

Strengths of the study include the qualitative inquiry on the timely important topic: patients' perspective on how to reduce rehospitalization and utilizing conceptual framework to analyze the complicated phenomenon and patients' decision making process in service utilization. The chart review was conducted for triangulation of the findings from patients' interviews; however, interviews from families and providers, and observation (e.g., teaching, admission or discharge process) could have strengthened the trustworthiness of the findings.

Limitations of this study include small sample size, recruitment only within a single academic teaching hospital, and findings possibly not generalizable to other hospital settings. Another limitation is that the researcher was the sole interviewer and chart reviewer for this study, so researcher's bias was possible. 


\section{Nursing Practice Implications: Integrating patient input into nursing process}

The findings of this qualitative study have several implications for nursing practice. The interview guide is simple and plausible for clinicians (e.g., HF navigator and case manager) to replicate as a readmission interview instrument in order to tailor interventional strategies. The chart review instrument can be also adapted and used as a worksheet to collect data and it will be useful for identifying whether clinicians missed any opportunities during the index stay and improving strategies to tailor interventions during the readmission period. The findings of the current study suggest that LACE index could be a powerful tool to identify the high risk patients for readmission. Currently, the LACE tool is being used only by social workers and case managers at the mid-Atlantic medical center. The investigator suggests extending the availability of this tool to staff nurses, HF nurse practitioners, and HF navigators for identifying high risk patients for readmission and tailor interventions.

The strengths of the interventions used at this mid-Atlantic medical center, found by the current study, are including caregivers in the self-care management process and reinforcement of coaching and utilizing timely follow-up care in the community by tapping into both intensive human and technology application. The identification of deteriorating conditions was ensued by continuous monitoring systems focusing on empowering interpersonal relationship. The optimization of therapy was achieved in the proactive care environment (e.g., remote communication through home health aide visits, telephone follow up, and clinic visits); thus, the care was perceived as satisfactory and positive by the patients.

The relevant findings of this study suggest the most important nursing practice toward a patient-centered approach: clinicians must listen to patients and their caregivers before mobilizing any evidence based interventional strategies to reduce HF readmission. Nurses are 
best positioned to be modeled by other clinicians for this most important basic nursing intervention: "being present and listening" to the patient's story. The story will reveal the patient's personal value and preference in learning and treatment goal, and the socio-cultural text that can provide clinicians with some knowledge and insight on how to initiate any intervention. For example, initiating talk about the end of life is recommended by the Evidence Based Practice guideline for patients with HF or chronic diseases; however, clinicians require more training to be sensitive in their choice of language or in exploring how to approach patients and families before initiating any therapy or consultation. Interprofessional education utilizing simulation at undergraduate or postgraduate residency programs may be an effective strategy. Clinicians require more practice on how to listen and talk in order to assist patients and families to learn about distressful prognosis and treatment options available for end of life care.

\section{Nursing Research Implications: Time for dissemination}

The innovative strategies (i.e., well-coordinated care and extraordinary efforts supported by evidence based collective intervention to reduce 30 day readmission for patients with HF) that worked at this mid-Atlantic medical center could be shared with other hospitals to be leaders in transitional care coordination for the communities. Researchers may replicate the interventions in other teaching and community hospitals focusing on the feasibility and cost effectiveness of the strategies.

It is time for researchers and clinicians at this mid-Atlantic medical center to pursue for the right outcomes research (Albert et al., 2015). This mid-Atlantic medical center may need to evaluate the cost effectiveness of collective interventions using a randomized controlled method; the questions of which patients, what interventions, and duration of interventions must be explored. 


\section{Conclusion}

At this mid-Atlantic medical center, HF readmission rate is lower than the national rate ( $17 \%$ in the hospital, and $7 \%$ in the $\mathrm{H} 2 \mathrm{H}$ program at this mid-Atlantic medical center). Exacerbation of heart failure or chronic illness was the main reason for readmission. The findings of the current study suggest that readmission trends at this medical center did not implicate poor quality of care during the index stay. Rather, the readmission experienced by study participants exemplified the high quality of inpatient care (teaching, optimization of treatment, and discharge planning) and seamless transitional care, although their readmissions were not prevented. Readmission was perceived as an opportunity for both patients and clinicians to reflect and research into new avenues for improvement. Patients voiced satisfaction and appreciation about care received during index, community, and rehospitalization. The reasons for readmission were multifactorial, and the readmission trend reflected the high risk patient population characteristics (e.g., severity of illness, coexisting conditions, race, and socioeconomic status) this mid-Atlantic medical center served. The findings of this qualitative study suggest that the root causes for readmission may be solved only at the health system level. The innovative strategies (i.e., well-coordinated care and extraordinary efforts supported by evidence based practice collective intervention to reduce 30 day readmission for patients with heart failure) that worked at this medical center could be shared with other hospitals to be leaders in transitional care coordination for the communities. 


\section{References}

Albert, N. M., \& Trupp, R. (2014). Decreasing heart failure revisits. Current Emergency and Hospital Medicine Reports, 2(2), 120-125.

Albert, N. M., Barnason, S., Deswal, A., Hernandez, A., Kociol, R., Lee, E., . . American Heart Association Complex Cardiovascular Patient and Family Care Committee of the Council on Cardiovascular and Stroke Nursing, Council on Clinical Cardiology, and Council on Quality of Care and Outcomes Research. (2015). Transitions of care in heart failure: A scientific statement from the American Heart Association. Circulation.Heart Failure, 8(2), 384-409. doi:10.1161/HHF.0000000000000006 [doi]

Anderson, K. M. (2014). Discharge clinical characteristics and 60-day readmission in patients hospitalized with heart failure. The Journal of Cardiovascular Nursing,

Annema, C., Luttik, M., \& Jaarsma, T. (2009). Reasons for readmission in heart failure:

Perspectives of patients, caregivers, cardiologists, and heart failure nurses. Heart \& Lung: The Journal of Acute and Critical Care, 38(5), 427-434.

Artinian, N. T., Harden, J. K., Kronenberg, M. W., Vander Wal, J. S., Daher, E., Stephens, Q., \& Bazzi, R. I. (2003). Pilot study of a web-based compliance monitoring device for patients with congestive heart failure. Heart \& Lung: The Journal of Acute and Critical Care, 32(4), 226-233. doi:http://dx.doi.org/10.1016/S0147-9563(03)00026-8

Baker, D. W., DeWalt, D. A., Schillinger, D., Hawk, V., Ruo, B., Bibbins-Domingo, K., . . . Pignone, M. (2011). "Teach to goal": Theory and design principles of an intervention to improve heart failure self-management skills of patients with low health literacy. Journal of Health Communication, 16(Suppl 3), 73-88. 
Berenson, J., \& Shih, A. (2012). Higher readmissions at safety-net hospitals and potential policy solutions. Issue Brief (Commonw Fund), 34, 1-16.

Black, J. T. (2014). POLICY. Learning about 30-day readmissions from patients with repeated hospitalizations. American Journal of Managed Care, 20(6), e200-e207. Retrieved from http://search.ebscohost.com/login.aspx?direct=true \&db=a9h\&AN=96892344\&site=ehostlive

Black, J. T., Romano, P. S., Sadeghi, B., Auerbach, A. D., Ganiats, T. G., Greenfield, S., .. . Ong, M. K. (2014). A remote monitoring and telephone nurse coaching intervention to reduce readmissions among patients with heart failure: Study protocol for the better effectiveness after transition - heart failure (BEAT-HF) randomized controlled trial. Trials, 15(1), 1-20. doi:10.1186/1745-6215-15-124

Boutwell, A. E., Johnson, M. B., Rutherford, P., Watson, S. R., Vecchioni, N., Auerbach, B. S., . . Wagner, C. (2011). An early look at a four-state initiative to reduce avoidable hospital readmissions. Health Affairs, 30(7), 1272-1280.

Boyd, K. J., Murray, S. A., Kendall, M., Worth, A., Benton, T. F., \& Clausen, H. (2004). Living with advanced heart failure: A prospective, community based study of patients and their carers. European Journal of Heart Failure, 6(5), 585-591.

Bradley, E. H., Curry, L., Horwitz, L. I., Sipsma, H., Thompson, J. W., Elma, M., . . Krumholz, H. M. (2012). Contemporary evidence about hospital strategies for reducing 30-day ReadmissionsA national study. Journal of the American College of Cardiology, 60(7), 607614. 
Brinkman-Stoppelenburg, A., Rietjens, J. A. C., \& van, d. H. (2014). The effects of advance care planning on end-of-life care: A systematic review. Palliative Medicine, 28(8), 1000-1025. doi: $10.1177 / 0269216314526272$

Browning, S., \& Waite, R. (2010). The gift of listening: JUST listening strategies. Nursing Forum, 45(3), 150-158. doi:10.1111/j.1744-6198.2010.00179.x

Champion, V. L., \& Skinner, C. S. (2008). The health belief model. Health Behavior and Health Education: Theory, Research, and Practice, 4, 45-65.

Charnock, L. A. (2014). End of life care services for patients with heart failure. Nursing Standard, 28(51), 35-41. Retrieved from http://search.ebscohost.com/login.aspx?direct=true \&db=a9h\&AN=97579484\&site=ehostlive

Clark, A. M., Freydberg, C. N., McAlister, F. A., Tsuyuki, R. T., Armstrong, P. W., \& Strain, L. A. (2009). Patient and informal caregivers' knowledge of heart failure: Necessary but insufficient for effective self-care. European Journal of Heart Failure, 11(6), 617-621. Clark, A. M., Savard, L. A., Spaling, M. A., Heath, S., Duncan, A. S., \& Spiers, J. A. (2012). Understanding help-seeking decisions in people with heart failure: A qualitative systematic review. International Journal of Nursing Studies, 49 (12), 1582-1597. doi:http://dx.doi.org/10.1016/j.ijnurstu.2012.05.010

Collins, S. P., Pang, P. S., Fonarow, G. C., Yancy, C. W., Bonow, R. O., \& Gheorghiade, M. (2013). Is hospital admission for heart failure really necessary? The role of the emergency department and observation unit in preventing hospitalization and rehospitalization. Journal of the American College of Cardiology, 61(2), 121-126. 
Corbin, J. M. (1998). The corbin and strauss chronic illness trajectory model: An update. Scholarly Inquiry for Nursing Practice,

Corbin, J., \& Strauss, A. (2014). Basics of qualitative research: Techniques and procedures for developing grounded theory Sage publications.

Covington, H. (2003). Caring presence delineation of a concept for holistic nursing. Journal of Holistic Nursing, 21(3), 301-317.

Creswell, J. W. (2012). Qualitative inquiry and research design: Choosing among five approaches Sage.

Creswell, J. W. (2013). Research design: Qualitative, quantitative, and mixed methods approaches Sage Publications, Incorporated.

Dansky, K. H., Vasey, J., \& Bowles, K. (2008). Use of telehealth by older adults to manage heart failure. Research in Gerontological Nursing, 1(1), 25-32.

Delaney, C., Apostolidis, B., Bartos, S., Robbins, R., \& Young, A. K. (2014). Pilot testing of the home care education, assessment, remote-monitoring, and therapeutic activities intervention. Home Health Care Management \& Practice, 26(4), 205-216.

Dickson, V. V., McCarthy, M. M., Howe, A., Schipper, J., \& Katz, S. M. (2013). Sociocultural influences on heart failure self-care among an ethnic minority black population. Journal of Cardiovascular Nursing, 28(2), 111-118.

Donabedian, A. (1968). Promoting quality through evaluating the process of patient care. Medical Care, 6(3), 181-202.

Fairbrother, P., Ure, J., Hanley, J., McCloughan, L., Denvir, M., Sheikh, A., \& McKinstry, B. (2014). Telemonitoring for chronic heart failure: The views of patients and healthcare 
professionals - a qualitative study. Journal of Clinical Nursing, 23(1), 132-144.

doi:10.1111/jocn.12137

Feigenbaum, P., Neuwirth, E., Trowbridge, L., Teplitsky, S., Barnes, C. A., Fireman, E., . .

Bellows, J. (2012). Factors contributing to all-cause 30-day readmissions: A structured case series across 18 hospitals. Medical Care, 50(7), 599-605.

doi:10.1097/MLR.0b013e318249ce72 [doi]

Feltner, C., Jones, C. D., Cené, C. W., Zhi-Jie Zheng, Sueta, C. A., Coker-Schwimmer, E., . . . Jonas, D. E. (2014). Transitional care interventions to prevent readmissions for persons with heart failure. Annals of Internal Medicine, 160(11), 774-784. Retrieved from http://search.ebscohost.com/login.aspx?direct=true \&db=a9h\&AN=96295546\&site=ehostlive

FERA, T., ANDERSON, C., KANEL, K. T., \& RAMUSIVICH, D. L. (2014). Role of a care transition pharmacist in a primary care resource center. American Journal of Health-System Pharmacy, 7l(18), 1585-1590. doi:10.2146/ajhp130684

Fredriksson, L. (1999). Modes of relating in a caring conversation: A research synthesis on presence, touch and listening. Journal of Advanced Nursing, 30(5), 1167-1176.

Freydberg, N., Strain, L., Tsuyuki, R. T., McAlister, F. A., \& Clark, A. M. (2010). "If he gives in, he will be gone...": The influence of work and place on experiences, reactions and selfcare of heart failure in rural Canada. Social Science \& Medicine, 70(7), 1077-1083.

Friedman, M. M., \& Quinn, J. R. (2008). Heart failure patients' time, symptoms, and actions before a hospital admission. Journal of Cardiovascular Nursing, 23(6), 506-512.

Gannuscio, J. R. (2012). Testing a 30-day readmission risk calculator in a veteran population with heart failure: A pilot study. 
Gheorghiade, M., Vaduganathan, M., Fonarow, G. C., \& Bonow, R. O. (2013). Rehospitalization for Heart Failure Problems and perspectives. Journal of the American College of Cardiology, 61(4), 391-403.

Goldman, L. E., Sarkar, U., Kessell, E., Guzman, D., Schneidermann, M., Pierluissi, E., .. . Kushel, M. (2014). Support from hospital to home for elders. Annals of Internal Medicine, 161(7), 472-481. doi:10.7326/M14-0094

Goldsmith, S. R., Bart, B. A., \& Burnett, J. (2014). Decongestive therapy and renal function in acute heart failure: Time for a new approach? Circulation. Heart Failure, 7(3), 531-535. doi:10.1161/CIRCHEARTFAILURE.113.000828 [doi]

Gorodeski, E. Z., Starling, R. C., \& Blackstone, E. H. (2010). Are all readmissions bad readmissions? New England Journal of Medicine, 363(3), 297-298.

Granger, B. B., Sandelowski, M., Tahshjain, H., Swedberg, K., \& Ekman, I. (2009). A qualitative descriptive study of the work of adherence to a chronic heart failure regimen: Patient and physician perspectives. Journal of Cardiovascular Nursing, 24(4), 308-315.

Granger, B. B., Sandelowski, M., Tahshjain, H., Swedberg, K., \& Ekman, I. (2009). A qualitative descriptive study of the work of adherence to a chronic heart failure regimen: Patient and physician perspectives. Journal of Cardiovascular Nursing, 24(4), 308-315. Green, J., \& Thorogood, N. (2004). Qualitative methods for health research Sage. Gruneir, A., Dhalla, I. A., van Walraven, C., Fischer, H. D., Camacho, X., Rochon, P. A., \& Anderson, G. M. (2011). Unplanned readmissions after hospital discharge among patients identified as being at high risk for readmission using a validated predictive algorithm. Open Medicine, 5(2), e104. 
Gu, Q., Koenig, L., Faerberg, J., Steinberg, C. R., Vaz, C., \& Wheatley, M. P. (2014). The medicare hospital readmissions reduction program: Potential unintended consequences for hospitals serving vulnerable populations. Health Services Research, 49(3), 818-837. doi:10.1111/1475-6773.12150

Hansen, L. O., Young, R. S., Hinami, K., Leung, A., \& Williams, M. V. (2011). Interventions to reduce 30-day rehospitalization: A systematic review. Annals of Internal Medicine, 155(8), $520-528$.

Heidenreich, P. A., Albert, N. M., Allen, L. A., Bluemke, D. A., Butler, J., Fonarow, G. C., . . . Maddox, T. M. (2013). Forecasting the impact of heart failure in the United States A policy statement from the American heart association. Circulation: Heart Failure, 6(3), 606-619.

Heidenreich, P. A., Hernandez, A. F., Yancy, C. W., Liang, L., Peterson, E. D., \& Fonarow, G. C. (2012). Get with the guidelines program participation, process of care, and outcome for Medicare patients hospitalized with heart failure. Circulation. Cardiovascular Quality and Outcomes, 5(1), 37-43. doi:10.1161/CIRCOUTCOMES.110.959122 [doi]

Hekmatpou, D., Mohammadi, E., Ahmadi, F., \& Arefi, S. H. (2009). Lack of sensitivity to readmission: A grounded theory study for explaining the process of readmitting patients suffering from congestive heart failure. European Journal of Cardiovascular Nursing, 8(5), $355-363$.

Hekmatpou, D., Mohammadi, E., Ahmadi, F., \& Arefi, S. H. (2010). Termination of professional responsibility: Exploring the process of discharging patients with heart failure from hospitals. International Journal of Nursing Practice, 16(4), 389-396. 
Helleso, R., Eines, J., \& Fagermoen, M. S. (2012). The significance of informal caregivers in information management from the perspective of heart failure patients. Journal of Clinical Nursing, 21(3-4), 495-503.

Heo, S., Lennie, T. A., Moser, D. K., \& Okoli, C. (2009). Heart failure patients' perceptions on nutrition and dietary adherence. European Journal of Cardiovascular Nursing, 8(5), 323328.

Herrin, J., St Andre, J., Kenward, K., Joshi, M. S., Audet, A. J., \& Hines, S. C. (2014). Community factors and hospital readmission rates. Health Services Research,

Hersh, A. M., Masoudi, F. A., \& Allen, L. A. (2013). Post-discharge environment following heart failure hospitalization: Expanding the view of hospital readmission. Journal of the American Heart Association, 2(2)

Hodges, P. (2009). Factors impacting readmissions of older patients with heart failure. Critical Care Nursing Quarterly, 32(1), 33-43.

Holland, D. E., Mistiaen, P., \& Bowles, K. H. (2011). Problems and unmet needs of patients discharged "home to self-care". Professional Case Management, 16(5), 240-250.

Hummel, S. L., Katrapati, P., Gillespie, B. W., DeFranco, A. C., \& Koelling, T. M. (2014). Impact of prior admissions on 30-day readmissions in Medicare heart failure inpatients. Mayo Clinic Proceedings, 89(5), 623-630. doi:10.1016/j.mayocp.2013.12.018

Jack, B. W., Chetty, V. K., Anthony, D., Greenwald, J. L., Sanchez, G. M., Johnson, A. E., . . . Manasseh, C. (2009). A reengineered hospital discharge program to decrease Rehospitalization A randomized trial. Annals of Internal Medicine, 150(3), 178-187.

Janz, N. K., \& Becker, M. H. (1984). The health belief model: A decade later. Health Education \& Behavior, 11(1), 1-47. 
Joynt, K. E., \& Jha, A. K. (2012). Thirty-day readmissions - truth and consequences. New England Journal of Medicine, 366(15), 1366-1369.

Jurgens, C. Y., Lee, C. S., Reitano, J. M., \& Riegel, B. (2013). Heart failure symptom monitoring and response training. Heart \& Lung: The Journal of Acute and Critical Care, 42(4), 273-280.

Jurgens, C. Y., Hoke, L., Byrnes, J., \& Riegel, B. (2009). Why do elders delay responding to heart failure symptoms? Nursing Research, 58(4), 274-282.

doi:10.1097/NNR.0b013e3181ac1581; 10.1097/NNR.0b013e3181ac1581

Jurgens, C. Y., Lee, C. S., Reitano, J. M., \& Riegel, B. (2013). Heart failure symptom monitoring and response training. Heart \& Lung: The Journal of Acute and Critical Care, 42(4), 273-280. doi:http://dx.doi.org/10.1016/j.hrtlng.2013.03.005

Kangovi, S., Grande, D., Meehan, P., Mitra, N., Shannon, R., \& Long, J. A. (2012). Perceptions of readmitted patients on the transition from hospital to home. Journal of Hospital Medicine, 7(9), 709-712.

Kansagara, D., Englander, H., Salanitro, A., Kagen, D., Theobald, C., Freeman, M., \& Kripalani, S. (2011). Risk prediction models for hospital readmission. JAMA: The Journal of the American Medical Association, 306(15), 1688-1698.

Kirk, E., Prasad, M. K., \& Abdelhafiz, A. H. (2006). Hospital readmissions: Patient, carer and clinician views. Acute Medicine, 5(3), 104-107.

Kleinman, A., Eisenberg, L., \& Good, B. (2006). Culture, illness, and care: Clinical lessons from anthropologic and cross-cultural research. FOCUS: The Journal of Lifelong Learning in Psychiatry, 4(1), 140-149. 
Lee, C. S., Mudd, J. O., Hiatt, S. O., Gelow, J. M., Chien, C., \& Riegel, B. (2014). Trajectories of heart failure self-care management and changes in quality of life. European Journal of Cardiovascular Nursing: Journal of the Working Group on Cardiovascular Nursing of the European Society of Cardiology, doi:1474515114541730 [pii]

Lees, C. (2011). Measuring the patient experience. Nurse Researcher, 19(1), 25-28.

Lekander, B. J., Lehmann, S., \& Lindquist, R. (1993). Therapeutic listening: Key intervention for several nursing diagnoses. Dimensions of Critical Care Nursing, 12(1), 24-30. Mahramus, T., Penoyer, D. A., Frewin, S., Chamberlain, L., Wilson, D., \& Sole, M. L. (2014). Assessment of an educational intervention on nurses' knowledge and retention of heart failure self-care principles and the teachback method. Heart \& Lung: The Journal of Acute and Critical Care, 43(3), 204-212.

McCarthy, D., Johnson, M. B., \& Audet, A. (2013). Recasting readmissions by placing the hospital role in community context. Jama, 309(4), 351-352.

McGreal, M. H., Hogan, M. J., Walsh-Irwin, C., Maggio, N. J., \& Jurgens, C. Y. (2014). Heart failure self-care interventions to reduce clinical events and symptom burden. Research Reports in Clinical Cardiology, 5, 243-257. doi:10.2147/RRCC.S48424

McSweeney, J. C., Allan, J. D., \& Mayo, K. (1997). Exploring the use of explanatory models in nursing research and practice. Journal of Nursing Scholarship, 29(3), 243-248.

Mead, H., Andres, E., Ramos, C., Siegel, B., \& Regenstein, M. (2010). Barriers to effective selfmanagement in cardiac patients: The patient's experience. Patient Education and Counseling, 79(1), 69-76. doi:http://dx.doi.org/10.1016/j.pec.2009.08.003 
Mozaffarian, D., Benjamin, E. J., Go, A. S., Arnett, D. K., Blaha, M. J., Cushman, M., . . .

Howard, V. J. (2015). Executive summary: Heart disease and stroke Statistics - 2015 update A report from the American heart association. Circulation, 131(4), 434-441.

Mulder, B. J., Tzeng, H., \& Vecchioni, N. D. (2012). Preventing avoidable rehospitalizations by understanding the characteristics of "Frequent fliers". Journal of Nursing Care Quality, 27(1), 77-82.

Naylor, M. D., Aiken, L. H., Kurtzman, E. T., Olds, D. M., \& Hirschman, K. B. (2011). The care span: The importance of transitional care in achieving health reform. Health Affairs (Project Hope), 30(4), 746-754. doi:10.1377/hlthaff.2011.0041 [doi]

Patel, H., Shafazand, M., Schaufelberger, M., \& Ekman, I. (2007). Reasons for seeking acute care in chronic heart failure. European Journal of Heart Failure, 9(6-7), 702-708.

People, H., \& US Department of Health and Human Services. (2011). Healthy People 2020,

Piamjariyakul, U., Smith, C. E., Werkowitch, M., \& Elyachar, A. (2012). Part I: Heart failure home management: Patients, multidisciplinary health care professionals and family caregivers' perspectives. Applied Nursing Research, 25(4), 239-245.

Polit, D. F., \& Beck, C. T. (2008). Nursing research: Generating and assessing evidence for nursing practice Lippincott Williams \& Wilkins.

Retrum, J. H., Boggs, J., Hersh, A., Wright, L., Main, D. S., Magid, D. J., \& Allen, L. A. (2013). Patient-identified factors related to heart failure readmissions. Circulation: Cardiovascular Quality and Outcomes, 6(2), 171-177.

Riegel, B., Dickson, V. V., Cameron, J., Johnson, J. C., Bunker, S., Page, K., \& Worrall-Carter, L. (2010). Symptom recognition in elders with heart failure. Journal of Nursing Scholarship, 42(1), 92-100. 
Riegel, B., Moser, D. K., Anker, S. D., Appel, L. J., Dunbar, S. B., Grady, K. L., . . Lindenfeld, J. (2009). State of the science promoting self-care in persons with heart failure: A scientific statement from the American Heart Association. Circulation, 120(12), 1141-1163.

Riegel, B., \& Dickson, V. V. (2008). A situation-specific theory of heart failure self-care. The Journal of Cardiovascular Nursing, 23(3), 190-196.

doi:10.1097/01.JCN.0000305091.35259.85 [doi]

Riegel, B., Dickson, V. V., Kuhn, L., Page, K., \& Worrall-Carter, L. (2010). Gender-specific barriers and facilitators to heart failure self-care: A mixed methods study. International Journal of Nursing Studies, 47(7), 888-895.

doi:http://dx.doi.org/10.1016/j.ijnurstu.2009.12.011

Rodriguez, K. L., Appelt, C. J., Switzer, G. E., Sonel, A. F., \& Arnold, R. M. (2008). “They diagnosed bad heart": A qualitative exploration of patients' knowledge about and experiences with heart failure. Heart \& Lung: The Journal of Acute and Critical Care, $37(4), 257-265$.

Rogers, A., Addington-Hall, J. M., McCoy, A. S., Edmonds, P. M., Abery, A. J., Coats, A. J., . . . Gibbs, R. (2002). A qualitative study of chronic heart failure patients' understanding of their symptoms and drug therapy. European Journal of Heart Failure, 4(3), 283-287.

Rogers, A., Kennedy, A., Nelson, E., \& Robinson, A. (2005). Uncovering the limits of patientcenteredness: Implementing a self-management trial for chronic illness. Qualitative Health Research, 15(2), 224-239.

Saldaña, J. (2012). The coding manual for qualitative researchers Sage.

Sandelowski, M. (1995). Sample size in qualitative research. Research in Nursing \& Health, $18(2), 179-183$. 
Sanford, J., Townsend-Rocchicciolli, J., Horigan, A., \& Hall, P. (2011). A process of decision making by caregivers of family members with heart failure. Research and Theory for Nursing Practice, 25(1), 55-70.

Schnell, K. N., Naimark, B. J., \& McClement, S. E. (2006). Influential factors for self-care in ambulatory care heart failure patients: A qualitative perspective. Canadian Journal of Cardiovascular Nursing, 16(1), 13-19. Scott, I. A., Shohag, H., \& Ahmed, M. (2014). Quality of care factors associated with unplanned readmissions of older medical patients: A case-control study. Internal Medicine Journal, 44(2), 161-170. doi:10.1111/imj.12334

Scotto, C. J. (2005). The lived experience of adherence for patients with heart failure. Journal of Cardiopulmonary Rehabilitation, 25(3), 158-163.

Sebern, M. D., \& Woda, A. (2012). Shared care dyadic intervention: Outcome patterns for heart failure care partners. Western Journal of Nursing Research, 34(3), 289-316. doi:10.1177/0193945911399088 [doi]

Seto, E., Leonard, K. J., Cafazzo, J. A., Barnsley, J., Masino, C., \& Ross, H. J. (2012). Mobile phone-based telemonitoring for heart failure management: A randomized controlled trial. Journal of Medical Internet Research, 14(1), e31. Seto, E., Leonard, K. J., Cafazzo, J. A., Barnsley, J., Masino, C., \& Ross, H. J. (2012). Perceptions and experiences of heart failure patients and clinicians on the use of mobile phone-based telemonitoring. Journal of Medical Internet Research, 14(1), e25.

Shchekochikhin, D., Al Ammary, F., Lindenfeld, J., \& Schrier, R. (2013). Role of diuretics and ultrafiltration in congestive heart failure. Pharmaceuticals, 6(7), 851-866. doi:10.3390/ph6070851 
Shearer, N. B., Cisar, N., \& Greenberg, E. A. (2007). A telephone-delivered empowerment intervention with patients diagnosed with heart failure. Heart \& Lung, 36(3), 159-169. Shi, L. (2007). Health services research methods Cengage Learning.

Shipley, S. D. (2010). Listening: A concept analysis. Paper presented at the Nursing Forum, , $45(2) 125-134$.

Slatyer, S., Toye, C., Popescu, A., Young, J., Matthews, A., Hill, A., \& Williamson, D. J. (2013). Early re-presentation to hospital after discharge from an acute medical unit: Perspectives of older patients, their family caregivers and health professionals. Journal of Clinical Nursing, 22(3), 445-455. doi:10.1111/jocn. 12029

Smith, A. C. (2013). Effect of telemonitoring on re-admission in patients with congestive heart failure. MEDSURG Nursing, 22(1), 39-44. Retrieved from http://search.ebscohost.com/login.aspx?direct=true \&db=a9h\&AN=85176674\&site=ehostlive

Snyderman, D., Salzman, B., Mills, G., Hersh, L., \& Parks, S. (2014). Strategies to help reduce hospital readmissions. Journal of Family Practice, 63(8), 430-438a.

Stefan, M., Pekow, P., Nsa, W., Priya, A., Miller, L., Bratzler, D., . . Lindenauer, P. (2013). Hospital performance measures and 30-day readmission rates. JGIM: Journal of General Internal Medicine, 28(3), 377-385. doi:10.1007/s11606-012-2229-8

Stephens, C., Sackett, N., Pierce, R., Schopfer, D., Schmajuk, G., Moy, N., . . Lee, S. J. (2013). Transitional care challenges of rehospitalized veterans: Listening to patients and providers. Population Health Management, 
Tao, H., Ellenbecker, C. H., Chen, J., Zhan, L., \& Dalton, J. (2012). The influence of social environmental factors on rehospitalization among patients receiving home health care services. Advances in Nursing Science, 35(4), 346-358.

van der Wal, M. H. L., Jaarsma, T., Moser, D. K., van Gilst, W. H., \& van Veldhuisen, D. J. (2010). Qualitative examination of compliance in heart failure patients in the Netherlands. Heart \& Lung: The Journal of Acute and Critical Care, 39(2), 121-130. doi:http://dx.doi.org/10.1016/j.hrtlng.2009.07.008

van Walraven, C., Jennings, A., \& Forster, A. J. (2012). A meta-analysis of hospital 30-day avoidable readmission rates. Journal of Evaluation in Clinical Practice, 18(6), 1211-1218. van Walraven, C., Wong, J., \& Forster, A. J. (2012). LACE index: Extension of a validated index to predict early death or urgent readmission after hospital discharge using administrative data. Open Medicine, 6(3), e80.

Voss, R., Gardner, R., Baier, R., Butterfield, K., Lehrman, S., \& Gravenstein, S. (2011). The care transitions intervention: Translating from efficacy to effectiveness. Archives of Internal Medicine, 171(14), 1232-1237.

White, M., Garbez, R., Carroll, M., Brinker, E., \& Howie-Esquivel, J. (2013). Is "teach-back" associated with knowledge retention and hospital readmission in hospitalized heart failure patients? The Journal of Cardiovascular Nursing, 28(2), 137-146.

doi:10.1097/JCN.0b013e31824987bd [doi]

Whittaker, B. D., Soine, L. A., \& Errico, K. M. (2015). Patient and process factors associated with all-cause 30-day readmission among patients with heart failure. Journal of the American Association of Nurse Practitioners, 27(2), 105-113. doi:10.1002/23276924.12123 
Whittemore, R., \& Knafl, K. (2005). The integrative review: Updated methodology. Journal of Advanced Nursing, 52(5), 546-553.

Willemse, E., Adriaenssens, J., Dilles, T., \& Remmen, R. (2014). Do telemonitoring projects of heart failure fit the chronic care model? International Journal of Integrated Care (IJIC), 14, $1-11$.

Williams, M. V. (2013). A requirement to reduce readmissions: Take care of the patient, not just the disease. Jama, 309(4), 394-396.

Zai, A. H., Ronquillo, J. G., Nieves, R., Chueh, H. C., Kvedar, J. C., \& Jethwani, K. (2013). Assessing hospital readmission risk factors in heart failure patients enrolled in a telemonitoring program. International Journal of Telemedicine \& Applications, , 1-6. doi:10.1155/2013/305819 


\section{Appendix A}

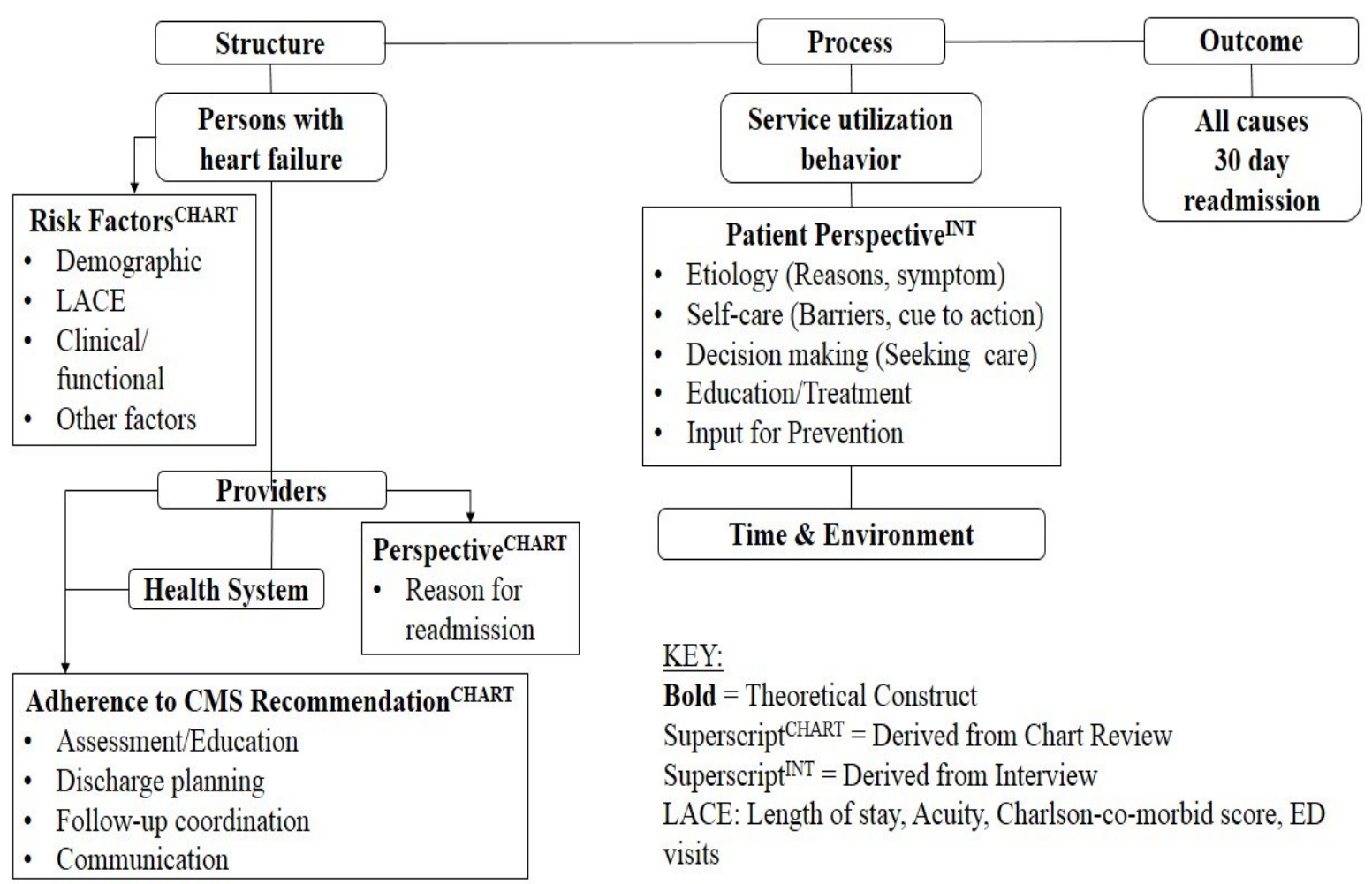

Figure A1. Conceptual model of factors influencing heart failure readmission Adapted from Donabedian, Explanatory Model, Health Belief Model, Heart Failure Trajectory Model 


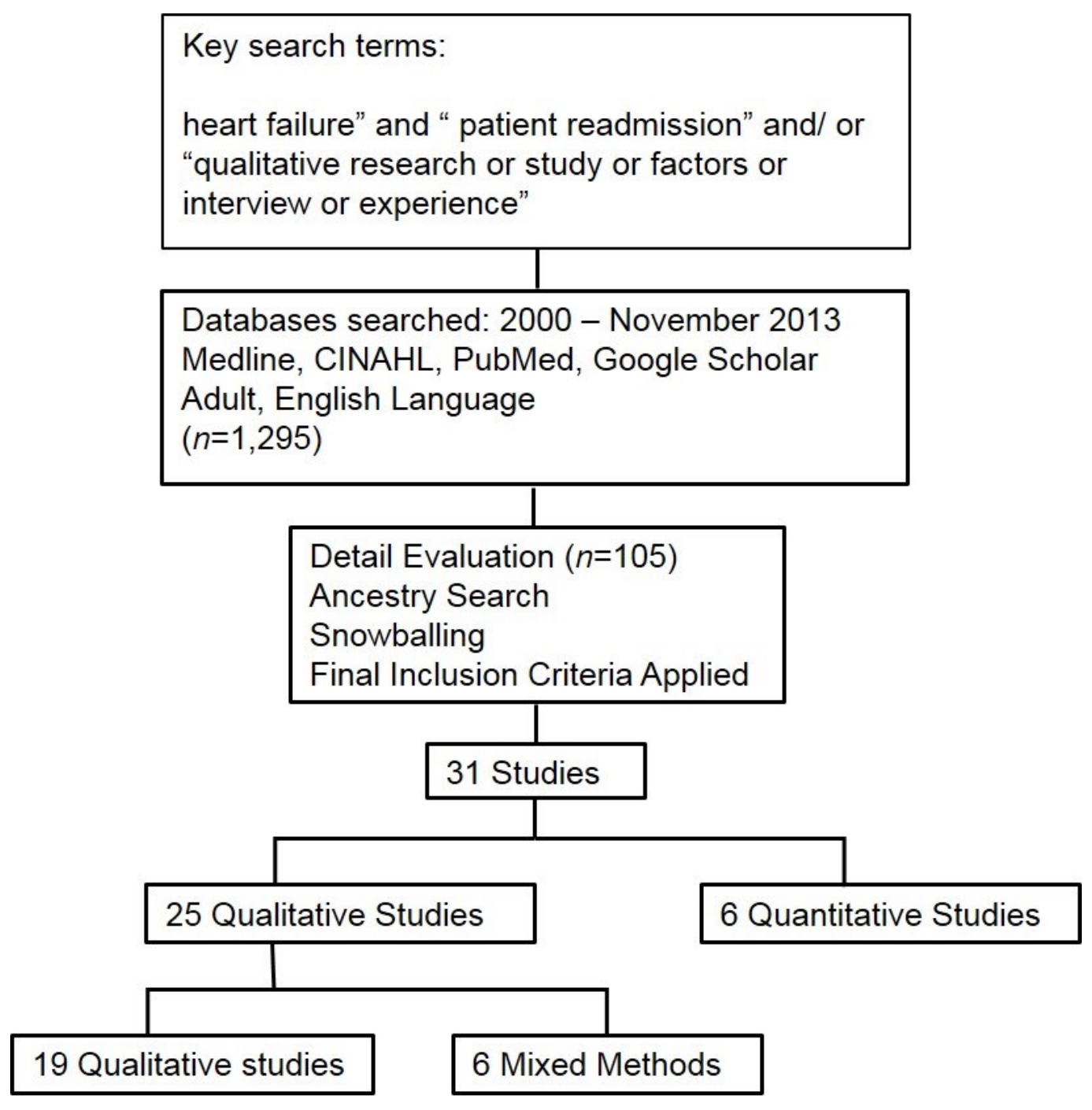

Figure A2. Literature Search Process 


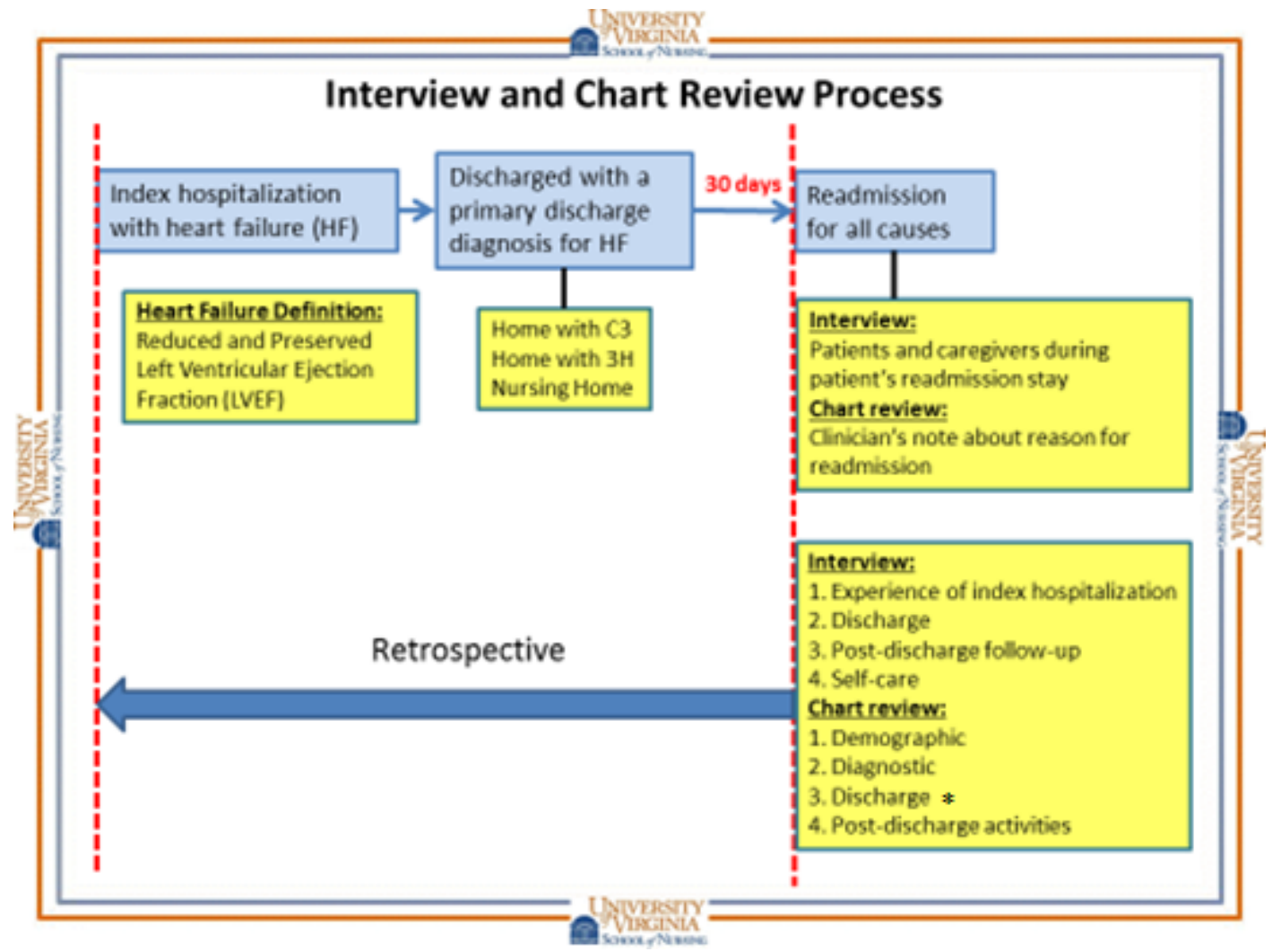

Figure A. Chart Review Process

* 'Discharge' includes discharge coordination and discharge medication 


\section{Appendix B}

A. Qualitative Studies: Factors influencing heart failure readmissions

\begin{tabular}{|c|c|c|c|c|c|}
\hline Study & Purpose & $\begin{array}{l}\text { Setting/Sample/ } \\
\text { Subjects/ } \\
\text { Genderl } \\
\text { Racial/ } \\
\text { Ethnicity/ } \\
\text { Age }\end{array}$ & $\begin{array}{l}\text { Research } \\
\text { Design/ } \\
\text { Theory }\end{array}$ & $\begin{array}{l}\text { Source of } \\
\text { Data/Method } \\
\text { Used/Type of } \\
\text { Analysis }\end{array}$ & $\begin{array}{l}\text { Strength/ Limitation/Research } \\
\text { Findings/Suggestion }\end{array}$ \\
\hline $\begin{array}{l}\text { Retrum } \\
\text { et al. } \\
\text { (2013) }\end{array}$ & $\begin{array}{l}\text { To systematically } \\
\text { investigate patient } \\
\text { perspectives about } \\
\text { reasons for HF } \\
\text { readmission }\end{array}$ & $\begin{array}{l}\text { Two centers } \\
28 \text { patients } \\
10 \text { women } \\
75 \% \text { White } \\
64.71 \text { years } \\
\text { Primary diagnosis of } \\
\text { HF \& readmitted in } \\
180 \text { days of } \\
\text { discharge }\end{array}$ & $\begin{array}{l}\text { Qualitative } \\
\text { Exploratory } \\
\text { Theory } \\
\text { non-stated }\end{array}$ & $\begin{array}{l}\text { Semi-structured } \\
\text { interviews } \\
\text { Medical records } \\
\text { Content analysis } \\
\text { Major topics covered } \\
\text { in } 28 \text { questions: } \\
\text { (a) reasons for } \\
\text { readmission } \\
\text { (b) experience of last } \\
\text { hospitalization } \\
\text { (c) readiness for } \\
\text { discharge } \\
\text { (d) adherence to } \\
\text { follow-ups } \\
\text { (e) symptom } \\
\text { monitoring } \\
\text { (f) medication } \\
\text { management } \\
\text { (g) social support } \\
\text { (h) diet } \\
\text { (i) activity } \\
\text { (j) substance abuse, } \\
\text { psychiatric } \\
\text { (k) emotional and } \\
\text { social economic } \\
\text { issues, etc. }\end{array}$ & $\begin{array}{l}\text { Limited generalization of findings due to sample } \\
\text { drawn from academic medical centers and } \\
\text { younger participants with greater left ventricular } \\
\text { systolic dysfunction cf. whole population } \\
\text { Major themes extracted as reasons for HF } \\
\text { readmission were (a) distressing symptoms; (b) } \\
\text { unavoidable progression of chronic disease; (c) } \\
\text { influence of psychological or social environmental } \\
\text { factors, e.g., for some, adequate support or } \\
\text { resources were not available when needed; (d) } \\
\text { imperfect self-care adherence; (e) health system } \\
\text { factors (e.g., suboptimal health care delivery: } \\
\text { premature discharge and ambulatory follow-up } \\
\text { care) } \\
\text { Insight from patient interview reveals complex } \\
\text { multiple factors behind reasons for readmission } \\
\text { and suggests the need for systemic, multifaceted } \\
\text { intervention and to integrate patient input }\end{array}$ \\
\hline
\end{tabular}


A. Qualitative Studies: Factors influencing heart failure readmissions

\begin{tabular}{|c|c|c|c|c|c|}
\hline Study & Purpose & $\begin{array}{l}\text { Setting/Sample/ } \\
\text { Subjects/ } \\
\text { Gender/ } \\
\text { Racial// } \\
\text { Ethnicity/ } \\
\text { Age }\end{array}$ & $\begin{array}{l}\text { Research } \\
\text { Design/ } \\
\text { Theory }\end{array}$ & $\begin{array}{l}\text { Source of } \\
\text { Data/Method } \\
\text { Used/Type of } \\
\text { Analysis }\end{array}$ & $\begin{array}{l}\text { Strength/ Limitation/Research } \\
\text { Findings/Suggestion }\end{array}$ \\
\hline $\begin{array}{l}\text { Mead et } \\
\text { al. } \\
(2010)\end{array}$ & $\begin{array}{l}\text { To explore } \\
\text { personal } \\
\text { experiences living } \\
\text { with serious heart } \\
\text { conditions (19\% } \\
\text { participants with } \\
\text { heart failure) } \\
\text { To examine how } \\
\text { resource barriers } \\
\text { interfere with } \\
\text { typical self- } \\
\text { management for } \\
\text { disadvantaged } \\
\text { populations }\end{array}$ & $\begin{array}{l}10 \text { US communities } \\
\text { Purposive sampling } \\
387 \text { participants } \\
69 \% \text { women } \\
41 \% \text { (>64 years) } \\
22 \% \text { White } \\
25 \% \text { Spanish } \\
\text { low income } \\
46 \% \text { poor health } \\
\text { status }\end{array}$ & $\begin{array}{l}\text { Qualitative } \\
\text { Exploratory } \\
\text { Theory } \\
\text { non-stated }\end{array}$ & $\begin{array}{l}33 \text { focus group } \\
\text { discussions using an } \\
\text { open ended } \\
\text { interview guide } \\
\text { Used bilingual } \\
\text { researcher or } \\
\text { professional } \\
\text { interpreter to reduce } \\
\text { potential } \\
\text { misunderstanding } \\
\text { Voice recording } \\
\text { Content analysis }\end{array}$ & $\begin{array}{l}\text { Strength: Appropriate sample size from } \\
\text { multicenter, and targeting for low-income, } \\
\text { minority patients } \\
9 \text { major themes emerged and grouped into } 3 \\
\text { domains: (a) barriers to accessing necessary } \\
\text { services (insurance limitation, lack of } \\
\text { coordination of care and lack of continuity); (b) } \\
\text { barriers to monitoring and managing heart } \\
\text { condition on a daily basis (inadequate } \\
\text { information, lack of provider support, and } \\
\text { psychosocial issues; (c) support to improving } \\
\text { self-management (secondary prevention and } \\
\text { disease management programs, and social } \\
\text { support) } \\
\text { Findings: (a) the cost of medication was the } \\
\text { most frequently cited barrier to medication } \\
\text { adherence; (b) poor communication with and } \\
\text { support from provider reasons stated by } \\
\text { participants for non-adherence to medication } \\
\text { (i.e., confusion and incorrect use) } \\
\text { Suggest considering the unique context within } \\
\text { which patients struggle to manage their care }\end{array}$ \\
\hline
\end{tabular}


A. Qualitative Studies: Factors influencing heart failure readmissions

\begin{tabular}{|c|c|c|c|c|c|}
\hline Study & Purpose & $\begin{array}{l}\text { Setting/Sample/ } \\
\text { Subjects/ } \\
\text { Gender/ } \\
\text { Racial/ } \\
\text { Ethnicity/ } \\
\text { Age }\end{array}$ & $\begin{array}{l}\text { Research } \\
\text { Design/ } \\
\text { Theory }\end{array}$ & $\begin{array}{l}\text { Source of } \\
\text { Data/Method } \\
\text { Used/Type of } \\
\text { Analysis }\end{array}$ & $\begin{array}{l}\text { Strength/ Limitation/Research } \\
\text { Findings/Suggestion }\end{array}$ \\
\hline $\begin{array}{l}\text { Hodges } \\
\text { (2009) }\end{array}$ & $\begin{array}{l}\text { Explore } \\
\text { relationships } \\
\text { among life purpose } \\
\text { (LP), health related } \\
\text { quality of life } \\
\text { (HRQOL), and } \\
\text { hospital } \\
\text { readmissions }\end{array}$ & $\begin{array}{l}\text { Single center } \\
41 \text { patients with } \\
\text { heart failure }(N=20 \\
\text { for qualitative }) \\
44 \% \text { female } \\
24 \% \text { Hispanic } \\
60+\end{array}$ & $\begin{array}{l}\text { Mixed } \\
\text { methods } \\
\text { (concurrent } \\
\text { triangulation) } \\
\text { Framework } \\
\text { of life } \\
\text { purpose and } \\
\text { health } \\
\text { related } \\
\text { quality of life }\end{array}$ & $\begin{array}{l}\text { Semi-structured } \\
\text { interviews } \\
\text { Content analysis }\end{array}$ & $\begin{array}{l}\text { Strength: (a) helpful for researcher incorporating } \\
\text { theoretical models as framework for } \\
\text { conceptualizing domains, developing research } \\
\text { questions, data analysis, and interpretation; (b) } \\
\text { useful for clinicians in evaluating the effect of } \\
\text { interventions on HRQOL outcomes. } \\
\text { Limitation with small sample size for quantitative } \\
\text { and possible researcher prejudice and bias } \\
\text { (principal investigator collected data, analyzed, } \\
\text { and interpreted) } \\
\text { Frequently emerged themes were the } \\
\text { importance of psychosocial wellbeing, lack of } \\
\text { physiologic well-being, hope, optimism and } \\
\text { spirituality. Supported conceptual orientation of } \\
\text { LP } \\
\text { Significant finding: (a) positive and moderate } \\
\text { relationship between life purpose and HRQOL; } \\
\text { (b) between higher number of hospital } \\
\text { readmissions and difficulty in HF self-care } \\
\text { management. } \\
\text { Implication: (a) patient's perspective can be } \\
\text { incorporated in HF program planning and } \\
\text { evaluation efforts; (b) insight and knowledge } \\
\text { provide foundation for effective and holistic } \\
\text { intervention to reduce readmission }\end{array}$ \\
\hline
\end{tabular}


A. Qualitative Studies: Factors influencing heart failure readmissions

\begin{tabular}{|c|c|c|c|c|c|}
\hline Study & Purpose & $\begin{array}{l}\text { Setting/Sample/ } \\
\text { Subjects/ } \\
\text { Gender/ } \\
\text { Racial/ } \\
\text { Ethnicity/ } \\
\text { Age }\end{array}$ & $\begin{array}{l}\text { Research } \\
\text { Design/ } \\
\text { Theory }\end{array}$ & $\begin{array}{l}\text { Source of } \\
\text { Data/Method } \\
\text { Used/Type of } \\
\text { Analysis }\end{array}$ & $\begin{array}{l}\text { Strength/ Limitation/Research } \\
\text { Findings/Suggestion }\end{array}$ \\
\hline $\begin{array}{l}\text { Annema } \\
\text { et al. } \\
\text { (2009) }\end{array}$ & $\begin{array}{l}\text { To gain insights } \\
\text { and describe } \\
\text { reasons for } \\
\text { readmission of } \\
\text { patients with HF } \\
\text { from different } \\
\text { perspectives }\end{array}$ & $\begin{array}{l}\text { patient } N=108 \\
\text { caregiver } N=76 \\
\text { cardiologist } N=94 \\
\text { HF nurse } N=103\end{array}$ & $\begin{array}{l}\text { Mixed } \\
\text { methods } \\
\text { Theory } \\
\text { non-stated }\end{array}$ & $\begin{array}{l}\text { Content analysis } \\
\mathrm{X}^{2} \text { and student } t \text { test } \\
\text { for between group } \\
\text { difference } \\
2 \text { interview questions } \\
\text { given to patient and } \\
\text { caregiver: (a) state } \\
\text { the reason for the } \\
\text { readmission in their } \\
\text { own words; (b) if and } \\
\text { how the readmission } \\
\text { could have been } \\
\text { prevented } \\
\text { Nurses and } \\
\text { cardiologists were } \\
\text { asked about the } \\
\text { opinions on the } \\
\text { reasons and whether } \\
\text { the readmission } \\
\text { could have been } \\
\text { prevented }\end{array}$ & $\begin{array}{l}\text { Limitation: asking opinions regarding preventable } \\
\text { readmission remains subjective judgment } \\
\text { Findings from quantitative: (a) } 23-31 \% \text { of the } \\
\text { readmission could have been prevented if } \\
\text { adherence was higher, if patients requested help } \\
\text { earlier, and if adequate multidisciplinary } \\
\text { professional help was available; (b) } 56 \% \\
\text { patients, } 36 \% \text { caregivers, and } 63-65 \% \text { health } \\
\text { care providers stated comorbidity, } \\
\text { nonadherence, and nonoptimal medication as } \\
\text { contributing factors for readmission besides the } \\
\text { most cited reason: worsening heart failure } \\
\text { Findings from qualitative: (a) perceptions of } \\
\text { patients and caregivers as important as } \\
\text { perceptions of providers; (b) patients report } \\
\text { enhancing adherence and seeking help earlier as } \\
\text { important interventions to prevent readmission; } \\
\text { (c) education alone is not enough to prevent } \\
\text { readmission; (d) not all admission can be } \\
\text { prevented when considering the role of } \\
\text { comorbidity as underlying reasons for } \\
\text { readmission }\end{array}$ \\
\hline
\end{tabular}


A. Qualitative Studies: Factors influencing heart failure readmissions

\begin{tabular}{|c|c|c|c|c|c|}
\hline Study & Purpose & $\begin{array}{l}\text { Setting/Sample/ } \\
\text { Subjects/ } \\
\text { Gender/ } \\
\text { Racial/ } \\
\text { Ethnicity/ } \\
\text { Age }\end{array}$ & $\begin{array}{l}\text { Research } \\
\text { Design/ } \\
\text { Theory }\end{array}$ & $\begin{array}{l}\text { Source of } \\
\text { Data/Method } \\
\text { Used/Type of } \\
\text { Analysis }\end{array}$ & $\begin{array}{l}\text { Strength/ Limitation/Research } \\
\text { Findings/Suggestion }\end{array}$ \\
\hline $\begin{array}{l}\text { Piamjariyakul } \\
\text { et al. (2012) }\end{array}$ & $\begin{array}{l}\text { To describe } \\
\text { patient, providers, } \\
\text { and caregiver } \\
\text { perspectives on } \\
\text { how to prepare for } \\
\text { HF self- } \\
\text { management }\end{array}$ & $\begin{array}{l}\text { Single center } \\
\text { Patient } N=30 \\
47 \% \text { female } \\
50 \% \text { African } \\
\text { American } \\
59.1 \pm 14.2 \\
\text { Caregiver } N=17 \\
\text { Provider } N=17\end{array}$ & $\begin{array}{l}\text { Qualitative } \\
\text { Theory } \\
\text { non-stated }\end{array}$ & $\begin{array}{l}8 \text { focused groups of } \\
\text { patients and } \\
\text { providers using } \\
\text { open-ended } \\
\text { structured interview } \\
\text { (used the same } \\
\text { types of questions } \\
\text { and probes to } \\
\text { ensure consistency) } \\
\text { Individual structured } \\
\text { telephone interviews } \\
\text { with caregivers } \\
\text { Content analysis } \\
\text { using software; } \\
\text { theoretical sampling; } \\
\text { and member } \\
\text { checking } \\
\text { Sample Interview } \\
\text { questions for the } \\
\text { patient group: } \\
\text { What factors are key } \\
\text { to managing heart } \\
\text { failure at home? } \\
\text { What changes } \\
\text { would you suggest } \\
\text { to make the } \\
\text { teaching more } \\
\text { helpful? }\end{array}$ & $\begin{array}{l}\text { Limited generalization of findings due to sample } \\
\text { drawn from single center and selection bias of } \\
\text { the participants } \\
\text { Themes from separate focus groups and } \\
\text { telephone interviews (patients, caregivers, and } \\
\text { providers) revealed congruence } \\
\text { Key factors identified: (a) family caregiver } \\
\text { involvement; (b) continuous learning about HF; } \\
\text { (c) acceptance of and coping with HF } \\
\text { diagnosis; (d) learning from other patients with } \\
\text { HF; (e) guidance for daily problem solving; (f) } \\
\text { life style changes and financial resources } \\
\text { Conclusion: (a) caregivers as a key to HF } \\
\text { management at home also lacked HF self- } \\
\text { management knowledge and were seldom } \\
\text { available at hospital discharge or clinic } \\
\text { appointments for education, therefore providers } \\
\text { may consider telephone teaching sessions; (b) } \\
\text { patients and caregivers can benefit from } \\
\text { individualized coaching on problem solving and } \\
\text { priority needs }\end{array}$ \\
\hline
\end{tabular}


A. Qualitative Studies: Factors influencing heart failure readmissions

\begin{tabular}{|c|c|c|c|c|c|}
\hline Study & Purpose & $\begin{array}{l}\text { Setting/Sample/ } \\
\text { Subjects/ } \\
\text { Genderl } \\
\text { Racial/ } \\
\text { Ethnicity/ } \\
\text { Age }\end{array}$ & $\begin{array}{l}\text { Research } \\
\text { Design/ } \\
\text { Theory }\end{array}$ & $\begin{array}{l}\text { Source of } \\
\text { Data/Method } \\
\text { Used/Type of } \\
\text { Analysis }\end{array}$ & $\begin{array}{l}\text { Strength/ Limitation/Research } \\
\text { Findings/Suggestion }\end{array}$ \\
\hline $\begin{array}{l}\text { Schnell } \\
\text { et al. } \\
\text { (2006) } \\
\text { Canada }\end{array}$ & $\begin{array}{l}\text { To describe the } \\
\text { influences that } \\
\text { enhance or impede } \\
\text { self-care and } \\
\text { explore behavioral } \\
\text { responses to these } \\
\text { influences }\end{array}$ & $\begin{array}{l}\text { An urban clinic } \\
\text { Purposive sampling } \\
\text { Theoretical } \\
\text { sampling } \\
11 \text { patients from the } \\
\text { parent study } \\
4 \text { female } \\
64 \text { years old }\end{array}$ & $\begin{array}{l}\text { Qualitative } \\
\text { Connelly's } \\
\text { model of } \\
\text { self-care in } \\
\text { chronic } \\
\text { illness }\end{array}$ & $\begin{array}{l}\text { Semi-structured } \\
\text { interview either in } \\
\text { person or by } \\
\text { telephone } \\
\text { No voice recording } \\
\text { Use comprehensive } \\
\text { notes only } \\
\text { Content analysis }\end{array}$ & $\begin{array}{l}\text { Limited generalization of findings due to the } \\
\text { small sample size } \\
\text { Conceptual themes emerged were consistent } \\
\text { with predisposing and enabling variables from } \\
\text { Connelly's model: satisfaction with care, cues to } \\
\text { action, social support, self-concept, health beliefs } \\
\text { motives along with the self-care strategies } \\
\text { practiced } \\
\text { Suggest the importance of individualized patient } \\
\text { care plans and frequent self-care monitoring }\end{array}$ \\
\hline $\begin{array}{l}\text { Stephens } \\
\text { et al. } \\
\text { (2013) }\end{array}$ & $\begin{array}{l}\text { To explore } \\
\text { perspectives of the } \\
\text { transitional care } \\
\text { needs and } \\
\text { challenges faced } \\
\text { by rehospitalized } \\
\text { veterans }\end{array}$ & $\begin{array}{l}\text { Veteran's Affairs } \\
\text { Medical Center } \\
\text { Convenience } \\
\text { Theoretical } \\
\text { sampling } \\
\text { Patients, } N=25 \\
60 \% \text { white } \\
68 \text { years old } \\
\text { Interdisciplinary } \\
\text { provider (including } \\
\text { social worker, PT, } \\
\text { OT; } N=14 \text { ) }\end{array}$ & $\begin{array}{l}\text { Qualitative } \\
\text { Theory } \\
\text { non-stated }\end{array}$ & $\begin{array}{l}\text { Semi-structured } \\
\text { interviews and } \\
\text { medical records } \\
\text { Verbal consent only } \\
\text { No voice recording } \\
\text { Thorough field notes } \\
\text { examined by second } \\
\text { investigator } \\
\text { Content analysis }\end{array}$ & $\begin{array}{l}\text { Three themes identified by patients: knowledge } \\
\text { gaps and deferred power, difficulties navigating } \\
\text { the health care systems, and complex psychiatric } \\
\text { and social needs } \\
\text { Four themes identified by providers: } \\
\text { substance abuse and mental illness, lack of } \\
\text { social and financial support and homelessness, } \\
\text { premature discharge and poor communication, } \\
\text { and non-adherence with follow-up } \\
\text { Suggest creating a culture of empowerment, } \\
\text { ownership, and engagement }\end{array}$ \\
\hline
\end{tabular}


A. Qualitative Studies: Factors influencing heart failure readmissions

\begin{tabular}{|c|c|c|c|c|c|}
\hline Study & Purpose & $\begin{array}{l}\text { Setting/Sample/ } \\
\text { Subjects/ } \\
\text { Genderl } \\
\text { Racial/ } \\
\text { Ethnicity/ } \\
\text { Age }\end{array}$ & $\begin{array}{l}\text { Research } \\
\text { Design/ } \\
\text { Theory }\end{array}$ & $\begin{array}{l}\text { Source of } \\
\text { Data/Method } \\
\text { Used/Type of } \\
\text { Analysis }\end{array}$ & $\begin{array}{l}\text { Strength/ Limitation/Research } \\
\text { Findings/Suggestion }\end{array}$ \\
\hline $\begin{array}{l}\text { Hekmatpou } \\
\text { et al. } \\
\text { (2009) } \\
\text { Iran }\end{array}$ & $\begin{array}{l}\text { To explain the } \\
\text { process of } \\
\text { readmission in HF } \\
\text { patients }\end{array}$ & $\begin{array}{l}2 \text { educational } \\
\text { hospitals } \\
\text { Purposive, maximal } \\
\text { variation } \\
\text { Patient } N=17 \\
4 \text { female } \\
65 \text { years } \\
\text { Caregiver } N=7 \\
\text { HCPs }=18\end{array}$ & Qualitative & $\begin{array}{l}\text { Interview and } \\
\text { observation } \\
\text { Filed notes } \\
\text { Constant } \\
\text { comparative } \\
\text { analysis } \\
\text { Sample interview } \\
\text { questions for } \\
\text { patients: } \\
\text { (a) Can you talk } \\
\text { about the conditions } \\
\text { that have occurred } \\
\text { since the previous } \\
\text { discharge to the } \\
\text { present admission? } \\
\text { (b) What have } \\
\text { doctors and nurses } \\
\text { done for you during } \\
\text { admission and at } \\
\text { your discharge? } \\
\text { For families: can you } \\
\text { talk about your } \\
\text { experience } \\
\text { concerning your } \\
\text { patients? }\end{array}$ & $\begin{array}{l}\text { Strength: detailed reporting on qualitative } \\
\text { methods (grounded theory methodology, data } \\
\text { saturation, theoretical sampling to ensure } \\
\text { diverse views reflected, source triangulation) } \\
\text { discussed } \\
\text { Major themes emerged: lack of sensitivity to } \\
\text { readmission, indifference of the treating team, } \\
\text { lack of comprehensive context-oriented } \\
\text { discharge planning, disease-oriented health care } \\
\text { system, failure of self-care and patients' } \\
\text { returning to community without preparation and } \\
\text { support, and hopelessness of definitive cure } \\
\text { Offers the theory of 'lack of sensitivity to } \\
\text { readmission' to guide policy discussions on } \\
\text { developing an interdisciplinary program to } \\
\text { reduce readmission }\end{array}$ \\
\hline
\end{tabular}


A. Qualitative Studies: Factors influencing heart failure readmissions

\begin{tabular}{|c|c|c|c|c|c|}
\hline Study & Purpose & $\begin{array}{l}\text { Setting/Sample/ } \\
\text { Subjects/ } \\
\text { Gender/ } \\
\text { Racial/ } \\
\text { Ethnicity/ } \\
\text { Age }\end{array}$ & $\begin{array}{l}\text { Research } \\
\text { Design/ } \\
\text { Theory }\end{array}$ & $\begin{array}{l}\text { Source of } \\
\text { Data/Method } \\
\text { Used/Type of } \\
\text { Analysis }\end{array}$ & $\begin{array}{l}\text { Strength/ Limitation/Research } \\
\text { Findings/Suggestion }\end{array}$ \\
\hline $\begin{array}{l}\text { Hekmatpou } \\
\text { et al. } \\
\text { (2010) } \\
\text { Iran }\end{array}$ & $\begin{array}{l}\text { To explore the } \\
\text { concept of } \\
\text { discharge and its } \\
\text { associated factors } \\
\text { in HF patients }\end{array}$ & $\begin{array}{l}2 \text { educational } \\
\text { hospitals } \\
\text { Purposive, maximal } \\
\text { variation } \\
\text { Patient } N=17 \\
\text { Caregiver } N=7 \\
\text { HCPs }=18\end{array}$ & $\begin{array}{l}\text { Qualitative } \\
\text { Theory } \\
\text { non-stated }\end{array}$ & $\begin{array}{l}\text { Semi-structured } \\
\text { interview } \\
\text { Observation } \\
\text { Constant } \\
\text { comparative } \\
\text { analysis } \\
\text { Sample interview } \\
\text { questions for } \\
\text { patients and } \\
\text { families: What have } \\
\text { the physicians and } \\
\text { nurses done for you } \\
\text { during your last stay } \\
\text { at the hospital? }\end{array}$ & $\begin{array}{l}\text { Strength: data collection from multi-sources to } \\
\text { enhance accuracy; detailed explanation on } \\
\text { verbatim data analysis process } \\
\text { Meaning of discharge: lack of sensitivity to } \\
\text { inadequate patient discharge, i.e., participants } \\
\text { considered discharge as the termination point for } \\
\text { health-care surveillance and responsibility of } \\
\text { physicians and nurses } \\
\text { Factors related to the discharge process: } \\
\text { treating team, health-care system, patients and } \\
\text { their families } \\
\text { Suggestions: need to change the attitude of } \\
\text { physicians and nurses towards the concept of } \\
\text { discharge and raise their sensitivity to organizing } \\
\text { and executing discharge plans }\end{array}$ \\
\hline
\end{tabular}


A. Qualitative Studies: Factors influencing heart failure readmissions

\begin{tabular}{|c|c|c|c|c|c|}
\hline Study & Purpose & $\begin{array}{l}\text { Setting/Sample/ } \\
\text { Subjects/ } \\
\text { Gender/ } \\
\text { Racial/ } \\
\text { Ethnicity/ } \\
\text { Age }\end{array}$ & $\begin{array}{l}\text { Research } \\
\text { Design/ } \\
\text { Theory }\end{array}$ & $\begin{array}{l}\text { Source of } \\
\text { Data/Method } \\
\text { Used/Type of } \\
\text { Analysis }\end{array}$ & $\begin{array}{l}\text { Strength/ Limitation/Research } \\
\text { Findings/Suggestion }\end{array}$ \\
\hline $\begin{array}{l}\text { Sanford } \\
\text { et al. } \\
\text { (2011) }\end{array}$ & $\begin{array}{l}\text { To describe } \\
\text { decision-making by } \\
\text { caregivers of } \\
\text { patients with HF }\end{array}$ & $\begin{array}{l}\text { Multicenter } \\
\text { (cardiology, } \\
\text { hospital, adult day } \\
\text { care) } \\
\text { Convenience } \\
20 \text { caregivers } \\
15 \text { female } \\
75 \% \text { white }\end{array}$ & $\begin{array}{l}\text { Qualitative } \\
\text { descriptive } \\
\text { Theory } \\
\text { non-stated }\end{array}$ & $\begin{array}{l}\text { Unstructured open- } \\
\text { ended interviews } \\
\text { Tape recording and } \\
\text { memo writing } \\
\text { Thematic analysis } \\
\text { using software/ } \\
\text { theory triangulation } \\
\text { Sample interview } \\
\text { questions: (a) Tell } \\
\text { me about your family } \\
\text { member's illness; (b) } \\
\text { Tell me about what } \\
\text { decisions you make } \\
\text { regarding care of } \\
\text { your family member; } \\
\text { (c) Everyone is } \\
\text { influenced in some } \\
\text { way when making a } \\
\text { decision. Who or } \\
\text { what influences you? }\end{array}$ & $\begin{array}{l}\text { Strength: use of theory triangulation } \\
\text { Findings: } 1 \text {. Decision making process by } \\
\text { caregivers of family members with HF is a } \\
\text { nonlinear one consisting of several phases: (a) } \\
\text { actualization of the challenge, issues, or } \\
\text { problem; (b) seeking input, information, or } \\
\text { support; (c) reflecting on the decision; (d) making } \\
\text { a decision choice; (e) evaluating decision, and (f) } \\
\text { validating the decision } \\
\text { 2. The process of decision-making is influenced } \\
\text { by situations, people, relationships and the } \\
\text { environment. }\end{array}$ \\
\hline
\end{tabular}


A. Qualitative Studies: Factors influencing heart failure readmissions

\begin{tabular}{|c|c|c|c|c|c|}
\hline Study & Purpose & $\begin{array}{l}\text { Setting/Sample/ } \\
\text { Subjects/ } \\
\text { Gender/ } \\
\text { Racial/ } \\
\text { Ethnicity/ } \\
\text { Age }\end{array}$ & $\begin{array}{l}\text { Research } \\
\text { Design/ } \\
\text { Theory }\end{array}$ & $\begin{array}{l}\text { Source of } \\
\text { Data/Method } \\
\text { Used/Type of } \\
\text { Analysis }\end{array}$ & $\begin{array}{l}\text { Strength/ Limitation/Research } \\
\text { Findings/Suggestion }\end{array}$ \\
\hline $\begin{array}{l}\text { Helleso } \\
\text { et al. } \\
\text { (2012) } \\
\text { Norway }\end{array}$ & $\begin{array}{l}\text { To explore HF } \\
\text { patients' } \\
\text { perspectives on the } \\
\text { significance of } \\
\text { informal caregivers } \\
\text { in their information } \\
\text { management } \\
\text { process }\end{array}$ & $\begin{array}{l}\text { Single center } \\
\text { Patient } N=14 \\
8 \text { female } \\
79.6 \text { years }\end{array}$ & $\begin{array}{l}\text { Qualitative } \\
\text { Theory } \\
\text { non-stated }\end{array}$ & $\begin{array}{l}\text { In-depth semi- } \\
\text { structured interviews } \\
\text { Tape recording } \\
\text { Field notes for one } \\
\text { participant who } \\
\text { refused recording } \\
\text { Content analysis } \\
\\
\text { Example questions: } \\
\text { (a) Who helped you } \\
\text { to find answers to } \\
\text { your questions? } \\
\text { (b) How was your } \\
\text { informal caregiver } \\
\text { involved when you } \\
\text { received } \\
\text { information? }\end{array}$ & $\begin{array}{l}\text { Strength: detailed explanation on method section } \\
\text { (e.g., inclusion procedure, effort to establish } \\
\text { rapport and use conversations to let patients talk } \\
\text { about what happened prior to their last } \\
\text { admission) } \\
\text { Limited generalization of findings due to sample } \\
\text { drawn from single center } \\
\text { Themes emerged: Informal caregiver's role } \\
\text { represents two phenomena: (a) 'variation in } \\
\text { involvement' is related to the background of the } \\
\text { informal caregiver, i.e., having a health care } \\
\text { background is vital for ensuring adequate } \\
\text { information; (b) 'information ambivalence' is } \\
\text { related to the relationship between the patient } \\
\text { and the informal caregiver with regard to the } \\
\text { information management at home, i.e., the } \\
\text { inherent complexity for patients to be both } \\
\text { dependent on informal caregivers for managing } \\
\text { all the information and struggling for control of } \\
\text { their own situation } \\
\text { Suggest: assessing patients regarding } \\
\text { information management problems and the role } \\
\text { of their informal caregivers in this process }\end{array}$ \\
\hline
\end{tabular}


A. Qualitative Studies: Factors influencing heart failure readmissions

\begin{tabular}{|c|c|c|c|c|c|}
\hline Study & Purpose & $\begin{array}{l}\text { Setting/Sample/ } \\
\text { Subjects/ } \\
\text { Gender/ } \\
\text { Racial/ } \\
\text { Ethnicity/ } \\
\text { Age }\end{array}$ & $\begin{array}{l}\text { Research } \\
\text { Design/ } \\
\text { Theory }\end{array}$ & $\begin{array}{l}\text { Source of } \\
\text { Data/Method } \\
\text { Used/Type of } \\
\text { Analysis }\end{array}$ & $\begin{array}{l}\text { Strength/ Limitation/Research } \\
\text { Findings/Suggestion }\end{array}$ \\
\hline $\begin{array}{l}\text { Boyd et } \\
\text { al. } \\
\text { (2004) } \\
\text { UK }\end{array}$ & $\begin{array}{l}\text { To describe how } \\
\text { patients and } \\
\text { caregivers view } \\
\text { health and social } \\
\text { care in the last year } \\
\text { of life }\end{array}$ & $\begin{array}{l}\text { Patients with } \\
\text { advanced HF } \\
\text { (NYHA class IV) } N \\
=50 \\
\text { Caregivers } N=27 \\
\text { Clinicians } N=30\end{array}$ & $\begin{array}{l}\text { Qualitative/ } \\
\text { prospective } \\
\text { longitudinal } \\
3 \text { monthly } \\
\text { intervals up } \\
\text { to } 1 \text { year } \\
\text { Theory } \\
\text { non-stated }\end{array}$ & $\begin{array}{l}\text { Interviews and } \\
\text { focused group } \\
\text { interview } \\
\text { Voice recording } \\
\text { Content analysis } \\
\text { using software }\end{array}$ & $\begin{array}{l}\text { Strength: Iongitudinal, and detailed explanation } \\
\text { on how to gain access to people's perspectives } \\
\text { in a non-directive manner } \\
\text { Themes emerged and raised by patients } \\
\text { Managing the physical symptoms } \\
\text { Managing the treatments } \\
\text { Information about diagnosis and prognosis } \\
\text { Frustration and progressive losses } \\
\text { Coping strategies } \\
\text { Social isolation and caregiver stress } \\
\text { End of life care } \\
\text { Findings: Patients and caregivers felt } \\
\text { unsupported, had little understanding of } \\
\text { condition, treatment goals or prognosis } \\
\text { Suggest: (a) patients and caregivers want a } \\
\text { more holistic approach (i.e., providers take } \\
\text { account of psychosocial, spiritual, information } \\
\text { and family needs); (b) heart failure services need } \\
\text { to include patient and caregiver-centered } \\
\text { perspectives to mobilize most effective } \\
\text { intervention and generate best outcomes for both } \\
\text { patients and caregivers }\end{array}$ \\
\hline
\end{tabular}


A. Qualitative Studies: Factors influencing heart failure readmissions

\begin{tabular}{|c|c|c|c|c|c|}
\hline Study & Purpose & $\begin{array}{l}\text { Setting/Sample/ } \\
\text { Subjects/ } \\
\text { Gender/ } \\
\text { Racial/ } \\
\text { Ethnicity/ } \\
\text { Age }\end{array}$ & $\begin{array}{l}\text { Research } \\
\text { Design/ } \\
\text { Theory }\end{array}$ & $\begin{array}{l}\text { Source of } \\
\text { Data/Method } \\
\text { Used/Type of } \\
\text { Analysis }\end{array}$ & $\begin{array}{l}\text { Strength/ Limitation/Research } \\
\text { Findings/Suggestion }\end{array}$ \\
\hline $\begin{array}{l}\text { Clark et } \\
\text { al. } \\
\text { (2009) } \\
\text { Canada }\end{array}$ & $\begin{array}{l}\text { Examine individual } \\
\text { and contextual } \\
\text { factors affecting HF } \\
\text { self-care }\end{array}$ & $\begin{array}{l}3 \text { rural cites } \\
\text { Quota sampling } \\
42 \text { patients } \\
36 \% \text { female } \\
76 \text { years old } \\
30 \text { caregivers }\end{array}$ & $\begin{array}{l}\text { Qualitative } \\
\text { Theory } \\
\text { non-stated }\end{array}$ & $\begin{array}{l}\text { Patient and } \\
\text { caregiver report } \\
\text { Semi-structured } \\
\text { interviews and } \\
\text { medical records } \\
\text { Interview schedules } \\
\text { developed by } \\
\text { literature review and } \\
\text { piloted for revision } \\
\text { Phenomenological } \\
\text { thematic analysis } \\
\text { using software }\end{array}$ & $\begin{array}{l}\text { Limited generalization of findings for urban } \\
\text { population due to the recruitment sites for urban } \\
\text { population } \\
\text { Findings: (a) participants reported using HF } \\
\text { management techniques (e.g., medication, } \\
\text { activity, and salt restriction); (b) demonstrated } \\
\text { poor knowledge of nature and causes of HF } \\
\text { (e.g., reported experiencing disturbing daily } \\
\text { symptoms, but unable to relate these symptoms } \\
\text { to HF; (c) individual and contextual factors (i.e., } \\
\text { faith in health professionals, belief about the local } \\
\text { health system, values linked to work associated } \\
\text { with place, history, and culture) influence } \\
\text { willingness and capacity to undertake effective } \\
\text { HF self-care (e.g., symptoms were viewed as } \\
\text { being influenced more by fate than management } \\
\text { techniques) } \\
\text { Suggestion: intervention needs to address not } \\
\text { only knowledge needs but also faith, beliefs, } \\
\text { perceptions, and values }\end{array}$ \\
\hline
\end{tabular}


A. Qualitative Studies: Factors influencing heart failure readmissions

\begin{tabular}{|c|c|c|c|c|c|}
\hline Study & Purpose & $\begin{array}{l}\text { Setting/Sample/ } \\
\text { Subjects/ } \\
\text { Gender/ } \\
\text { Racial/ } \\
\text { Ethnicity/ } \\
\text { Age }\end{array}$ & $\begin{array}{l}\text { Research } \\
\text { Design/ } \\
\text { Theory }\end{array}$ & $\begin{array}{l}\text { Source of } \\
\text { Data/Method } \\
\text { Used/Type of } \\
\text { Analysis }\end{array}$ & $\begin{array}{l}\text { Strength/ Limitation/Research } \\
\text { Findings/Suggestion }\end{array}$ \\
\hline $\begin{array}{l}\text { Rodriguez } \\
\text { et al. } \\
\text { (2008) }\end{array}$ & $\begin{array}{l}\text { Explore patients' } \\
\text { knowledge } \\
\text { regarding HF } \\
\text { diagnosis, } \\
\text { understanding of } \\
\text { providers' } \\
\text { treatment re- } \\
\text { commendations, } \\
\text { and their views on } \\
\text { the impact of HF } \\
\text { concerning their } \\
\text { daily lives and } \\
\text { prognosis }\end{array}$ & $\begin{array}{l}\text { Veteran Affair } \\
\text { Medical Center } \\
\text { Random sampling } \\
\text { from a parent study } \\
(N=90) \\
25 \text { patients } \\
1 \text { female } \\
70.4 \text { years }\end{array}$ & $\begin{array}{l}\text { Qualitative } \\
\text { Cross- } \\
\text { sectional } \\
\text { Theory } \\
\text { non-stated }\end{array}$ & $\begin{array}{l}\text { Semi structured } \\
\text { interviews } \\
\text { Telephone interview } \\
\text { Grounded theory } \\
\text { technique of } \\
\text { constant } \\
\text { comparative analysis } \\
17 \text { open-ended } \\
\text { interview questions } \\
\text { regarding patients' } \\
\text { knowledge, } \\
\text { experiences of HF, } \\
\text { communication with } \\
\text { providers } \\
\text { Sample questions: } \\
\text { (a) Tell me how your } \\
\text { health problems } \\
\text { started. } \\
\text { (b) Tell me about } \\
\text { your experiences or } \\
\text { problems with your } \\
\text { heart. } \\
\text { (c) What could your } \\
\text { health care providers } \\
\text { have done to involve } \\
\text { you more (or less) in } \\
\text { decision-making? }\end{array}$ & $\begin{array}{l}\text { Strength: detailed reporting on qualitative } \\
\text { methods (e.g., establishing reliability with code } \\
\text { agreement in the first } 20 \% \text { of the transcribed } \\
\text { data) } \\
\text { Limited generalization of findings due to } \\
\text { small sample with homogeneity (elderly, male, } \\
\text { and Caucasian) } \\
\text { Five themes emerged: } \\
\text { (a) diagnostic process delayed with comorbidity; } \\
\text { (b) life changing effects of HF; (c) } 64 \text { coded } \\
\text { examples of past, current, and future treatments; } \\
\text { (d) self-monitoring and ongoing testing; (e) } \\
\text { uncertain prognosis and advance care planning } \\
\text { Conclusion: Patients need more information } \\
\text { regarding their medical condition and prognosis } \\
\text { with more enhanced communication opportunity }\end{array}$ \\
\hline
\end{tabular}


A. Qualitative Studies: Factors influencing heart failure readmissions

\begin{tabular}{|c|c|c|c|c|c|}
\hline Study & Purpose & $\begin{array}{l}\text { Setting/Sample/ } \\
\text { Subjects/ } \\
\text { Genderl } \\
\text { Racial/ } \\
\text { Ethnicity/ } \\
\text { Age }\end{array}$ & $\begin{array}{l}\text { Research } \\
\text { Design/ } \\
\text { Theory }\end{array}$ & $\begin{array}{l}\text { Source of } \\
\text { Data/Method } \\
\text { Used/Type of } \\
\text { Analysis }\end{array}$ & $\begin{array}{l}\text { Strength/ Limitation/Research } \\
\text { Findings/Suggestion }\end{array}$ \\
\hline $\begin{array}{l}\text { van der Wal } \\
\text { et al. (2009) } \\
\text { Netherlands }\end{array}$ & $\begin{array}{l}\text { Explore reason's } \\
\text { and motivations for } \\
\text { compliance with } \\
\text { self-care regimens } \\
\text { (medication, } \\
\text { sodium-restricted } \\
\text { diet, fluid } \\
\text { restriction, and } \\
\text { daily weighing) }\end{array}$ & $\begin{array}{l}\text { Purposive sampling } \\
\text { Recruited from } \\
3 \text { centers from a } \\
\text { parent study } \\
15 \text { HF patients } \\
6 \text { female } \\
70 \pm 13 \text { years }\end{array}$ & $\begin{array}{l}\text { Descriptive } \\
\text { Health } \\
\text { Belief } \\
\text { Model }\end{array}$ & $\begin{array}{l}\text { Patient report } \\
\text { Semi-structured } \\
\text { interviews and } \\
\text { medical records } \\
\text { Interview at home } \\
\text { Voice recording } \\
\text { content analysis } \\
\text { Sample interview } \\
\text { questions: } \\
\text { Most patients with } \\
\text { HF have many } \\
\text { recommendations } \\
\text { they have to follow. } \\
\text { (a) What makes it } \\
\text { difficult (or not) to } \\
\text { follow the } \\
\text { recommendations? } \\
\text { (b) What helps you } \\
\text { to follow the } \\
\text { recommendations? }\end{array}$ & $\begin{array}{l}\text { Limited generalization of findings due to } \\
\text { small sample with homogeneity (elderly, and } \\
\text { male) } \\
\text { Major themes derived from interviews } \\
\text { (a) reasons for compliance: fear of } \\
\text { hospitalization, fluid retention, or HF symptoms; } \\
\text { (b) barriers to compliance: negative aspects of a } \\
\text { regimen (e.g., taste of the sodium restricted food } \\
\text { and thirst in case of fluid restriction); (c) } \\
\text { managing lifestyle recommendations in daily life; } \\
\text { (d) tips and tricks that help in complying with the } \\
\text { regimen; (e) misunderstanding or knowledge } \\
\text { deficits regarding HF regimen } \\
\text { Suggestions: (a) patient-tailored interventions } \\
\text { must include a comprehensive assessment to } \\
\text { target specific problems and provide more } \\
\text { specific advice about HF regimen; (b) group } \\
\text { interventions may be beneficial in helping } \\
\text { patients integrate the regimen into their daily } \\
\text { lives }\end{array}$ \\
\hline
\end{tabular}


A. Qualitative Studies: Factors influencing heart failure readmissions

\begin{tabular}{|c|c|c|c|c|c|}
\hline Study & Purpose & $\begin{array}{l}\text { Setting/Sample/ } \\
\text { Subjects/ } \\
\text { Gender/ } \\
\text { Racial/ } \\
\text { Ethnicity/ } \\
\text { Age }\end{array}$ & $\begin{array}{l}\text { Research } \\
\text { Design/ } \\
\text { Theory }\end{array}$ & $\begin{array}{l}\text { Source of } \\
\text { Data/Method } \\
\text { Used/Type of } \\
\text { Analysis }\end{array}$ & $\begin{array}{l}\text { Strength/ Limitation/Research } \\
\text { Findings/Suggestion }\end{array}$ \\
\hline $\begin{array}{l}\text { Granger } \\
\text { et al. } \\
\text { (2009) }\end{array}$ & $\begin{array}{l}\text { Explore patient and } \\
\text { physician } \\
\text { perspectives about } \\
\text { adherence and how } \\
\text { the exchange of } \\
\text { information about } \\
\text { HF regimen } \\
\text { between patient } \\
\text { and their } \\
\text { physicians is } \\
\text { experienced and } \\
\text { understood by both } \\
\text { partners }\end{array}$ & $\begin{array}{l}\text { Single center } \\
\text { (inpatient) } \\
\text { Purposive sampling } \\
6 \text { dyads ( } 6 \text { patients } \\
\& 6 \text { physicians) } \\
1 \text { female patient } \\
58 \text { years old }\end{array}$ & $\begin{array}{l}\text { Qualitative } \\
\text { descriptive } \\
\text { Trajectory } \\
\text { of chronic } \\
\text { illness } \\
\text { theory }\end{array}$ & $\begin{array}{l}\text { Semi-structured in- } \\
\text { depth interviews } \\
\text { Voice recording with } \\
\text { digital transcription } \\
\text { Thematic analysis } \\
\text { using software } \\
\text { Sample Interview } \\
\text { questions and } \\
\text { probes for patients: } \\
\text { (a) What instructions } \\
\text { did you receive } \\
\text { about taking care of } \\
\text { yourself (or HF) at } \\
\text { home? } \\
\text { (b) Do you think the } \\
\text { instructions are easy } \\
\text { to understand? } \\
\text { (c) Do you feel the } \\
\text { instructions fit into } \\
\text { your everyday life? }\end{array}$ & $\begin{array}{l}\text { Limited generalization of findings due to } \\
\text { small sample size } \\
\text { Findings: (a) patients perceived they knew what } \\
\text { to do for self-care, but expressed difficulty on } \\
\text { how to do self-care; (b) physicians attempted } \\
\text { repeating what to do (HF care regimen) since } \\
\text { physicians perceived that patients did not } \\
\text { understand the regimen; (c) both patients and } \\
\text { physicians were unable to carry out the work of } \\
\text { the regimen due to symptom exacerbations or } \\
\text { time constraints in the clinic (i.e., fitting the } \\
\text { regimen into everyday life was challenging to } \\
\text { both parties); (d) resultant delegation of } \\
\text { responsibility to others: patients' significant } \\
\text { others (siblings, spouses, neighbors, etc.), } \\
\text { nurses, and nutritionists do the work (regimen- } \\
\text { related responsibilities) } \\
\text { Assert current teaching strategies may be } \\
\text { ineffective and suggest exploring alternative } \\
\text { strategies (home-based models of care, } \\
\text { electronic reminders, teamwork among all } \\
\text { caregivers, etc.) to facilitate adherence and } \\
\text { improve clinical outcomes. }\end{array}$ \\
\hline
\end{tabular}


A. Qualitative Studies: Factors influencing heart failure readmissions

\begin{tabular}{|c|c|c|c|c|c|}
\hline Study & Purpose & $\begin{array}{l}\text { Setting/Sample/ } \\
\text { Subjects/ } \\
\text { Gender/ } \\
\text { Racial/ } \\
\text { Ethnicity/ } \\
\text { Age }\end{array}$ & $\begin{array}{l}\text { Research } \\
\text { Design/ } \\
\text { Theory }\end{array}$ & $\begin{array}{l}\text { Source of } \\
\text { Data/Method } \\
\text { Used/Type of } \\
\text { Analysis }\end{array}$ & $\begin{array}{l}\text { Strength/ Limitation/Research } \\
\text { Findings/Suggestion }\end{array}$ \\
\hline $\begin{array}{l}\text { Scotto } \\
(2005)\end{array}$ & $\begin{array}{l}\text { Explore patient's } \\
\text { lived experience of } \\
\text { adherence to } \\
\text { prescribed regimen } \\
\text { of care }\end{array}$ & $\begin{array}{l}\text { Purposive } \\
\text { /convenience } \\
\text { sample } \\
\text { patient } N=14 \\
\text { (recent history of } \\
\text { hospital admission } \\
\text { with HF) } \\
5 \text { female } \\
42-84\end{array}$ & $\begin{array}{l}\text { Qualitative } \\
\text { Theory } \\
\text { non-stated }\end{array}$ & $\begin{array}{l}\text { Phenomenological } \\
\text { thematic analysis } \\
\text { Semi-structured } \\
\text { interview } \\
\frac{5 \text { interview }}{\text { questions: }} \\
\text { 1. Tell me about } \\
\text { when you were } \\
\text { diagnosed with HF } \\
2 \text {. Tell me about the } \\
\text { last time you were } \\
\text { admitted to the } \\
\text { hospital because of } \\
\text { HF } \\
3 . \text { Tell me about the } \\
\text { things you do to take } \\
\text { care of yourself on a } \\
\text { daily basis } \\
4 . \text { What makes it } \\
\text { easier to take care of } \\
\text { yourself? } \\
5 . \text { What makes it } \\
\text { harder to take care } \\
\text { of yourself? }\end{array}$ & $\begin{array}{l}\text { Strength: detailed reporting on qualitative } \\
\text { methods (examining researcher's bias, data } \\
\text { saturation, and member checking } \\
\text { discussed) } \\
\text { Limited generalization of findings due to } \\
\text { small sample size } \\
\text { Findings: (a) patients' adherence was dependent } \\
\text { on their acceptance of changed health status and } \\
\text { integration of a new self-image; (b) patients } \\
\text { made daily decisions about whether to adhere to } \\
\text { prescribed regimen } \\
\text { Identified themes influencing adherence: } \\
\text { personal beliefs and values, support from } \\
\text { significant others and health care professionals, } \\
\text { unusual circumstances, and temptation } \\
\text { overcoming motivation }\end{array}$ \\
\hline
\end{tabular}


A. Qualitative Studies: Factors influencing heart failure readmissions

\begin{tabular}{|c|c|c|c|c|c|}
\hline Study & Purpose & $\begin{array}{l}\text { Setting/Sample/ } \\
\text { Subjects/ } \\
\text { Genderl } \\
\text { Racial/ } \\
\text { Ethnicity/ } \\
\text { Age }\end{array}$ & $\begin{array}{l}\text { Research } \\
\text { Design/ } \\
\text { Theory }\end{array}$ & $\begin{array}{l}\text { Source of } \\
\text { Data/Method } \\
\text { Used/Type of } \\
\text { Analysis }\end{array}$ & $\begin{array}{l}\text { Strength/ Limitation/Research } \\
\text { Findings/Suggestion }\end{array}$ \\
\hline $\begin{array}{l}\text { Heo et } \\
\text { al. } \\
(2009)\end{array}$ & $\begin{array}{l}\text { Explore patients' } \\
\text { perceptions on } \\
\text { nutrition and dietary } \\
\text { adherence in heart } \\
\text { failure }\end{array}$ & $\begin{array}{l}2 \text { outpatient clinics } \\
\text { of } 2 \text { hospitals } \\
\text { Convenience } \\
20 \text { patients } \\
6 \text { female } \\
95 \% \text { white } \\
58 \pm 10 \text { years }\end{array}$ & $\begin{array}{l}\text { Qualitative } \\
\text { Theory } \\
\text { non-stated }\end{array}$ & $\begin{array}{l}\text { Semi-structured } \\
\text { interview } \\
\text { Tape recording } \\
\text { Content analysis } \\
\text { Major topics covered } \\
\text { in interview guide: } \\
\text { (a) perceptions } \\
\text { about the effect of } \\
\text { food on HF } \\
\text { symptoms } \\
\text { (b) patient's } \\
\text { comprehension of } \\
\text { the low sodium diet } \\
\text { and other dietary } \\
\text { recommendations } \\
\text { received from } \\
\text { providers } \\
\text { (c) factors that affect } \\
\text { adherence to } \\
\text { recommended diets }\end{array}$ & $\begin{array}{l}\text { Limitation: small sample with homogeneity } \\
\text { (young, male, and Caucasian); therefore, caution } \\
\text { for generalizability of findings } \\
\text { Findings: (a) less than half of the patients } \\
\text { thought sodium could affect HF symptoms; (b) } \\
40 \% \text { reported non-adherence to recommended } \\
\text { diet regimen } \\
\text { Factors identified as influencing adherence were } \\
\text { (a) knowledge; (b) social pressure and } \\
\text { encouragement from others; (c) social situations, } \\
\text { and (d) food as a source of pleasure and } \\
\text { enjoyment } \\
\text { Suggestion: need creative strategies aligned } \\
\text { with patients' values and priorities regarding food } \\
\text { to promote adherence }\end{array}$ \\
\hline
\end{tabular}


A. Qualitative Studies: Factors influencing heart failure readmissions

\begin{tabular}{|c|c|c|c|c|c|}
\hline Study & Purpose & $\begin{array}{l}\text { Setting/Sample/ } \\
\text { Subjects/ } \\
\text { Genderl } \\
\text { Racial/ } \\
\text { Ethnicity/ } \\
\text { Age }\end{array}$ & $\begin{array}{l}\text { Research } \\
\text { Design/ } \\
\text { Theory }\end{array}$ & $\begin{array}{l}\text { Source of } \\
\text { Data/Method } \\
\text { Used/Type of } \\
\text { Analysis }\end{array}$ & $\begin{array}{l}\text { Strength/ Limitation/Research } \\
\text { Findings/Suggestion }\end{array}$ \\
\hline $\begin{array}{l}\text { Riegel } \\
\text { et al. } \\
(2010 \text { b) } \\
\text { Australia }\end{array}$ & $\begin{array}{l}\text { Identify gender - } \\
\text { specific barriers } \\
\text { and facilitators } \\
\text { influencing HF self- } \\
\text { care }\end{array}$ & $\begin{array}{l}4 \text { outpatient sites } \\
\text { Purposive with } \\
\text { maximum variation } \\
27 \text { patients } \\
8 \text { female } \\
68.7 \pm 14.7 \text { years }\end{array}$ & $\begin{array}{l}\text { Mixed } \\
\text { methods } \\
\text { Theory } \\
\text { non-stated }\end{array}$ & $\begin{array}{l}\text { In-depth interviews } \\
\text { survey } \\
\text { Medical record } \\
\text { review } \\
\text { Audiotaped } \\
\text { content analysis } \\
\text { Interviewers trained } \\
\text { by the qualitative } \\
\text { research expert } \\
\text { Interview topics: } \\
\text { (a) preventing and } \\
\text { managing symptoms } \\
\text { (b) complexity of the } \\
\text { treatment plan } \\
\text { (c) factors } \\
\text { contributing to } \\
\text { success and } \\
\text { impeded success in } \\
\text { self-care } \\
\text { (d) advantages and } \\
\text { disadvantages to } \\
\text { practicing self-care } \\
\text { (e) personal } \\
\text { motivators for self- } \\
\text { care }\end{array}$ & $\begin{array}{l}\text { Strength: detailed reporting on qualitative } \\
\text { methods (Iterative process to track variability of } \\
\text { themes, use of an audit trail, and periodic } \\
\text { debriefing, etc.) } \\
\text { Limitation: (a) cross-sectional nature, small } \\
\text { number of women even with purposive sampling; } \\
\text { (b) poor concordance between the qualitative } \\
\text { and quantitative data for mood } \\
\text { Findings: (a) no consistent gender-specific } \\
\text { differences in self-care practices; (b) distinct } \\
\text { gender differences in the decision made in } \\
\text { interpreting and responding to symptoms and } \\
\text { they are associated with differences in self-care } \\
\text { confidence, social support and mood between } \\
\text { gender (e.g., men reported relying on others for } \\
\text { help in recognizing symptoms; women reported } \\
\text { better emotional support from family and friends } \\
\text { than the men) }\end{array}$ \\
\hline
\end{tabular}


A. Qualitative Studies: Factors influencing heart failure readmissions

\begin{tabular}{|c|c|c|c|c|c|}
\hline Study & Purpose & $\begin{array}{l}\text { Setting/Sample/ } \\
\text { Subjects/ } \\
\text { Genderl } \\
\text { Racial/ } \\
\text { Ethnicity/ } \\
\text { Age }\end{array}$ & $\begin{array}{l}\text { Research } \\
\text { Design/ } \\
\text { Theory }\end{array}$ & $\begin{array}{l}\text { Source of } \\
\text { Data/Method } \\
\text { Used/Type of } \\
\text { Analysis }\end{array}$ & $\begin{array}{l}\text { Strength/ Limitation/Research } \\
\text { Findings/Suggestion }\end{array}$ \\
\hline $\begin{array}{l}\text { Freydberg } \\
\text { et al. } \\
(2010) \\
\text { Canada }\end{array}$ & $\begin{array}{l}\text { To examine } \\
\text { experiences and } \\
\text { reactions to HF and } \\
\text { aspects of self-care }\end{array}$ & $\begin{array}{l}3 \text { rural settings } \\
\text { Theoretical } \\
\text { sampling } \\
\text { patient } N=42 \\
\text { Caregiver } N=30\end{array}$ & $\begin{array}{l}\text { Qualitative } \\
\text { Critical } \\
\text { realist } \\
\text { theory }\end{array}$ & $\begin{array}{l}\text { Semi-structured } \\
\text { interview } \\
\text { Recruitment bias } \\
\text { discussed } \\
\text { Thematic analysis } \\
\text { using software }\end{array}$ & $\begin{array}{l}\text { Strength: large sample size from several } \\
\text { recruitment sites and detailed reporting on } \\
\text { qualitative methods (examining researcher's } \\
\text { bias, methodological coherence fostered by the } \\
\text { use of theory) } \\
\text { Themes emerged: (a) the influence of place and } \\
\text { context was integrated into disease experiences, } \\
\text { reactions, and self-care process for both patients } \\
\text { and caregivers; (b) HF threatens the self by } \\
\text { impacting capacity to work that is essential in } \\
\text { rural places (land work, housework, and } \\
\text { community work); (c) HF perceived as a threat to } \\
\text { the individual's ontological security; (d) work as a } \\
\text { core and valued way of life in place, decreased } \\
\text { sense of psychological wellbeing if perceived } \\
\text { lack of contributing to rural community; (e) coping } \\
\text { with HF by adapting through monitoring } \\
\text { symptoms, reducing expectation, and relying } \\
\text { more on caregivers or hired helper } \\
\text { Suggest mobilizing families and lay caregivers to } \\
\text { assist elderly patients with HF to remain actively } \\
\text { and symbolically involved in home setting until } \\
\text { transitional care need arises }\end{array}$ \\
\hline
\end{tabular}


A. Qualitative Studies: Factors influencing heart failure readmissions

\begin{tabular}{|c|c|c|c|c|c|}
\hline Study & Purpose & $\begin{array}{l}\text { Setting/Sample/ } \\
\text { Subjects/ } \\
\text { Gender/ } \\
\text { Racial/ } \\
\text { Ethnicity/ } \\
\text { Age }\end{array}$ & $\begin{array}{l}\text { Research } \\
\text { Design/ } \\
\text { Theory }\end{array}$ & $\begin{array}{l}\text { Source of } \\
\text { Data/Method } \\
\text { Used/Type of } \\
\text { Analysis }\end{array}$ & $\begin{array}{l}\text { Strength/ Limitation/Research } \\
\text { Findings/Suggestion }\end{array}$ \\
\hline $\begin{array}{l}\text { Dickson } \\
\text { et al. } \\
\text { (2013) }\end{array}$ & $\begin{array}{l}\text { Describe self-care } \\
\text { practices, and } \\
\text { sociocultural } \\
\text { influences of self- } \\
\text { care in ethnic } \\
\text { minority black } \\
\text { population with HF }\end{array}$ & $\begin{array}{l}\text { Single urban center } \\
\text { Purposive } \\
\text { homogenous } \\
\text { sampling } \\
\text { Patient } N=30 \\
40 \% \text { female } \\
\text { African American } \\
59.63 \text { years }\end{array}$ & $\begin{array}{l}\text { Mixed } \\
\text { methods } \\
\text { Naturalistic } \\
\text { decision- } \\
\text { making } \\
\text { model of } \\
\text { HF self- } \\
\text { care }\end{array}$ & $\begin{array}{l}\text { Tape recording and } \\
\text { field notes } \\
\text { Thematic analysis } \\
\text { using software } \\
\text { Open-ended } \\
\text { questions: } \\
\text { (a) Tell me about } \\
\text { your heart failure } \\
\text { (b) What does heart } \\
\text { failure mean to you? }\end{array}$ & $\begin{array}{l}\text { Strength: detailed reporting on qualitative } \\
\text { methods (use of an audit trail, and periodic peer } \\
\text { debriefing, and member checking to increase the } \\
\text { credibility) discussed } \\
\text { Limitation: small sample with homogeneity } \\
\text { (African American); therefore, caution for } \\
\text { generalizability of findings } \\
\text { Findings: (a) self-care poor by Self-care of Heart } \\
\text { Failure index (SCHFI); (b) cultural meaning of HF } \\
\text { influences self-care; (c) spirituality shapes self- } \\
\text { care; (d) social norms drive social supports (e.g., } \\
\text { selectivity in a designated confidante) and social } \\
\text { isolation with decreased capacity to participate } \\
\text { and reluctance to ask for help } \\
\text { Suggestion: assessing social support beyond } \\
\text { tangible resources; developing community-based } \\
\text { interventions that can provide culturally } \\
\text { acceptable resources }\end{array}$ \\
\hline
\end{tabular}


A. Qualitative Studies: Factors influencing heart failure readmissions

\begin{tabular}{|c|c|c|c|c|c|}
\hline Study & Purpose & $\begin{array}{l}\text { Setting/Sample/ } \\
\text { Subjects/ } \\
\text { Gender/ } \\
\text { Racial/ } \\
\text { Ethnicity/ } \\
\text { Age }\end{array}$ & $\begin{array}{l}\text { Research } \\
\text { Design/ } \\
\text { Theory }\end{array}$ & $\begin{array}{l}\text { Source of } \\
\text { Data/Method } \\
\text { Used/Type of } \\
\text { Analysis }\end{array}$ & $\begin{array}{l}\text { Strength/ Limitation/Research } \\
\text { Findings/Suggestion }\end{array}$ \\
\hline $\begin{array}{l}\text { Patel et } \\
\text { al. } \\
\text { (2007) } \\
\text { Sweden }\end{array}$ & $\begin{array}{l}\text { To explore reasons } \\
\text { to why patients with } \\
\text { deteriorating CHF } \\
\text { seek acute care at } \\
\text { an emergency } \\
\text { department }\end{array}$ & $\begin{array}{l}\text { Single urban center } \\
\text { Convenience } \\
88 \text { patients/ } \\
34 \text { women/ } \\
77.7 \pm 9.5 \text { years/ } \\
\text { Acute exacerbation } \\
\text { with HF history }\end{array}$ & $\begin{array}{l}\text { Qualitative } \\
\text { Descriptive } \\
\text { Symptom } \\
\text { Management } \\
\text { Model }\end{array}$ & $\begin{array}{l}\text { Semi-structured } \\
\text { open-ended } \\
\text { interview } \\
\text { Medical records } \\
\text { Content analysis } \\
\text { 3interview } \\
\text { questions: } \\
\text { (a) Could you please } \\
\text { explain why you } \\
\text { sought care at the } \\
\text { ED today? } \\
\text { (b) Did you consider } \\
\text { seeking care at an } \\
\text { earlier time? } \\
\text { (c) Did you have any } \\
\text { idea what your } \\
\text { condition was? }\end{array}$ & $\begin{array}{l}\text { Limitation: no information asked about social } \\
\text { background or previous HF education received } \\
\text { Findings: (a) majority ( } 58 \% \text { ) sought emergency } \\
\text { care due to symptoms; (b) dyspnea and fatigue } \\
\text { were the most frequent reported; (c) } 15 \% \\
\text { patients sent by caregivers; } 27 \% \text { referred by } \\
\text { outpatient clinics; (d) } 57 \% \text { delayed seeking care } \\
\text { earlier since they could not recognize worsening } \\
\text { symptoms or uncertain whether needed care; (e) } \\
10 \% \text { avoided hospital care because of previous } \\
\text { unpleasant experiences with ED care; (f) } 11 \% \\
\text { postponed seeking care with feeling of } \\
\text { hopelessness } \\
\text { Suggest including caregivers in educating } \\
\text { symptom recognition and response }\end{array}$ \\
\hline
\end{tabular}


A. Qualitative Studies: Factors influencing heart failure readmissions

\begin{tabular}{|c|c|c|c|c|c|}
\hline Study & Purpose & $\begin{array}{l}\text { Setting/Sample/ } \\
\text { Subjects/ } \\
\text { Gender/ } \\
\text { Racial/ } \\
\text { Ethnicity/ } \\
\text { Age }\end{array}$ & $\begin{array}{l}\text { Research } \\
\text { Design/ } \\
\text { Theory }\end{array}$ & $\begin{array}{l}\text { Source of } \\
\text { Data/Method } \\
\text { Used/Type of } \\
\text { Analysis }\end{array}$ & $\begin{array}{l}\text { Strength/ Limitation/Research } \\
\text { Findings/Suggestion }\end{array}$ \\
\hline $\begin{array}{l}\text { Jurgens } \\
\text { et al. } \\
\text { (2009) }\end{array}$ & $\begin{array}{l}\text { Examine individual } \\
\text { and contextual } \\
\text { factors influencing } \\
\text { the process of HF } \\
\text { self-care (symptom } \\
\text { recognition and } \\
\text { response among } \\
\text { elders hospitalized } \\
\text { with } \\
\text { decompensated } \\
\text { HF) }\end{array}$ & $\begin{array}{l}2 \text { hospitals } \\
\text { Convenience } \\
\text { sample } \\
77 \text { patients } \\
48.1 \% \text { female } \\
85.7 \% \text { white } \\
75.9 \pm 7.7\end{array}$ & $\begin{array}{l}\text { Mixed } \\
\text { methods } \\
\text { Self- } \\
\text { Regulation } \\
\text { Model of } \\
\text { Illness }\end{array}$ & $\begin{array}{l}\text { Patient report (HF } \\
\text { somatic perception } \\
\text { scale, response to } \\
\text { symptom } \\
\text { questionnaire, NYHA } \\
\text { functional class, } \\
\text { Charlson } \\
\text { Comorbidity Index) } \\
\text { Semi-structured } \\
\text { open-ended } \\
\text { interview } \\
\text { Medical records } \\
\text { Interview questions: } \\
\text { (a) Tell me more } \\
\text { about the time } \\
\text { leading up to this } \\
\text { hospitalization } \\
\text { (b) What did you do } \\
\text { when you first } \\
\text { noticed your } \\
\text { symptoms? } \\
\text { (c) What did you } \\
\text { think was causing } \\
\text { your symptoms? }\end{array}$ & $\begin{array}{l}\text { Strength: detailed reporting on qualitative } \\
\text { methods (use of an audit trail, and periodic peer } \\
\text { debriefing, discussion with expert in HF self-care } \\
\text { knowledge to increase the credibility) discussed } \\
\text { and robust sample size } \\
\text { Limitation: small sample with homogeneity } \\
\text { (Caucasian); therefore, caution for generalization } \\
\text { of findings } \\
\text { Findings: (a) dyspnea and fatigue were the most } \\
\text { frequent reported; (b) lack of cognitive response } \\
\text { to symptoms (over half had no idea what was } \\
\text { causing symptoms); (c) lack of emotional } \\
\text { response (majority had no fear or anxiety } \\
\text { regarding symptoms); (d) majority did not report } \\
\text { symptoms to caregivers (family influenced into } \\
\text { care-seeking in } 25 \% \text { of the sample); (e) use of } \\
\text { alternative strategies (energy conservation, deep } \\
\text { breaths, calming, and pray); (f) } 80 \% \text { waited for } \\
\text { serious symptoms to subside and } 54 \% \text { believed } \\
\text { they had little or no control } \\
\text { Conclusion: few intentionally ignored symptoms } \\
\text { or avoided hospitalization but knowledge about } \\
\text { HF and symptom recognition abilities were poor } \\
\text { Suggest including caregivers in educating the } \\
\text { significance and necessity of early intervention } \\
\text { for worsening symptoms }\end{array}$ \\
\hline
\end{tabular}


A. Qualitative Studies: Factors influencing heart failure readmissions

\begin{tabular}{|c|c|c|c|c|c|}
\hline Study & Purpose & $\begin{array}{l}\text { Setting/Sample/ } \\
\text { Subjects/ } \\
\text { Gender/ } \\
\text { Racial/ } \\
\text { Ethnicity/ } \\
\text { Age }\end{array}$ & $\begin{array}{l}\text { Research } \\
\text { Design/ } \\
\text { Theory }\end{array}$ & $\begin{array}{l}\text { Source of } \\
\text { Data/Method } \\
\text { Used/Type of } \\
\text { Analysis }\end{array}$ & $\begin{array}{l}\text { Strength/ Limitation/Research } \\
\text { Findings/Suggestion }\end{array}$ \\
\hline $\begin{array}{l}\text { Riegel } \\
\text { et al. } \\
\text { (2010 a) } \\
\text { Australia }\end{array}$ & $\begin{array}{l}\text { To assess if aging } \\
\text { is associated with } \\
\text { ability to detect and } \\
\text { interpret symptom } \\
\text { recognition }\end{array}$ & $\begin{array}{l}4 \text { outpatient sites } \\
\text { Purposive with } \\
\text { maximum variation } \\
29 \text { patients } \\
8(27.6 \%) \text { female } \\
68.7 \pm 14.4 \\
\text { (divided the sample } \\
\text { into young: }<73 \\
\text { versus old: } \geq 73 \\
\text { years old) }\end{array}$ & $\begin{array}{l}\text { Mixed } \\
\text { methods } \\
\text { cross- } \\
\text { sectional } \\
\text { Non- } \\
\text { specific } \\
\text { theory } \\
\text { stated: age- } \\
\text { related } \\
\text { decline in } \\
\text { the ability } \\
\text { to attend to } \\
\text { internal } \\
\text { physical } \\
\text { symptoms }\end{array}$ & $\begin{array}{l}\text { Survey } \\
\text { In-depth semi- } \\
\text { structured interviews } \\
\text { Medical record } \\
\text { review } \\
\text { Audiotaping } \\
\text { Content analysis }\end{array}$ & $\begin{array}{l}\text { Strength: detailed reporting on qualitative } \\
\text { methods (use of an audit trail, and periodic peer } \\
\text { debriefing, discussion with expert in HF self-care } \\
\text { knowledge, etc., to increase the credibility) } \\
\text { discussed } \\
\text { Limitation: homogeneity (male, married, born in } \\
\text { Australia), therefore, caution for generalization of } \\
\text { findings and recall bias due to data collection } \\
\text { during a secondary session } \\
\text { Findings: (a) older patients ( } \geq 73 \text { years old) had } \\
\text { more difficulties in recognizing and responding to } \\
\text { HF symptoms compared to younger ones; (b) } \\
\text { younger ones were able to detect early, subtle } \\
\text { cues of HF and interpret the meaning of } \\
\text { worsening symptoms in order to avoid an HF } \\
\text { exacerbation; (c) older patients perceived their } \\
\text { health more favorably, which may contribute to } \\
\text { poorer detection and interpretation of HF } \\
\text { symptoms } \\
\text { Suggest: developing interventions that focus on } \\
\text { the symptom experience to help patients in } \\
\text { somatic awareness and symptom interpretation }\end{array}$ \\
\hline
\end{tabular}


A. Qualitative Studies: Factors influencing heart failure readmissions

\begin{tabular}{|c|c|c|c|c|c|}
\hline Study & Purpose & $\begin{array}{l}\text { Setting/Sample/ } \\
\text { Subjects/ } \\
\text { Gender/ } \\
\text { Racial/ } \\
\text { Ethnicity/ } \\
\text { Age }\end{array}$ & $\begin{array}{l}\text { Research } \\
\text { Design/ } \\
\text { Theory }\end{array}$ & $\begin{array}{l}\text { Source of } \\
\text { Data/Method } \\
\text { Used/Type of } \\
\text { Analysis }\end{array}$ & $\begin{array}{l}\text { Strength/ Limitation/Research } \\
\text { Findings/Suggestion }\end{array}$ \\
\hline $\begin{array}{l}\text { Rogers } \\
\text { et al. } \\
\text { (2002) } \\
\text { UK }\end{array}$ & $\begin{array}{l}\text { To explore the } \\
\text { experience of } \\
\text { people living with } \\
\text { heart failure } \\
\text { (understanding of } \\
\text { HF symptoms, } \\
\text { treatment, daily life) }\end{array}$ & $\begin{array}{l}\text { Variation sampling } \\
\text { by differing } \\
\text { experiences } \\
\text { (theoretical } \\
\text { sampling) } \\
27 \text { patients } \\
7 \text { female } \\
69 \text { years }\end{array}$ & $\begin{array}{l}\text { Qualitative } \\
\text { Theory } \\
\text { non-stated }\end{array}$ & $\begin{array}{l}\text { In-depth interview } \\
\text { Tape recording } \\
\text { Thematic analysis } \\
\text { (constant } \\
\text { comparative } \\
\text { approach) } \\
\text { using software } \\
\text { Sample interview } \\
\text { questions: } \\
\text { Can you tell me how } \\
\text { your heart failure } \\
\text { started? }\end{array}$ & $\begin{array}{l}\text { Strength: adequate sample size, theoretical } \\
\text { sampling to ensure diverse views reflected } \\
\text { Limitation: reported tape recorder failure } \\
\text { Key areas identified relating to symptoms and } \\
\text { the use of drug therapy (a) the purpose of the } \\
\text { drugs; (b) concerns about the drug therapy; (c) } \\
\text { difficulties in differentiating between side effects } \\
\text { of drugs and symptoms of HF; (d) interpretation } \\
\text { and treatment of changing symptoms (e.g., } \\
\text { patients sought medical help when their } \\
\text { symptoms became unmanageable) } \\
\text { Suggest educating HF symptoms, side effects of } \\
\text { medication to improve patients' ability to } \\
\text { interpret, treat, or relieve symptoms }\end{array}$ \\
\hline
\end{tabular}


B. Quantitative Studies: Factors influencing heart failure readmissions

\begin{tabular}{|c|c|c|c|c|c|}
\hline Study & Purpose & $\begin{array}{l}\text { Setting/Sample/ } \\
\text { Subjects/ } \\
\text { Gender/ } \\
\text { Racial/ } \\
\text { Ethnicity/ } \\
\text { Age }\end{array}$ & $\begin{array}{l}\text { Research } \\
\text { Design/ } \\
\text { Theory }\end{array}$ & $\begin{array}{l}\text { Source of } \\
\text { Data/Method } \\
\text { Used/Type of } \\
\text { Analysis }\end{array}$ & $\begin{array}{l}\text { Strength/ Limitation/Research } \\
\text { Findings/Suggestion }\end{array}$ \\
\hline $\begin{array}{l}\text { Gruneir et } \\
\text { al. (2011) } \\
\text { Canada }\end{array}$ & $\begin{array}{l}\text { To describe } \\
\text { medical patients } \\
\text { identified using } \\
\text { LACE index as } \\
\text { being at high risk } \\
\text { (LACE } \geq 10 \text { ) for } \\
\text { readmission and to } \\
\text { examine their } \\
\text { actual hospital } \\
\text { readmission rates }\end{array}$ & $\begin{array}{l}20,645 \text { patients } \\
\text { Population-based } \\
\text { administrative data } \\
\text { from } 6 \text { hospitals }\end{array}$ & $\begin{array}{l}\text { Validating } \\
\text { predictive } \\
\text { algorithm } \\
\text { Theory } \\
\text { non-stated }\end{array}$ & $\begin{array}{l}\text { LACE index: } \\
\text { L: Length of hospital } \\
\text { stay } \\
\text { A: Acuity on } \\
\text { admission } \\
\text { (emergent versus } \\
\text { urgent) } \\
\text { C: Comorbidity } \\
\text { measured by } \\
\text { Charlson score with } \\
\text { updated disease } \\
\text { category weights } \\
\text { E: Emergency } \\
\text { department visits }\end{array}$ & $\begin{array}{l}\text { Limited generalization of findings due to data } \\
\text { from single urban center; LACE only validated } \\
\text { for } 30 \text {-day readmission and death } \\
\text { Findings: (a) High-risk patients (LACE } \geq 10 \text { ) } \\
\text { were readmitted with twice the frequency as } \\
\text { other patients, stayed longer and had higher } \\
\text { mortality during the readmission; (b) LACE is } \\
\text { useful in identifying appropriate patients for } \\
\text { post-discharge interventions }\end{array}$ \\
\hline $\begin{array}{l}\text { Anderson } \\
(2013)\end{array}$ & $\begin{array}{l}\text { To explore the } \\
\text { clinical and } \\
\text { diagnostic } \\
\text { indicators in } \\
\text { individuals who did } \\
\text { and did not } \\
\text { experience a heart } \\
\text { failure } \\
\text { hospitalization } \\
\text { within } 60 \text { days of } \\
\text { the index stay. }\end{array}$ & $\begin{array}{l}134 \text { individuals } \\
\text { discharged with a } \\
\text { primary diagnosis } \\
\text { of heart failure } \\
\text { Single center } \\
55 \% \text { women } \\
65 \% \text { White } \\
75.25 \text { years }\end{array}$ & $\begin{array}{l}\text { Descriptive, } \\
\text { correlational, } \\
\text { quantitative } \\
\text { retrospective } \\
\text { Theory } \\
\text { non-stated }\end{array}$ & $\begin{array}{l}\text { Medical records } \\
\text { reviewed for } \\
\text { sociodemographic } \\
\text { characteristics, } \\
\text { health histories, } \\
\text { clinical assessment } \\
\text { findings, and } \\
\text { diagnostic } \\
\text { information }\end{array}$ & $\begin{array}{l}\text { Limitation in control for number of factors or } \\
\text { accuracy of documentation over factors due } \\
\text { to retrospective data } \\
\text { Findings: nursing-sensitive factors, dyspnea, } \\
\text { crackles, and assistance with activities of } \\
\text { daily living (ADL) at the time of discharge } \\
\text { were more predictive of } 60 \text {-day heart failure } \\
\text { readmissions than were gender, age, } \\
\text { ethnicity, left ventricular function, serum } \\
\text { sodium, blood pressure, blood urea nitrogen, } \\
\text { creatinine, BNP, and cardiac medications }\end{array}$ \\
\hline
\end{tabular}


B. Quantitative Studies: Factors influencing heart failure readmissions

\begin{tabular}{|c|c|c|c|c|c|}
\hline Study & Purpose & $\begin{array}{l}\text { Setting/Sample/ } \\
\text { Subjects/ } \\
\text { Genderl } \\
\text { Racial/ } \\
\text { Ethnicity/ } \\
\text { Age } \\
\end{array}$ & $\begin{array}{l}\text { Research } \\
\text { Design/ } \\
\text { Theory }\end{array}$ & $\begin{array}{l}\text { Source of } \\
\text { Data/Method } \\
\text { Used/Type of } \\
\text { Analysis }\end{array}$ & $\begin{array}{l}\text { Strength/ Limitation/Research } \\
\text { Findings/Suggestion }\end{array}$ \\
\hline $\begin{array}{l}\text { Mulder, } \\
\text { Tzeng, } \\
\text { Vecchioni. } \\
\text { (2012) }\end{array}$ & $\begin{array}{l}\text { To assess whether } \\
\text { IHI's } \\
\text { recommendations } \\
\text { to prevent } \\
\text { rehospitalization } \\
\text { were implemented }\end{array}$ & $\begin{array}{l}\text { One center } \\
\text { participating IHI } \\
\text { STAAR initiative } \\
22 \text { patients labeled } \\
\text { as 'noncompliant' or } \\
\text { 'frequent fliers' with } \\
4 \text { to } 8 \text { readmissions } \\
\text { over } 6 \text { months } \\
10 \text { women/ } \\
58 \text { years }\end{array}$ & $\begin{array}{l}\text { Explorative } \\
\text { quality } \\
\text { improvement } \\
\text { project/ } \\
\text { non-stated } \\
\text { Theory } \\
\text { non-stated }\end{array}$ & $\begin{array}{l}\text { Electronic medical } \\
\text { record review } \\
\frac{9 \text { chart review }}{\text { questions to assess }} \\
\text { whether } 4 \text { key areas } \\
\text { identified by IHI for } \\
\text { process } \\
\text { improvement in } \\
\text { preventing } \\
\text { rehospitalization } \\
\text { were implemented }\end{array}$ & $\begin{array}{l}\text { Limited generalization of findings due to } \\
\text { small sample size } \\
4 \text { key areas: (a) enhanced admission } \\
\text { assessment for post hospital needs; ( b) } \\
\text { effective teaching and enhanced learning; (c) } \\
\text { real time patient and family-centered } \\
\text { handover communication; (d) post hospital } \\
\text { care follow up } \\
\text { Finding: IHI recommendations not } \\
\text { implemented or failed to document } \\
\text { systematically }\end{array}$ \\
\hline $\begin{array}{l}\text { Kirk et al. } \\
(2006) \\
\text { UK }\end{array}$ & $\begin{array}{l}\text { To explore } \\
\text { patients', } \\
\text { caregivers', } \\
\text { clinician's view and } \\
\text { identify factors } \\
\text { influencing the } \\
\text { likelihood of } \\
\text { hospital } \\
\text { readmission }\end{array}$ & $\begin{array}{l}\text { Single center } \\
\text { Patients } N=77 \\
\text { admitted to adult } \\
\text { medical unit within } \\
28 \text { days of } \\
\text { discharge from the } \\
\text { index } \\
\text { hospitalization } \\
38 \text { female } \\
71.3 \pm 14.6 \\
\text { Caregivers } N=68 \\
\text { Clinicians }\end{array}$ & $\begin{array}{l}\text { Cross- } \\
\text { sectional } \\
\text { retrospective } \\
\text { Theory } \\
\text { non-stated }\end{array}$ & $\begin{array}{l}\text { Interviews with } \\
\text { simple survey } \\
\text { questions and } \\
\text { analyzed findings } \\
\text { with descriptive } \\
\text { statistics } \\
\text { Medical and nursing } \\
\text { record reviews }\end{array}$ & $\begin{array}{l}\text { Limited generalization of findings single } \\
\text { center, retrospective collection of memory } \\
\text { Findings: (a) most patients, caregivers and } \\
\text { clinicians believed that the readmission was } \\
\text { unavoidable by reflecting the chronicity of } \\
\text { illness; (b) about one third of the patients and } \\
\text { caregivers expressed the readmission could } \\
\text { be avoidable if the patients stayed longer in } \\
\text { hospital during first admission or had greater } \\
\text { support in the community after discharge } \\
\text { Suggest patients' readiness for discharge } \\
\text { should be consulted before leaving hospital }\end{array}$ \\
\hline
\end{tabular}


B. Quantitative Studies: Factors influencing heart failure readmissions

\begin{tabular}{|c|c|c|c|c|c|}
\hline Study & Purpose & $\begin{array}{l}\text { Setting/Sample/ } \\
\text { Subjects/ } \\
\text { Gender/ } \\
\text { Racial/ } \\
\text { Ethnicity/ } \\
\text { Age }\end{array}$ & $\begin{array}{l}\text { Research } \\
\text { Design/ } \\
\text { Theory }\end{array}$ & $\begin{array}{l}\text { Source of } \\
\text { Data/Method } \\
\text { Used/Type of } \\
\text { Analysis }\end{array}$ & $\begin{array}{l}\text { Strength/ Limitation/Research } \\
\text { Findings/Suggestion }\end{array}$ \\
\hline $\begin{array}{l}\text { Jack et } \\
\text { al. } \\
\text { (2009) }\end{array}$ & $\begin{array}{l}\text { To test the effects } \\
\text { of an intervention } \\
\text { designed to } \\
\text { minimize } \\
\text { hospital utilization } \\
\text { after discharge } \\
\text { (RED) on hospital } \\
\text { utilization rate } \\
\text { (combined } \\
\text { emergency } \\
\text { department visits } \\
\text { and readmissions) } \\
\text { within } 30 \text { days of } \\
\text { the index } \\
\text { discharge }\end{array}$ & $\begin{array}{l}\text { An urban single } \\
\text { center, general } \\
\text { medical services } \\
\text { English speaking } \\
\text { hospitalized adults } \\
\\
\text { Intervention versus } \\
\text { control group } \\
(N=373 \text { versus } \\
376) \\
50 \% \text { female } \\
28 \% \text { white } \\
49.9 \text { years }\end{array}$ & $\begin{array}{l}\text { Randomized } \\
\text { trial using block } \\
\text { randomization } \\
\text { Theory } \\
\text { non-stated }\end{array}$ & $\begin{array}{l}\frac{\text { Interview questions }}{\text { (a) How well were }} \\
\text { your questions } \\
\text { answered before } \\
\text { you left the } \\
\text { hospital? } \\
\text { (b) How well did you } \\
\text { understand your } \\
\text { appointments after } \\
\text { you left the } \\
\text { hospital? } \\
\text { (c) How well did you } \\
\text { understand how to } \\
\text { take your } \\
\text { medications after } \\
\text { leaving the } \\
\text { hospitals? } \\
\text { (d) How well did you } \\
\text { understand your } \\
\text { main problem or } \\
\text { diagnosis when you } \\
\text { left the hospital? } \\
\text { (e) How prepared } \\
\text { were you to leave } \\
\text { the hospital? }\end{array}$ & $\begin{array}{l}\text { Limited generalization of findings due to: }(a) \\
\text { urban, young, underserved population; }(b) \\
\text { unable to enroll participants during weekends } \\
\text { and holidays due to staffing limitation; (c) } \\
\text { patient's self-report } \\
\text { Findings: participants in the intervention group } \\
\text { had a lower rate of hospital utilization than } \\
\text { those receiving usual care } \\
(0.314 \text { vs. } 0.451 \text { visit per person per month; } \\
\text { incidence rate ratio, } 0.695 \text { [ } 95 \% \text { Cl, } 0.515 \text { to } \\
0.937] ; P=0.009) \text {. That is, the RED } \\
\text { intervention decreased hospital utilization by } \\
\text { about } 30 \%\end{array}$ \\
\hline
\end{tabular}


B. Quantitative Studies: Factors influencing heart failure readmissions

\begin{tabular}{|l|l|l|l|l|l|}
\hline Study & Purpose & $\begin{array}{l}\text { Setting/Sample/ } \\
\text { Subjects/ } \\
\text { Genderl } \\
\text { Racial/ } \\
\text { Ethnicity/ } \\
\text { Age }\end{array}$ & $\begin{array}{l}\text { Research } \\
\text { Design/ } \\
\text { Theory }\end{array}$ & $\begin{array}{l}\text { Source of } \\
\text { Data/Method } \\
\text { Used/Type of } \\
\text { Analysis }\end{array}$ & $\begin{array}{l}\text { Strength/ Limitation/Research } \\
\text { Findings/Suggestion }\end{array}$ \\
\hline $\begin{array}{l}\text { Holland } \\
\text { Bowles } \\
(2012)\end{array}$ & $\begin{array}{l}\text { To identify and } \\
\text { address the } \\
\text { continuing care } \\
\text { needs and to } \\
\text { identify patients } \\
\text { who would benefit } \\
\text { from post-acute } \\
\text { care. }\end{array}$ & $\begin{array}{l}\text { Single academic } \\
\text { medical center } \\
130 \text { patients in } \\
\text { control and } \\
\text { intervention groups }\end{array}$ & $\begin{array}{l}\text { Prospective } \\
\text { cohort study/ } \\
\text { quasi- } \\
\text { experimental }\end{array}$ & $\begin{array}{l}\text { The Problems after } \\
\text { Discharge } \\
\text { Questionnaires } \\
(83 \% \text { response rate) })\end{array}$ & $\begin{array}{l}\text { Limited generalization due to single center } \\
\text { identify and address the continuing care needs } \\
\text { and to identify patients who would benefit from } \\
\text { post-acute care }\end{array}$ \\
& & & $\begin{array}{l}\text { Intervention group reported fewer unmet needs } \\
(p=0.01) \text { and fewer problems complying with } \\
\text { discharge instructions }(p=0.04) \text { compared to } \\
\text { the control group }\end{array}$ \\
\hline
\end{tabular}




\section{Appendix C}

\section{Interview Guide}

Our hospital team believes that listening to the stories of patients can help us improve our care. It may take 30-45 minutes for you to answer these questions. You can skip any questions that you prefer not to answer.

\section{Etiology and symptom:}

1. Why do you think you had to come back to the hospital?

(Patients may talk about their diagnosis, symptom, onset, and severity of illness: permit them to explore their experience)

$>$ Why do you think it (the symptom) started when it did?

$>$ How severe was it (the symptom)?

Self-care:

The doctors and nurses ask patients with heart failure to do things at home.

2. Tell me what you do to take care of yourself every day.

(Let them answer related to heart failure or conditions that they believe led to rehospitalization)

$>$ What difficulties do you have with taking care of yourself?

(If the previous answers do not elicit any information about diet restriction, ask the following question):

$>$ Tell me what you typically eat on an average day at home.

Education and Treatment:

3. How prepared did you feel about returning home when you left the hospital?

$>$ What do you want to learn from the doctors and nurses (health care providers)?

$>$ What medical treatment do you want from doctors and nurses (health care providers)?

$>$ What do you think the doctors and nurses need to know about you to keep you from coming back to the hospital?

Decision-making for seeking care

4. What finally made you decide to come back to the hospital? (How did you come up with that decision?)

Concluding question:

5. What do you think could have prevented you from coming back to the hospital? 
Chart Review Guide

\section{Appendix D}

Date of assessment

Date review completed

Reviewer

Age:

Sex:

Race:

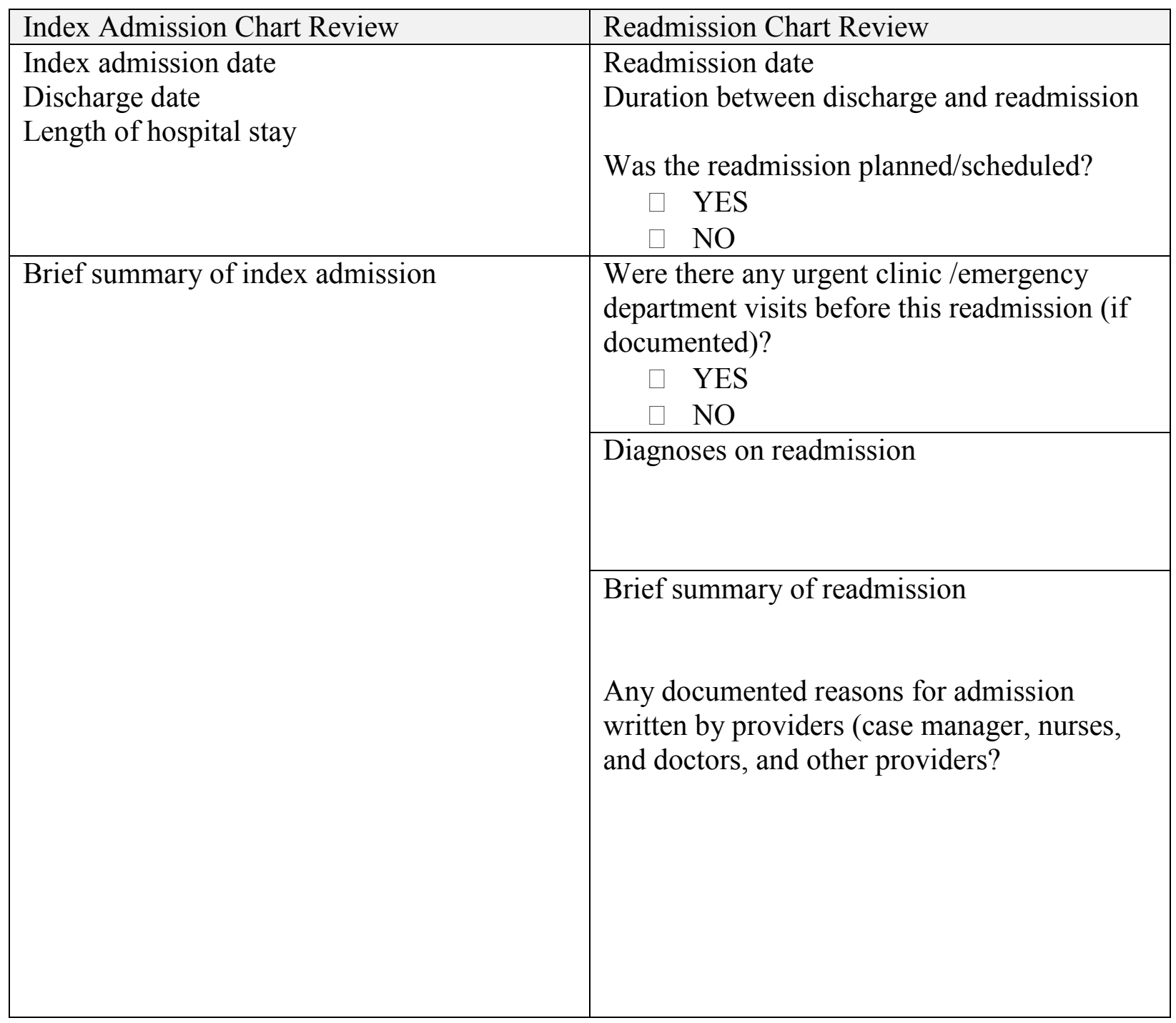


Chart Review Guide, continued

\begin{tabular}{|c|c|}
\hline Index Admission Chart Review & Readmission Chart Review \\
\hline $\begin{array}{l}\text { Where was the patient discharged? } \\
\quad \square \quad \text { Home } \\
\square \quad \text { Home with Home Care } \\
\square \quad \text { Home with physical therapy } \\
\square \quad \text { Acute Rehabilitation facility } \\
\square \quad \text { Nursing Home } \\
\square \quad \text { Hospice } \\
\square \quad \text { Other: }\end{array}$ & \\
\hline 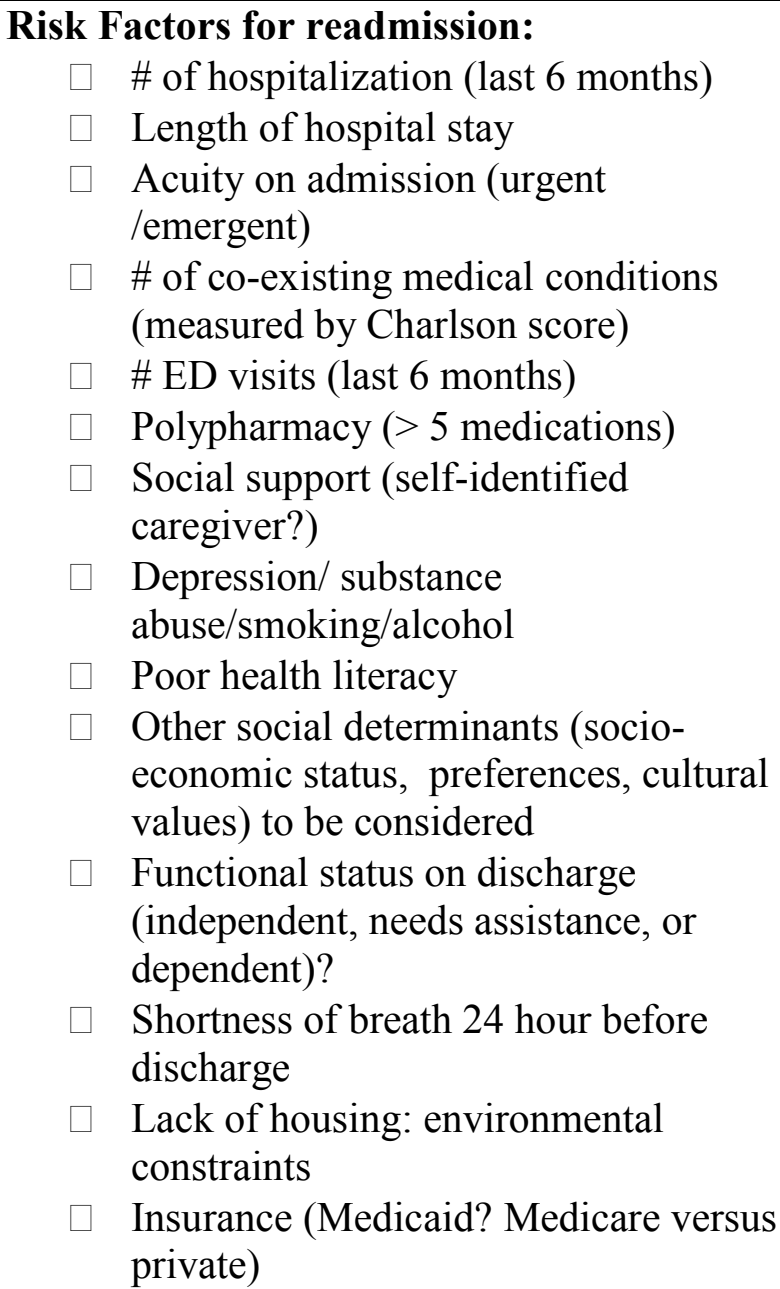 & \\
\hline
\end{tabular}


Chart Review Guide, continued

\begin{tabular}{|c|c|}
\hline Index Admission Chart Review & Readmission Chart Review \\
\hline $\begin{array}{l}\square \quad \text { Was the patient seen by physical } \\
\text { therapist/occupational therapist? } \\
\square \quad \text { Was the patient seen by dietician? }\end{array}$ & \\
\hline $\begin{array}{l}\square \quad \text { Was the patient seen by } \mathrm{H}_{2} \mathrm{H} \text { ? } \\
\square \quad \text { Was the patient seen by } 3 \mathrm{H} \text { ? } \\
\square \quad \text { Was the patient seen by inpatient heart } \\
\text { failure nurse practitioner? } \\
\square \quad \text { Was the patient seen by nurse } \\
\text { navigator? }\end{array}$ & \\
\hline $\begin{array}{l}\square \quad \text { Evidence of use of teach back } \\
\text { documented? } \\
\square \quad \text { Evidence of use of health literacy } \\
\text { screening tool? } \\
\square \quad \text { Evidence of contacting family } \\
\text { members to enhance teaching and } \\
\text { sharing responsibilities? }\end{array}$ & \\
\hline $\begin{array}{ll}\square & \text { Evidence of enhanced teaching } \\
\text { documented? } \\
\square \quad \text { HF knowledge/ self-care maintenance } \\
\square \quad \text { Medication management } \\
\square \quad \text { How to seek care } \\
\square \quad \text { Follow-up appointments }\end{array}$ & \\
\hline $\begin{array}{l}\text { Discharge medication information } \\
\square \quad \text { Was medication reconciliation } \\
\text { documented during the index } \\
\text { admission? }\end{array}$ & \\
\hline $\begin{array}{l}\text { Discharge follow-up information } \\
\square \quad \text { Was outpatient follow-up scheduled at } \\
\text { the time of discharge? } \\
\square \quad \text { Was the patient provided with the } \\
\text { post-discharge hotline phone number? }\end{array}$ & $\begin{array}{l}\square \text { Did the patient receive a follow-up } \\
\text { phone call after discharge? } \\
\square \text { Did the patient attend the } \\
\text { appointment? } \\
\square \quad \text { If the patient did not attend, explain } \\
\text { why (e.g. lack of transportation?) } \\
\square \quad \text { Was the patient readmitted prior to the } \\
\text { physician follow-up? }\end{array}$ \\
\hline
\end{tabular}


Appendix E

IRB-HSR \# 17345: Exploring Factors Influencing Heart Failure Readmission

\section{Consent of an Adult to Be in a Research Study}

In this form "you" means a person 18 years of age or older who is being asked to volunteer to participate in this study.

\section{Participant's Name}

Principal Investigator: Arlene Keeling, PhD, Professor

CMNEB 2111,UVA School of Nursing

University of Virginia

Charlottesville, VA 22903

Telephone: (434)924-5906 , (434) 960-3239

\section{What is the purpose of this form?}

This form will provide you with information about this research study. You do not have to be in the study if you do not want to. You should have all your questions answered before you give your permission or consent to be in the study.

Please read this form carefully. If you want to be in the study, you will need to sign this form. You will be given a signed copy of this form.

\section{Why is this research being done?}

The reason for this research study is to ask patients with heart failure why they think they had to come back to the hospital. Patients can help us make care better by sharing their stories. We found out that past studies did not ask patients about coming back to the hospital. We think that the patient's ideas are important for us to make care better.

\section{What will happen if you are in the study?}

If you agree to be in this study, you will sign this consent form before any study related procedures take place. Then, the following will occur:

A member of the study team will review your medical record, and arrange to talk with you about coming back to the hospital.

The interviewer will ask you about:

- Reason why you decided to come back to the hospital

- Your activities at home, and any difficulties you might have had taking care of yourself

IRB-HSR

Page 1 of 6

Version Date: 04/07/14

APPROVAL DATEO $4 / 09 / 14$

EXPIRATION DATE $04 / 08 / 15$ 
- What you would like to learn from the doctors and nurses, and what you would like them to know about you

- Suggestions you might have to help us prevent people with heart failure from having to be admitted again

Once the interview is over, you participation in the study will be complete.

\section{WHAT ARE YOUR RESPONSIBILITIES IN THE STUDY?}

If you decide to be in the study, we will ask you to answer the interview questions as completely and truthfully as possible.

\section{How long will this study take?}

The interview will take about 30 to 45 minutes of your time.

\section{If you want to know about the results before the study is done:}

The final results of the research will not be known until all the information from everyone is combined and reviewed. At that time you can ask for more information about the study results.

Could you be helped by being in this study?

You will not benefit from being in this study. However the information researchers get from this study may help others in the future.

What are the risks of being in this study?

There is a very small risk that someone might see your private information.

Please let the study team know if you become tired or have other problems during the interview. We will stop, and call your nurse for assistance.

What are your other choices if you do not join this study?

You do not have to be in this study to be treated for your illness or condition. You can get the usual treatment even if you choose not to be in this study. The usual treatment would include continuing to be treated for your heart failure or other problems here at UVa Medical Center.

If you are an employee of UVA, your job will not be affected if you decide not to participate in this study.

If you are a student at UVA, your grades will not be affected if you decide not to participate in this study. 
Will you be paid for being in this study?

You will not get any money for being in this study.

Will being in this study cost you any money?

All of the procedures in this study (the interview) will be provided at no cost to you or your health insurance. You will continue to be responsible for the cost of your hospitalization, and for any travel costs or parking costs related to your medical care or hospital stay.

\section{What if you are hurt in this study?}

If you are hurt as a result of being in this study, there are no plans to pay you for medical expenses, lost wages, disability, or discomfort. The charges for any medical treatment you receive will be billed to your insurance. You will be responsible for any amount your insurance does not cover. You do not give up any legal rights, such as seeking compensation for injury, by signing this form.

What happens if you leave the study early?

You can change your mind about being in the study any time. You can agree to be in the study now and change your mind later. If you decide to stop, please tell us right away. You do not have to be in this study to get services you can normally get at the University of Virginia.

If you decide to stop being in the study, we will ask you to tell the interviewer, who will stop the interview and leave the room. At that time, the audio recording of the interview will be immediately destroyed.

How will your personal information be shared?

The UVA researchers are asking for your permission to gather, use and share information about you for this study. If you decide not to give your permission, you cannot be in this study, but you can continue to receive regular medical care at UVA.

\section{If you sign this form, we may collect any or all of the following information about you:}

- Personal information such as name, address and date of birth

- Social Security number ONLY IF you are being paid to be in this study

- Your health information if required for this study. This may include a review of your medical records and test results from before, during and after the study from any of your doctors or health care providers. This may include mental health care records, substance abuse records, and/or HIV/AIDS records. 


\section{Who will see your private information?}

- The researchers to make sure they can conduct the study the right way, observe the effects of the study and understand its results

- People or groups that oversee the study to make sure it is done correctly

- The sponsor(s) of this study, and the people or groups it hires to help perform or review this research

- Insurance companies or other organizations that may need the information in order to pay your medical bills or other costs of your participation in the study

- Tax reporting offices (if you are paid for being in the study)

- People who evaluate study results, which can include sponsors and other companies that make the drug or device being studied, researchers at other sites conducting the same study, and government agencies that provide oversight such as the Food and Drug Administration (FDA) if the study is regulated by the FDA.

Some of the people outside of UVA who will see your information may not have to follow the same privacy laws that we follow. They may release your information to others, and it may no longer be protected by those laws.

The information collected from you might be published in a medical journal. This would be done in a way that protects your privacy. No one will be able to find out from the article that you were in the study.

A description of this clinical trial will be available on $h t t p: / / w w w$.ClinicalTrials.gov, as required by U.S. Law. This Web site will not include information that can identify you. At most, the Web site will include a summary of the results. You can search this Web site at any time.

\section{What if you sign the form but then decide you don't want your private information shared?}

You can change your mind at any time. Your permission does not end unless you cancel it. To cancel it, please send a letter to the researchers listed on this form. Then you will no longer be in the study. The researchers will still use information about you that was collected before you ended your participation.

\section{Please contact the researchers listed below to:}

- Obtain more information about the study

- Ask a question about the study procedures or treatments

- Report an illness, injury, or other problem (you may also need to tell your regular doctors)

- Leave the study before it is finished

- Express a concern about the study 


\author{
Principal Investigator: Arlene Keeling \\ Academic Divisions, School of Nursing \\ CMNEB 2111, UVA School of Nursing \\ University of Virginia \\ Charlottesville, VA 22903
}

Telephone: (434)924-5906

\title{
What if you have a concern about this study?
}

You may also report a concern about this study or ask questions about your rights as a research subject by contacting the Institutional Review Board listed below.

University of Virginia Institutional Review Board for Health Sciences Research

PO Box 800483

Charlottesville, Virginia 22908

Telephone: 434-924-9634

When you call or write about a concern, please give as much information as you can. Include the name of the study leader, the IRB-HSR Number (at the top of this form), and details about the problem. This will help officials look into your concern. When reporting a concern, you do not have to give your name.

\section{Signatures}

What does your signature mean?

Before you sign this form, please ask questions about any part of this study that is not clear to you. Your signature below means that you have received this information and all your questions have been answered. If you sign the form it means that you agree to join the study. You will receive a copy of this signed document.

\section{Consent From Adult}

PARTICIPANT

(SIGNATURE)
PARTICIPANT

(PRINT)

To be completed by participant if $\mathbf{1 8}$ years of age or older.

\section{Consent From Impartial Witness}

If this consent form is read to the subject because the subject is blind or illiterate, an impartial witness not affiliated with the research or study doctor must be present for the 
consenting process and sign the following statement. The subject may place an $X$ on the Participant Signature line above.

I agree the information in this informed consent form was presented orally in my presence to the subject and the subject had the opportunity to ask any questions he/she had about the study. I also agree that the subject freely gave their informed consent to participate in this trial.

IMPARTIAL WITNESS

(SIGNATURE)
IMPARTIAL WITNESS

(PRINT)
DATE

\section{Person Obtaining Consent}

By signing below you confirm that you have fully explained this study to the potential subject, allowed them time to read the consent or have the consent read to them, and have answered all their questions.

PERSON OBTAINING CONSENT (SIGNATURE)
PERSON OBTAINING CONSENT (PRINT)
DATE 


\section{Appendix F}

UVA IRB OnLine

Page 1 of 2

University of Virginia

Institutional Review Board for Health Sciences Research

Protection of Human Subjects Approval

Assurance Identification/Certification/Declaration

(Common Federal Rule)

\begin{tabular}{|c|c|c|}
\hline \multicolumn{3}{|c|}{ HSR \# 17345} \\
\hline \multirow[t]{2}{*}{$\begin{array}{l}\text { Event: } \\
\text { Approval New Protocol - Expedited }\end{array}$} & \multirow[t]{2}{*}{$\begin{array}{l}\text { Type: } \\
\text { Protocol }\end{array}$} & \multirow{2}{*}{$\begin{array}{l}\text { Sponsor(s): } \\
\text { Sponsor Protocol \#: } \\
\text { Principal Investigator: Arlene Keeling, PhD RN }\end{array}$} \\
\hline & & \\
\hline \multicolumn{3}{|c|}{ Title: Exploring Factors Influencing Heart Failure Readmission } \\
\hline \multicolumn{3}{|l|}{ Assurance: Federal Wide Assurance (FWA)\#: 00006183} \\
\hline \multicolumn{3}{|c|}{$\begin{array}{l}\text { Certification of IRB Review: The IRB-HSR abides by } 21 \text { CFR50, } 21 \text { CFR56, 45CFR46, 45CFR160, 45CFR164, } 32 \text { CFR219 and ICH guidelines. This activity has } \\
\text { been reviewed and approved by the IRB in accordance with these regulations. }\end{array}$} \\
\hline \multicolumn{3}{|l|}{$\begin{array}{l}\text { Approval Date: } 04 / 09 / 14 \\
\text { Protocol Expiration Date: } 04 / 08 / 15 \\
\text { Approved to Enroll } 15 \text { subjects. } \\
\text { HSR Protocol Version Date: } 04 / 04 / 14\end{array}$} \\
\hline \multicolumn{3}{|l|}{ Current Status: Open to enrollment } \\
\hline \multicolumn{2}{|l|}{ Consent Version Dates: } & Adult Consent -- 04/07/2014 \\
\hline \multicolumn{3}{|l|}{ Committee Members (did not vote): } \\
\hline \multicolumn{3}{|c|}{$\begin{array}{l}\text { Comments: The purpose of this study is to learn more at } \\
\text { Center within } 30 \text { days of discharge from initial hospitaliza } \\
\text { combined with a review of their medical record. Descripti } \\
\text { There is no outside sponsor for this study. } \\
N=15\end{array}$} \\
\hline \multicolumn{3}{|l|}{$\mathrm{N}=15$} \\
\hline \multicolumn{3}{|c|}{ The following items were reviewed with this approval: data collection form and interview tool. } \\
\hline \multicolumn{3}{|l|}{ No additional committee approvals are required. } \\
\hline \multicolumn{3}{|l|}{ No compensation. } \\
\hline \multicolumn{3}{|c|}{ Vulnerable populations to be enrolled in this study include potential subjects who are elderly. } \\
\hline \multicolumn{3}{|l|}{ REGULATORY INFORMATION: } \\
\hline \multicolumn{3}{|c|}{ The IRB determined this protocol met the criteria of minimal risk. } \\
\hline $\begin{array}{l}\text { Protocol Expedited by Category \#5: Researcl } \\
\text { collected solely for non-research purposes ( } \mathrm{s}\end{array}$ & $\begin{array}{l}\text { h involving } \mathrm{m} \\
\text { such as medice }\end{array}$ & $\begin{array}{l}\text { Is (data, documents, records or specimens) that have been } \\
\text { tment and/or diagnosis). }\end{array}$ \\
\hline
\end{tabular}

http://www.irb.virginia.edu/index.cfm?fuseAction=hsr_HTMLReports.reportProtocolAssur... 4/9/2014 
research on perception, cognition, motivation, identity, language, communication, cultural beliefs or practices and social behavior) or research employing survey, interview, oral history, focus group, program evaluation, human factors evaluation, or quality assurance methodologies.

This protocol has been granted a Waiver of Consent to identify potential subjects via 45CFR46.116.

This protocol has been granted a Waiver of Consent via 45CFR46.116 and a Waiver of HIPAA Authorization via 45CFR 164.512 (i)(2) to contact subjects by direct contact by a person who is not their health care provider.

Direct contact may include phone, letter, direct email or approaching potential subjects while at UVa.

Phone, letter or emails will be approved by the IRB-HSR prior to use.

The following HIPAA identifiers may be collected: Name, medical record number, date of birth and contact information appropriate to the recruitment plan.

The minimum necessary $\mathrm{PHI}$ to be collected includes only those items related to the inclusion/ exclusion criteria.

Subjects will sign a consent form to participate in this study. The consent form signed will have a non-expired IRB-HSR approval stamp.

PLEASE REMEMBER:

* If an outside sponsor is providing funding or supplies, you must contact the SOM Grants and Contracts Office/ OSP regarding the need for a contract and letter of indemnification. If it is determined that either of these documents is required, participants cannot be enrolled until these documents are complete.

* You must notify the IRB of any new personnel working on the protocol PRIOR to them beginning work.

* You must obtain IRB approval prior to implementing any changes to the approved protocol or consent form except in an

emergency, if necessary to safeguard the well-being of currently enrolled subjects.

* If you are obtaining consent from subjects, prisoners are not allowed to be enrolled in this study unless the IRB-HSR previously approved the enrollment of prisoners. If one of your subjects becomes a prisoner after they are enrolled in the protocol you must notify the IRB immediately.

* You must notify the IRB-HSR office within 30 days of the closure of this study.

* Continuation of this study past the expiration date requires re-approval by the IRB-HSR.

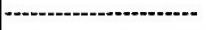

The official signing below certifies that the information provided above is correct and that, as required, future reviews will be performed and certification will be provided.

Name: Lynn R. Noland, RN PhD

Title: Vice Chair, Institutional Review Board for

Health Sciences Research

Phone: 434-924-9634 Fax: 434-924-2932

Name and Address of Institution:

Institutional Review Board for Health Sciences

Research

PO Box 800483

University of Virginia

Charlottesville, VA 22908

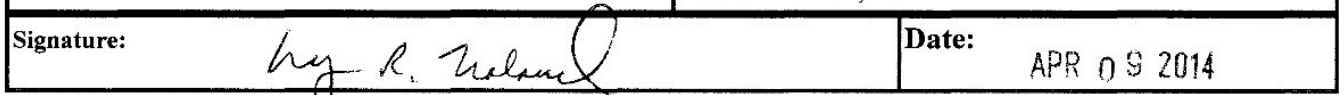

(C) 2014 by the Rector and Visiters of the University of Virginia. All rights reserved. 


\begin{tabular}{|c|c|c|}
\hline \multicolumn{3}{|c|}{$\begin{array}{c}\text { University of Virginia } \\
\text { Institutional Review Board for Health Sciences Research } \\
\text { Protection of Human Subjects Approval } \\
\text { Assurance Identification/Certification/Declaration } \\
\text { (Common Federal Rule) }\end{array}$} \\
\hline \multicolumn{3}{|c|}{ HSR \# 17345} \\
\hline \multirow{2}{*}{$\begin{array}{l}\text { Event: } \\
\text { Approval Protocol Continuation - } \\
\text { Expedited }\end{array}$} & \multirow[t]{2}{*}{\begin{tabular}{|l|} 
Type: \\
Protocol
\end{tabular}} & $\begin{array}{l}\text { Sponsor(s): } \\
\text { Sponsor Protocol \#: }\end{array}$ \\
\hline & & Principal Investigator: Arlene Keeling, PhD RN \\
\hline \multicolumn{3}{|c|}{ Title: Exploring Factors Influencing Heart Failure Readmission } \\
\hline \multicolumn{3}{|c|}{ Assurance: Federal Wide Assurance (FWA)\#: 00006183} \\
\hline \multicolumn{3}{|c|}{$\begin{array}{l}\text { Certification of IRB Review: The IRB-HSR abides by } 21 \text { CFR } 50,21 \text { CFR } 56,45 \text { CFR } 46,45 \text { CFR } 160 \text {, } \\
45 \text { CFR } 164,32 \text { CFR } 219 \text { and ICH guidelines. This activity has been reviewed by the IRB in accordance with } \\
\text { these regulations. }\end{array}$} \\
\hline \multicolumn{3}{|l|}{$\begin{array}{l}\text { Event Date: } 02 / 18 / 15 \\
\text { Protocol Expiration Date: } 02 / 17 / 16 \\
\text { Number of Subjects: } 15 \\
\text { HSR Protocol Version Date: } 04 / 04 / 14\end{array}$} \\
\hline \multicolumn{3}{|c|}{ Current Status: Closed to Enrollment, Performing Data Analysis } \\
\hline \multicolumn{3}{|l|}{ Consent Version Dates: } \\
\hline \multicolumn{3}{|l|}{ Committee Members (did not vote): } \\
\hline \multicolumn{3}{|c|}{$\begin{array}{l}\text { Comments: Protocol Expedited by Category \#5: Research involving materials (data, documents, records or } \\
\text { specimens) that have been collected solely for non-research purposes (such as medical treatment and/or } \\
\text { diagnosis). }\end{array}$} \\
\hline \multicolumn{3}{|c|}{$\begin{array}{l}\text { Protocol Expedited by Category \#7: Research on individual or group characteristics or behavior (including, } \\
\text { but not limited to, research on perception, cognition, motivation, identity, language, communication, } \\
\text { cultural beliefs or practices and social behavior) or research employing survey, interview, oral history, } \\
\text { focus group, program evaluation, human factors evaluation, or quality assurance methodologies. }\end{array}$} \\
\hline \multicolumn{3}{|c|}{ Protocol Expedited by Category \#8C: Continuing review data analysis only. } \\
\hline \multicolumn{3}{|c|}{ Protocol status changed from Open to Enrollment to Data Analysis per Status Form. } \\
\hline \multicolumn{3}{|c|}{$\begin{array}{l}\text { PLEASE REMEMBER: } \\
\text { * If an outside sponsor is providing funding or supplies, you must contact the SOM Grants and Contracts } \\
\text { Office/ OSP regarding the need for a contract and letter of indemnification. If it is determined that either of } \\
\text { these documents is required, participants cannot be enrolled until these documents are complete. } \\
\text { * You must notify the IRB of any new personnel working on the protocol PRIOR to them beginning work. } \\
\text { * You must obtain IRB approval prior to implementing any changes to the approved protocol or consent } \\
\text { form except in an emergency, if necessary to safeguard the well-being of currently enrolled subjects. } \\
\text { * If you are obtaining consent from subjects, prisoners are not allowed to be enrolled in this study unless } \\
\text { the IRB-HSR previously approved the enrollment of prisoners. If one of your subjects becomes a prisoner } \\
\text { after they are enrolled in the protocol you must notify the IRB immediately. }\end{array}$} \\
\hline
\end{tabular}


* You must notify the IRB-HSR office within 30 days of the closure of this study. * Continuation of this study past the expiration date requires re-approval by the IRB-HSR.

The official signing below certifies that the information provided above is correct and that, as required, future reviews will be performed and certification will be provided.

Name: Lynn R. Noland, RN PhD

Title: Vice Chair, Institutional Review Board for

Health Sciences Research

Phone: 434-924-9634

Fax: $434-924-2932$
Name and Address of Institution:

Institutional Review Board for Health Sciences Research

PO Box 800483

University of Virginia

Charlottesville, VA 22908

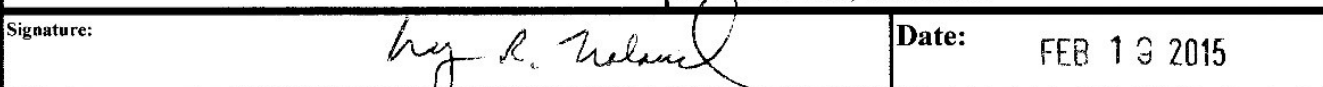

(C) 2014 by the Rector and Visitors of the University of Virginia. All rights reserved. 


\section{Appendix G}

Table1. Demographics and Medical Characteristics (N=9)

\section{Characteristics}

Age

Gender Male

Female

Race White

African American

Immigrant Status

Days to readmission

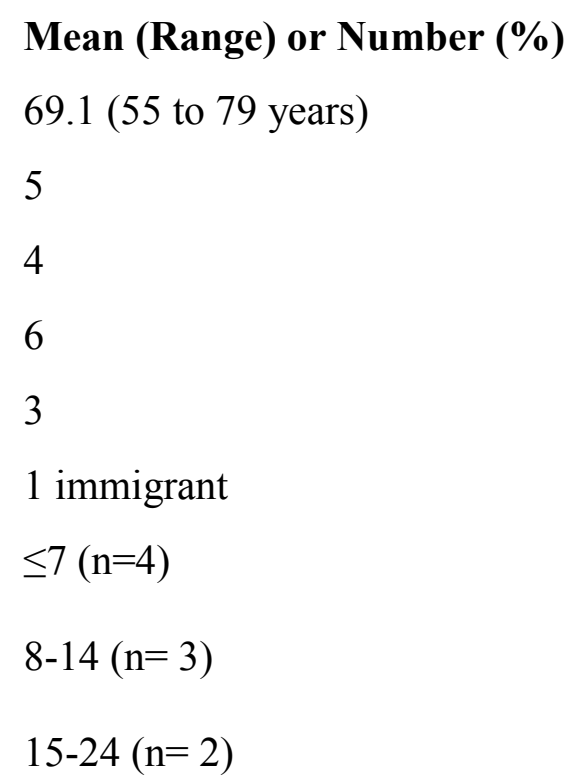

Insurance

Medicare/Medicaid

7

Private 2

No Insurance 1

Programs Arranged during Index

$\mathrm{H} 2 \mathrm{H}$ (Hospital to Home) 6

3H (Heart Health at Home) 5

C3 (Care Coordination Centers) 5

PT (Physical Therapy) 3 


\section{Appendix H}

Instructions for Authors, Heart \& Lung 


\section{HEART \& LUNG - THE JOURNAL OF ACUTE AND CRITICAL CARE}

\section{AUTHOR INFORMATION PACK}

\section{TABLE OF CONTENTS}

- Description

- Impact Factor

- Abstracting and Indexing

- Editorial Board

- Guide for Authors

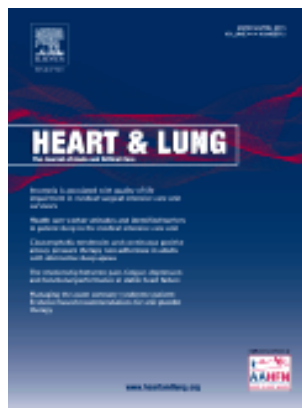

ISSN: 0147-9563 


\section{DESCRIPTION}

Heart \& Lung: The Journal of Acute and Critical Care, the official publication of The American Association of Heart Failure Nurses, presents original, peer-reviewed articles on techniques, advances, investigations, and observations related to the care of patients with acute and critical illness and patients with chronic cardiac or pulmonary disorders.

The Journal's acute care articles focus on the care of hospitalized patients, including those in the critical and acute care settings. Because most patients who are hospitalized in acute and critical care settings have chronic conditions, we are also interested in the chronically critically ill, the care of patients with chronic cardiopulmonary disorders, their rehabilitation, and disease prevention. The Journal's heart failure articles focus on all aspects of the care of patients with this condition. Manuscripts that are relevant to populations across the human lifespan are welcome.

We are interested in publishing articles representing a broad range of science and clinical practice in a variety of settings as it pertains to our target population. Because health care and the health sciences are global, interdisciplinary, multidisciplinary, and transdisciplinary, we encourage authors to submit manuscripts that reflect these perspectives. Many articles also provide nurses with a framework for applying research results in clinical practice.

We publish original research, case reports, reviews, and observations that are on the cutting edge of science and clinical practice. Discussions of costs of care, patient education, and health policy are relevant to our focus. Reports of well-designed clinical trials and systematic reviews are especially welcome.

\section{IMPACT FACTOR}

2013: 1.320 @ Thomson Reuters Journal Citation Reports 2014

\section{ABSTRACTING AND INDEXING}

CINAHL

MEDLINE®

Scopus 


\section{EDITORIAL BOARD}

\section{Editor}

Nancy Redeker, PhD, RN, FAHA, FAAN, Yale University, New Haven, Connecticut, USA

\section{Managing Editor}

Ardis O'Meara

\section{Editorial Board}

Nancy Albert, Cleveland Clinic, Cleveland, Ohio, USA

Jerilyn K. Allen, RN, ScD, FAAN, Johns Hopkins University, Baltimore, Maryland, USA

Nancy T. Artinian, PhD, RN, FAHA, FPCNA, FAAN, Wayne State University, Detroit, Michigan, USA

Jacquie Byers, PhD, RN, NEA-BC, CPHQ, FAAN, University of Central Florida, Orlando, Florida, USA

Diane L. Carroll, PhD, Massachusetts General Hospital, Boston, Massachusetts, USA

Linda Chlan, PhD, RN, Ohio State University

Eileen Collins, PhD, RN, FAAN, University of Illinois at Chicago, Chicago, Illinois, USA

Yvette Conley, PhD, University of Pittsburgh, Pittsburgh, Pennsylvania, USA

Richard J Contrada, PhD, Rutgers University, Piscataway, New Jersey, USA

Sandi Dunbar, RN, DSN, Emory University, Atlanta, Georgia, USA

Charles Fiske Emery, PhD, Ohio State University, Columbus, Ohio, USA

Carol Diane Epstein, PhD, RN, FCCM, Pace University, Pleasantville, New York, USA

Lorraine Frazier, PhD, RN, FAHA, FAAN, University of Arkansas for Medical Sciences, Little Rock, Arkansas, USA

Susan K. Frazier, PhD, RN, University of Kentucky, Lexington, Kentucky, USA

Erica Froelicher, PhD, RN, University of California at San Francisco (UCSF), San Francisco, California, USA

Kathleen Grady, PhD, APN, FAAN, Northwestern University, Chicago, Illinois, USA

Angela Green, PhD, APN, NNP-BC, Arkansas Children's Hospital, Little Rock, Arkansas, USA

Susan Grove, PhD, University of Texas at Arlington, Arlington, Texas, USA

Mary B Happ, University of Pittsburgh, Pittsburgh, Pennsylvania, USA

Chrisopher S. Hollenbeak, PhD, Penn State College of Medicine, Hershey, Pennsylvania, USA

Judith E. Hupcey, EdD, Pennsylvania State University, Hershey, Pennsylvania, USA

Karen Huss, PhD, RN

Tiny Jaarsma, PhD, RN, NFESC, FAHA, Linköping University, Norrköpin, Sweden

Ruth Kleinpell, PhD, RN, FAAN, FCCM, Rush University, Chicago, Illinois, USA

Carl V. Leier, Ohio State University Medical Center, Columbus, Ohio, USA

Ruth Lindquist, PhD, RN, ACNS-BC, FAAN, University of Minnesota, Minneapolis, Minnesota, USA

Elizabeth Madigan, PhD, RN, FAAN

Jean McSweeney, PhD, RN, FAHA, FAAN, University of Arkansas for Medical Sciences, Little Rock, Arkansas, USA

Eric Michelson, MD, FACC, American College of Cardiology Foundation, Haverford, Pennsylvania, USA

Sheila M. Moore, PhD, RN, FAAN, Case Western Reserve University, Cleveland, Ohio, USA

Margaret Pisani, MD, MPH, Yale University School of Medicine, New Haven, Connecticut, USA

W. Rainer, University of Colorado Health Sciences Center, Denver, Colorado, USA

Anne Rosenfeld, PhD, RN, CNS, FAHA, FAAN, University of Arizona, Tucson, Arizona, USA

Kristine Anne Scordo, PhD, RN, ACNP-BC, FAANP, Wright State University, Dayton, Ohio, USA

Mary Lou Sole, PhD, RN, CCNS, FAAN, FCCM, University of Central Florida, Orlando, Florida, USA

Marilyn S. Sommers, PhD, RN, FAAN

Mi-Kyung Song, PhD, RN, University of North Carolina at Chapel Hill, Chapel Hill, North Carolina, USA

Theodore Stern, Massachusetts General Hospital, Boston, Massachusetts, USA

Simon Stewart, PhD, NFESC, FAHA, FCSANZ, Baker IDI Heart and Diabetes Institute, Melbourne, Victoria, Australia

Patricia Stone, PhD, RN, Columbia University School of Nursing, New York, New York, USA

David R. Thompson, BSc, MA, PhD, MBA, RN, FRCN, FESC, Australian Catholic University, North Sydney, New South Wales, Australia

Robin J. Trupp, PhD, ARNP-BC, CHFN, Ohio State University, Columbus, Ohio, USA

Barbara S. Turner, DNSc, FAAN

David Vawdrey, PhD, Columbia University School of Nursing, New York, New York, USA

Julie Zerwic, PhD, RN 


\section{GUIDE FOR AUTHORS}

\section{Introduction}

Heart and Lung: The Journal of Acute and Critical Care, the official publication of The American Association of Heart Failure Nurses, presents original, peer-reviewed articles on techniques, advances, investigations, and observations related to the care of patients with acute and critical illness and patients with chronic cardiac or pulmonary disorders.

The Journal's acute care articles focus on the care of hospitalized patients, including those in the critical and acute care settings. Because most patients who are hospitalized in acute and critical care settings have chronic conditions, we are also interested in the chronically critically ill, the care of patients with chronic cardiopulmonary disorders, their rehabilitation, and disease prevention. The Journal's heart failure articles focus on all aspects of the care of patients with this condition. Manuscripts that are relevant to populations across the human lifespan are welcome.

We are interested in publishing articles representing a broad range of science and clinical practice in a variety of settings as it pertains to our target population. Because health care and the health sciences are global, interdisciplinary, multidisciplinary, and transdisciplinary, we encourage authors to submit manuscripts that reflect these perspectives. Many articles also provide nurses with a framework for applying research results in clinical practice.

\section{Editor:}

Nancy S. Redeker, PhD, RN, FAHA, FAAN

Yale University, New Haven, CT

Managing Editor:

Ardis O'Meara

Towson, MD

heartlungjournal@gmail.com

Publisher:

Mercedes Simoncelli

Elsevier Inc.

1600 JFK Blvd, Suite 1800

Philadelphia, PA 19103-2899

Journal Manager:

Swaminathan Nagarajan

Sw.Nagarajan@elsevier.com

\section{Types of paper}

We publish original research, case reports, reviews, and observations that are on the cutting edge of science and clinical practice. Reports of well-designed clinical trials and systematic reviews are especially welcome. Discussions of translational research and implementation and improvement science, as well as costs of care, patient education, and health policy are of high relevance to our focus.

\section{ARTICLE CATEGORIES}

Letters to the Editor

Letters to the Editor raising some point of current interest or commenting on an article that appeared in the Journal will be considered for publication. The Editor reserves the right to accept, reject, or excerpt letters without changing the views expressed by the writer. The author of an original article will have an opportunity to reply to published comments. All such letters should be sent to Dr. Redeker.

\section{Reports of Original Research}

\section{Systematic Reviews}

Reports of analyses of healthy policy, education, economic or organizational issues pertaining to the care of patients with acute and critical illness and patients with chronic cardiac or pulmonary disorders. 
Case Studies describe unusual clinical problems and their management. Please include in the body of the text an abstract, introduction, case report, discussion, and a conclusion.

\section{BEFORE YOU BEGIN}

\section{Ethics in publishing}

For information on Ethics in publishing and Ethical guidelines for journal publication see http://www.elsevier.com/publishingethics and http://www.elsevier.com/journal-authors/ethics.

\section{Protection of Human Subjects and Animals in \\ Research}

All manuscripts that involve human subjects or animals in research must conform to the principles of the International Committee of Medical Journal Editors, available at http://www.icmje.org/ ethical_6protection.html.

\section{Conflict of interest}

All authors must disclose any financial and personal relationships with other people or organizations that could inappropriately influence (bias) their work. Examples of potential conflicts of interest include employment, consultancies, stock ownership, honoraria, paid expert testimony, patent applications/registrations, and grants or other funding. If there are no conflicts of interest then please state this: 'Conflicts of interest: none'. See also http://www.elsevier.com/conflictsofinterest. Further information and an example of a Conflict of Interest form can be found at: http://help.elsevier.com/app/answers/detail/a_id/286/p/7923.

\section{Submission declaration}

Submission of an article implies that the work described has not been published previously (except in the form of an abstract or as part of a published lecture or academic thesis or as an electronic preprint, see http://www.elsevier.com/sharingpolicy), that it is not under consideration for publication elsewhere, that its publication is approved by all authors and tacitly or explicitly by the responsible authorities where the work was carried out, and that, if accepted, it will not be published elsewhere including electronically in the same form, in English or in any other language, without the written consent of the copyright-holder.

\section{Authorship}

All authors should have made substantial contributions to all of the following: (1) the conception and design of the study, or acquisition of data, or analysis and interpretation of data, (2) drafting the article or revising it critically for important intellectual content, (3) final approval of the version to be submitted.

\section{Changes to authorship}

This policy concerns the addition, deletion, or rearrangement of author names in the authorship of accepted manuscripts:

Before the accepted manuscript is published in an online issue: Requests to add or remove an author, or to rearrange the author names, must be sent to the Journal Manager from the corresponding author of the accepted manuscript and must include: (a) the reason the name should be added or removed, or the author names rearranged and (b) written confirmation (e-mail, fax, letter) from all authors that they agree with the addition, removal or rearrangement. In the case of addition or removal of authors, this includes confirmation from the author being added or removed. Requests that are not sent by the corresponding author will be forwarded by the Journal Manager to the corresponding author, who must follow the procedure as described above. Note that: (1) Journal Managers will inform the Journal Editors of any such requests and (2) publication of the accepted manuscript in an online issue is suspended until authorship has been agreed.

After the accepted manuscript is published in an online issue: Any requests to add, delete, or rearrange author names in an article published in an online issue will follow the same policies as noted above and result in a corrigendum.

\section{Copyright}

Upon acceptance of an article, authors will be asked to complete a 'Journal Publishing Agreement' (for more information on this and copyright, see http://www.elsevier.com/copyright). An e-mail will be sent to the corresponding author confirming receipt of the manuscript together with a 'Journal Publishing Agreement' form or a link to the online version of this agreement.

Subscribers may reproduce tables of contents or prepare lists of articles including abstracts for internal circulation within their institutions. Permission of the Publisher is required for resale or distribution outside the institution and for all other derivative works, including compilations and translations 
(please consult http://www.elsevier.com/permissions). If excerpts from other copyrighted works are included, the author(s) must obtain written permission from the copyright owners and credit the source(s) in the article. Elsevier has preprinted forms for use by authors in these cases: please consult http://www.elsevier.com/permissions.

For open access articles: Upon acceptance of an article, authors will be asked to complete an 'Exclusive License Agreement' (for more information see http://www.elsevier.com/OAauthoragreement). Permitted third party reuse of open access articles is determined by the author's choice of user license (see http://www.elsevier.com/openaccesslicenses).

\section{Author rights}

As an author you (or your employer or institution) have certain rights to reuse your work. For more information see http://www.elsevier.com/copyright.

\section{Role of the funding source}

You are requested to identify who provided financial support for the conduct of the research and/or preparation of the article and to briefly describe the role of the sponsor(s), if any, in study design; in the collection, analysis and interpretation of data; in the writing of the report; and in the decision to submit the article for publication. If the funding source(s) had no such involvement then this should be stated.

\section{Funding body agreements and policies}

Elsevier has established a number of agreements with funding bodies which allow authors to comply with their funder's open access policies. Some authors may also be reimbursed for associated publication fees. To learn more about existing agreements please visit http://www.elsevier.com/fundingbodies.

After acceptance, open access papers will be published under a noncommercial license. For authors requiring a commercial CC BY license, you can apply after your manuscript is accepted for publication.

\section{Open access}

This journal offers authors a choice in publishing their research:

\section{Open access}

- Articles are freely available to both subscribers and the wider public with permitted reuse

- An open access publication fee is payable by authors or on their behalf e.g. by their research funder or institution

\section{Subscription}

- Articles are made available to subscribers as well as developing countries and patient groups through our universal access programs (http://www.elsevier.com/access).

- No open access publication fee payable by authors.

Regardless of how you choose to publish your article, the journal will apply the same peer review criteria and acceptance standards.

For open access articles, permitted third party (re)use is defined by the following Creative Commons user licenses:

\section{Creative Commons Attribution-NonCommercial-NoDerivs (CC BY-NC-ND)}

For non-commercial purposes, lets others distribute and copy the article, and to include in a collective work (such as an anthology), as long as they credit the author(s) and provided they do not alter or modify the article.

The open access publication fee for this journal is USD 2500, excluding taxes. Learn more about Elsevier's pricing policy: http://www.elsevier.com/openaccesspricing.

\section{Language (usage and editing services)}

Please write your text in good English (American or British usage is accepted, but not a mixture of these). Authors who feel their English language manuscript may require editing to eliminate possible grammatical or spelling errors and to conform to correct scientific English may wish to use the English Language Editing service available from Elsevier's WebShop (http://webshop.elsevier.com/languageediting/) or visit our customer support site (http://support.elsevier.com) for more information. 


\section{Informed consent and patient details}

Studies on patients or volunteers require ethics committee approval and informed consent, which should be documented in the paper. Appropriate consents, permissions and releases must be obtained where an author wishes to include case details or other personal information or images of patients and any other individuals in an Elsevier publication. Written consents must be retained by the author and copies of the consents or evidence that such consents have been obtained must be provided to Elsevier on request. For more information, please review the Elsevier Policy on the Use of Images or Personal Information of Patients or other Individuals, http://www.elsevier.com/patient-consent-policy. Unless you have written permission from the patient (or, where applicable, the next of kin), the personal details of any patient included in any part of the article and in any supplementary materials (including all illustrations and videos) must be removed before submission.

\section{Submission}

Our online submission system guides you stepwise through the process of entering your article details and uploading your files. The system converts your article files to a single PDF file used in the peer-review process. Editable files (e.g., Word, LaTeX) are required to typeset your article for final publication. All correspondence, including notification of the Editor's decision and requests for revision, is sent by e-mail.

\section{Submit your article}

Please submit your article via http://ees.elsevier.com/hl/.

\section{PREPARATION}

Manuscript submissions should conform to the guidelines set forth in the "Uniform Requirements for Manuscripts Submitted to Biomedical Journals: Writing and Editing for Biomedical Publication," available from http://www.ICMJE.org. Please refer to http://www.consort-statement.org/consortstatement/ for CONSORT guidelines for clinical trials. The CONSORT Statement is intended to improve the reporting of a randomized controlled trial (RCT), enabling readers to understand a trial's design, conduct, analysis and interpretation, and to assess the validity of its results.

\section{Manuscript Components}

The manuscript should be arranged as follows: 1) title; 2) structured abstract and key words; 3 ) abbreviations list; 4) text; 5) references; 6) figure titles and legends; and 7) tables. Page numbering should begin with the first page.

Manuscript style should follow the AMA Style, 10th edition. Articles should be no more than 15 pages in length, not including title page, figures, tables, and references. Case studies should be no more than 10 pages in length. Author(s) name and credentials should be listed according to the AMA-10 recommendations.

Text

Manuscript text should be double-spaced, left-aligned (unjustified), and in a 12-point font. The body of text should be structured with the following headings: Introduction, Methods, Results, and Discussion. Sub-headings may be used as appropriate. Each reference, figure and table should be cited in the text in numerical order according to order of first mention.

\section{Double-blind review}

This journal uses double-blind review, which means that both the reviewer and author name(s) are not allowed to be revealed to one another for a manuscript under review. The identities of the authors are concealed from the reviewers, and vice versa. For more information please refer to http://www.elsevier.com/reviewers/peer-review. To facilitate this, please include the following separately:

Title page (with author details): This should include the title, authors' names and affiliations, and a complete address for the corresponding author including an e-mail address.

Blinded manuscript (no author details): The main body of the paper (including the references, figures, tables and any Acknowledgements) should not include any identifying information, such as the authors' names or affiliations.

\section{Use of word processing software}

It is important that the file be saved in the native format of the word processor used. The text should be in single-column format. Keep the layout of the text as simple as possible. Most formatting codes will be removed and replaced on processing the article. In particular, do not use the word 
processor's options to justify text or to hyphenate words. However, do use bold face, italics, subscripts, superscripts etc. When preparing tables, if you are using a table grid, use only one grid for each individual table and not a grid for each row. If no grid is used, use tabs, not spaces, to align columns. The electronic text should be prepared in a way very similar to that of conventional manuscripts (see also the Guide to Publishing with Elsevier: http://www.elsevier.com/guidepublication). Note that source files of figures, tables and text graphics will be required whether or not you embed your figures in the text. See also the section on Electronic artwork.

To avoid unnecessary errors you are strongly advised to use the 'spell-check' and 'grammar-check' functions of your word processor.

\section{Article structure}

Subdivision - unnumbered sections

Divide your article into clearly defined sections. Each subsection is given a brief heading. Each heading should appear on its own separate line. Subsections should be used as much as possible when crossreferencing text: refer to the subsection by heading as opposed to simply 'the text'.

\section{Introduction}

State the objectives of the work and provide an adequate background, avoiding a detailed literature survey or a summary of the results.

\section{Material and methods}

Provide sufficient detail to allow the work to be reproduced. Methods already published should be indicated by a reference: only relevant modifications should be described.

\section{Theory/calculation}

A Theory section should extend, not repeat, the background to the article already dealt with in the Introduction and lay the foundation for further work. In contrast, a Calculation section represents a practical development from a theoretical basis.

\section{Results}

Results should be clear and concise.

\section{Discussion}

This should explore the significance of the results of the work, not repeat them. A combined Results and Discussion section is often appropriate. Avoid extensive citations and discussion of published literature.

\section{Conclusions}

The main conclusions of the study may be presented in a short Conclusions section, which may stand alone or form a subsection of a Discussion or Results and Discussion section.

\section{Appendices}

If there is more than one appendix, they should be identified as $A, B$, etc. Formulae and equations in appendices should be given separate numbering: Eq. (A.1), Eq. (A.2), etc.; in a subsequent appendix, Eq. (B.1) and so on. Similarly for tables and figures: Table A.1; Fig. A.1, etc.

\section{Essential title page information}

- Title. Concise and informative. Titles are often used in information-retrieval systems. Avoid abbreviations and formulae where possible.

- Author names and affiliations. Please clearly indicate the given name(s) and family name(s) of each author and check that all names are accurately spelled. Present the authors' affiliation addresses (where the actual work was done) below the names. Indicate all affiliations with a lowercase superscript letter immediately after the author's name and in front of the appropriate address. Provide the full postal address of each affiliation, including the country name and, if available, the e-mail address of each author.

- Corresponding author. Clearly indicate who will handle correspondence at all stages of refereeing and publication, also post-publication. Ensure that the e-mail address is given and that contact details are kept up to date by the corresponding author.

- Present/permanent address. If an author has moved since the work described in the article was done, or was visiting at the time, a 'Present address' (or 'Permanent address') may be indicated as a footnote to that author's name. The address at which the author actually did the work must be retained as the main, affiliation address. Superscript Arabic numerals are used for such footnotes. 


\section{Abstract}

Provide a structured abstract of no more than 150 words, essential data should be presented in 5 paragraphs under separate headings in the following order: Objectives, Background, Methods, Results, and Conclusions. A non-structured abstract is appropriate for review articles.

\section{Highlights}

Highlights are a short collection of bullet points that convey the core findings of the article. Highlights are optional and should be submitted in a separate editable file in the online submission system. Please use 'Highlights' in the file name and include 3 to 5 bullet points (maximum 85 characters, including spaces, per bullet point). See http://www. elsevier.com/highlights for examples.

\section{Keywords}

Immediately after the abstract, provide a maximum of 6 keywords, using American spelling and avoiding general and plural terms and multiple concepts (avoid, for example, 'and', 'of'). Be sparing with abbreviations: only abbreviations firmly established in the field may be eligible. These keywords will be used for indexing purposes.

\section{Abbreviations}

Define abbreviations that are not standard in this field in a footnote to be placed on the first page of the article. Such abbreviations that are unavoidable in the abstract must be defined at their first mention there, as well as in the footnote. Ensure consistency of abbreviations throughout the article.

\section{Acknowledgments}

Include acknowledgments on the title page. List here those individuals who provided help during the research (e.g., providing language help, writing assistance or proof reading the article, etc.).

\section{Units}

Follow internationally accepted rules and conventions: use the international system of units (SI). If other units are mentioned, please give their equivalent in SI.

\section{Math formulae}

Please submit math equations as editable text and not as images. Present simple formulae in line with normal text where possible and use the solidus $(/)$ instead of a horizontal line for small fractional terms, e.g., X/Y. In principle, variables are to be presented in italics. Powers of e are often more conveniently denoted by exp. Number consecutively any equations that have to be displayed separately from the text (if referred to explicitly in the text).

\section{Footnotes}

Footnotes should be used sparingly. Number them consecutively throughout the article. Many word processors can build footnotes into the text, and this feature may be used. Otherwise, please indicate the position of footnotes in the text and list the footnotes themselves separately at the end of the article. Do not include footnotes in the Reference list.

\section{Artwork}

Electronic artwork General points

- Make sure you use uniform lettering and sizing of your original artwork.

- Embed the used fonts if the application provides that option.

- Aim to use the following fonts in your illustrations: Arial, Courier, Times New Roman, Symbol, or use fonts that look similar.

- Number the illustrations according to their sequence in the text.

- Use a logical naming convention for your artwork files.

- Provide captions to illustrations separately.

- Size the illustrations close to the desired dimensions of the published version.

- Submit each illustration as a separate file.

A detailed guide on electronic artwork is available on our website:

http://www.elsevier.com/artworkinstructions.

\section{You are urged to visit this site; some excerpts from the detailed information are given here.}

\section{Formats}

If your electronic artwork is created in a Microsoft Office application (Word, PowerPoint, Excel) then please supply 'as is' in the native document format.

Regardless of the application used other than Microsoft Office, when your electronic artwork is finalized, please 'Save as' or convert the images to one of the following formats (note the resolution requirements for line drawings, halftones, and line/halftone combinations given below): 
EPS (or PDF): Vector drawings, embed all used fonts.

TIFF (or JPEG): Color or grayscale photographs (halftones), keep to a minimum of $300 \mathrm{dpi}$.

TIFF (or JPEG): Bitmapped (pure black \& white pixels) line drawings, keep to a minimum of $1000 \mathrm{dpi}$. TIFF (or JPEG): Combinations bitmapped line/half-tone (color or grayscale), keep to a minimum of $500 \mathrm{dpi}$.

\section{Please do not:}

- Supply files that are optimized for screen use (e.g., GIF, BMP, PICT, WPG); these typically have a low number of pixels and limited set of colors;

- Supply files that are too low in resolution;

- Submit graphics that are disproportionately large for the content.

Color artwork

Please make sure that artwork files are in an acceptable format (TIFF (or JPEG), EPS (or PDF), or MS Office files) and with the correct resolution. If, together with your accepted article, you submit usable color figures then Elsevier will ensure, at no additional charge, that these figures will appear in color online (e.g., ScienceDirect and other sites) regardless of whether or not these illustrations are reproduced in color in the printed version. For color reproduction in print, you will receive information regarding the costs from Elsevier after receipt of your accepted article. Please indicate your preference for color: in print or online only. For further information on the preparation of electronic artwork, please see http://www.elsevier.com/artworkinstructions.

Please note: Because of technical complications that can arise by converting color figures to 'gray scale' (for the printed version should you not opt for color in print) please submit in addition usable black and white versions of all the color illustrations.

\section{Illustration services}

Elsevier's WebShop (http://webshop.elsevier.com/illustrationservices) offers Illustration Services to authors preparing to submit a manuscript but concerned about the quality of the images accompanying their article. Elsevier's expert illustrators can produce scientific, technical and medicalstyle images, as well as a full range of charts, tables and graphs. Image 'polishing' is also available, where our illustrators take your image(s) and improve them to a professional standard. Please visit the website to find out more.

\section{Figure captions}

Ensure that each illustration has a caption. Supply captions separately, not attached to the figure. A caption should comprise a brief title (not on the figure itself) and a description of the illustration. Keep text in the illustrations themselves to a minimum but explain all symbols and abbreviations used.

\section{Tables}

Please submit tables as editable text and not as images. Tables can be placed either next to the relevant text in the article, or on separate page(s) at the end. Number tables consecutively in accordance with their appearance in the text and place any table notes below the table body. Be sparing in the use of tables and ensure that the data presented in them do not duplicate results described elsewhere in the article. Please avoid using vertical rules.

\section{References}

Citation in text

Please ensure that every reference cited in the text is also present in the reference list (and vice versa). Any references cited in the abstract must be given in full. Unpublished results and personal communications are not recommended in the reference list, but may be mentioned in the text. If these references are included in the reference list they should follow the standard reference style of the journal and should include a substitution of the publication date with either 'Unpublished results' or 'Personal communication'. Citation of a reference as 'in press' implies that the item has been accepted for publication.

\section{Reference links}

Increased discoverability of research and high quality peer review are ensured by online links to the sources cited. In order to allow us to create links to abstracting and indexing services, such as Scopus, CrossRef and PubMed, please ensure that data provided in the references are correct. Please note that incorrect surnames, journal/book titles, publication year and pagination may prevent link creation. When copying references, please be careful as they may already contain errors. Use of the DOI is encouraged. 


\section{Web references}

As a minimum, the full URL should be given and the date when the reference was last accessed. Any further information, if known (DOI, author names, dates, reference to a source publication, etc.), should also be given. Web references can be listed separately (e.g., after the reference list) under a different heading if desired, or can be included in the reference list.

References in a special issue

Please ensure that the words 'this issue' are added to any references in the list (and any citations in the text) to other articles in the same Special Issue.

\section{Reference management software}

Most Elsevier journals have a standard template available in key reference management packages. This covers packages using the Citation Style Language, such as Mendeley (http://www.mendeley.com/features/reference-manager) and also others like EndNote (http://www.endnote.com/support/enstyles.asp) and Reference Manager (http://refman.com/support/rmstyles.asp). Using plug-ins to word processing packages which are available from the above sites, authors only need to select the appropriate journal template when preparing their article and the list of references and citations to these will be formatted according to the journal style as described in this Guide. The process of including templates in these packages is constantly ongoing. If the journal you are looking for does not have a template available yet, please see the list of sample references and citations provided in this Guide to help you format these according to the journal style.

If you manage your research with Mendeley Desktop, you can easily install the reference style for this journal by clicking the link below:

http://open.mendeley.com/use-citation-style/heart-and-lung-the-journal-of-acute-and-critical-care When preparing your manuscript, you will then be able to select this style using the Mendeley plugins for Microsoft Word or LibreOffice. For more information about the Citation Style Language, visit http://citationstyles.org.

\section{Reference formatting}

There are no strict requirements on reference formatting at submission. References can be in any style or format as long as the style is consistent. Where applicable, author(s) name(s), journal title/book title, chapter title/article title, year of publication, volume number/book chapter and the pagination must be present. Use of DOI is highly encouraged. The reference style used by the journal will be applied to the accepted article by Elsevier at the proof stage. Note that missing data will be highlighted at proof stage for the author to correct. If you do wish to format the references yourself they should be arranged according to the following examples:

\section{Reference style}

Text: Indicate references by (consecutive) superscript arabic numerals in the order in which they appear in the text. The numerals are to be used outside periods and commas, inside colons and semicolons. For further detail and examples you are referred to the AMA Manual of Style, A Guide for Authors and Editors, Tenth Edition, ISBN 0-978-0-19-517633-9 (see http://www.amamanualofstyle.com).

List: Number the references in the list in the order in which they appear in the text.

Examples:

Reference to a journal publication:

1. Van der Geer J, Hanraads JAJ, Lupton RA. The art of writing a scientific article. J Sci Commun. 2010;163:51-59.

Reference to a book:

2. Strunk W Jr, White EB. The Elements of Style. 4th ed. New York, NY: Longman; 2000.

Reference to a chapter in an edited book:

3. Mettam GR, Adams LB. How to prepare an electronic version of your article. In: Jones BS, Smith RZ, eds. Introduction to the Electronic Age. New York, NY: E-Publishing Inc; 2009:281-304.

\section{Journal abbreviations source}

Journal names should be abbreviated according to the List of Title Word Abbreviations: http://www.issn.org/services/online-services/access-to-the-Itwa/.

\section{Video data}

Elsevier accepts video material and animation sequences to support and enhance your scientific research. Authors who have video or animation files that they wish to submit with their article are strongly encouraged to include links to these within the body of the article. This can be done in the 
same way as a figure or table by referring to the video or animation content and noting in the body text where it should be placed. All submitted files should be properly labeled so that they directly relate to the video file's content. In order to ensure that your video or animation material is directly usable, please provide the files in one of our recommended file formats with a preferred maximum size of $150 \mathrm{MB}$. Video and animation files supplied will be published online in the electronic version of your article in Elsevier Web products, including ScienceDirect: http://www.sciencedirect.com. Please supply 'stills' with your files: you can choose any frame from the video or animation or make a separate image. These will be used instead of standard icons and will personalize the link to your video data. For more detailed instructions please visit our video instruction pages at http://www.elsevier.com/artworkinstructions. Note: since video and animation cannot be embedded in the print version of the journal, please provide text for both the electronic and the print version for the portions of the article that refer to this content.

\section{Audioslides}

The journal encourages authors to create an AudioSlides presentation with their published article. AudioSlides are brief, webinar-style presentations that are shown next to the online article on ScienceDirect. This gives authors the opportunity to summarize their research in their own words and to help readers understand what the paper is about. More information and examples are available at http://www.elsevier.com/audioslides. Authors of this journal will automatically receive an invitation e-mail to create an AudioSlides presentation after acceptance of their paper.

\section{Supplementary material}

Elsevier accepts electronic supplementary material to support and enhance your scientific research. Supplementary files offer the author additional possibilities to publish supporting applications, highresolution images, background datasets, sound clips and more. Supplementary files supplied will be published online alongside the electronic version of your article in Elsevier Web products, including ScienceDirect: http://www.sciencedirect.com. In order to ensure that your submitted material is directly usable, please provide the data in one of our recommended file formats. Authors should submit the material in electronic format together with the article and supply a concise and descriptive caption for each file. For more detailed instructions please visit our artwork instruction pages at http://www.elsevier.com/artworkinstructions.

\section{Submission checklist}

The following list will be useful during the final checking of an article prior to sending it to the journal for review. Please consult this Guide for Authors for further details of any item.

\section{Ensure that the following items are present:}

One author has been designated as the corresponding author with contact details:

- E-mail address

- Full postal address

All necessary files have been uploaded, and contain:

- Keywords

- All figure captions

- All tables (including title, description, footnotes)

Further considerations

- Manuscript has been 'spell-checked' and 'grammar-checked'

- References are in the correct format for this journal

- All references mentioned in the Reference list are cited in the text, and vice versa

- Permission has been obtained for use of copyrighted material from other sources (including the Internet)

Printed version of figures (if applicable) in color or black-and-white

- Indicate clearly whether or not color or black-and-white in print is required.

- For reproduction in black-and-white, please supply black-and-white versions of the figures for printing purposes.

For any further information please visit our customer support site at http://support.elsevier.com.

\section{AFTER ACCEPTANCE}

\section{Use of the Digital Object Identifier}

The Digital Object Identifier (DOI) may be used to cite and link to electronic documents. The DOI consists of a unique alpha-numeric character string which is assigned to a document by the publisher upon the initial electronic publication. The assigned DOI never changes. Therefore, it is an ideal 
medium for citing a document, particularly 'Articles in press' because they have not yet received their full bibliographic information. Example of a correctly given DOI (in URL format; here an article in the journal Physics Letters B):

http://dx.doi.org/10.1016/j.physletb.2010.09.059

When you use a DOI to create links to documents on the web, the DOIs are guaranteed never to change.

\section{Online proof correction}

Corresponding authors will receive an e-mail with a link to our online proofing system, allowing annotation and correction of proofs online. The environment is similar to MS Word: in addition to editing text, you can also comment on figures/tables and answer questions from the Copy Editor. Web-based proofing provides a faster and less error-prone process by allowing you to directly type your corrections, eliminating the potential introduction of errors.

If preferred, you can still choose to annotate and upload your edits on the PDF version. All instructions for proofing will be given in the e-mail we send to authors, including alternative methods to the online version and PDF.

We will do everything possible to get your article published quickly and accurately. Please use this proof only for checking the typesetting, editing, completeness and correctness of the text, tables and figures. Significant changes to the article as accepted for publication will only be considered at this stage with permission from the Editor. It is important to ensure that all corrections are sent back to us in one communication. Please check carefully before replying, as inclusion of any subsequent corrections cannot be guaranteed. Proofreading is solely your responsibility.

\section{AUTHOR INQUIRIES}

You can track your submitted article at http://help.elsevier.com/app/answers/detail/a_id/89/p/8045/. You can track your accepted article at http://www.elsevier.com/trackarticle. You are also welcome to contact Customer Support via http://support.elsevier.com. 
Appendix I

Draft Manuscript 
30-day Heart Failure Readmission: Patients' Perspectives in a mid-Atlantic Medical Center Authors:

Mee Young Sowa, DNP, RN, ACNS-BC, CHFN

Arlene Keeling, PhD, RN, FAAN

Catherine Kane, PhD, RN, FAAN

Juanita Reigle, MSN, ACNP-BC

Craig Thomas, MSN, ACNP-BC

Correspondence:

Mee Young Sowa, DNP, RN, ACNS-BC, CHFN

Assistant Professor of Nursing

Piedmont College, Demorest, GA 30535

mys7m@virginia.edu

Acknowledgements: None

Number of Tables and Figures: 3 


\begin{abstract}
Background: Heart Failure (HF) readmission is complicated and influenced by multiple factors. Few studies have directly investigated patients' perspectives regarding reasons for HF readmission. Objective: The purpose of this descriptive qualitative study was to examine the experiences of persons who were readmitted to the mid-Atlantic medical center for all causes within 30 days of discharge from the initial hospitalization with HF. Methods: A descriptive qualitative study was conducted. Nine HF patients over 50 years of age were recruited to complete a semi-structured interview. The participants described the reasons they believe they were readmitted; and, they shared their insight into how they believe they could have prevented readmission. A review of the medical record was performed to collect demographic, clinical, diagnostic, and post discharge activity. The interview utilized five open-ended questions on etiology, self-care, and decision-making on seeking care, education/treatment, and input for prevention. Results: Several themes emerged: inevitable or unavoidable readmission due to the severity of the condition; optimal self-care adherence; symptom monitoring and taking action with family and provider's support; heart failure readmission decision appreciated as a shared result of well-coordinated transitional care; appreciation on evidence based programs; and patient satisfaction regarding self-care teaching. Conclusion: The readmission trend reflected the challenges from the patients' severity of condition and population characteristics that are faced by an academic teaching hospital. The readmission experienced by study participants exemplified the high quality of inpatient care and seamless transitional care, although their readmissions were not prevented.
\end{abstract}

Keywords: readmissions, heart failure, qualitative research, patient perspectives, transitional care 


\section{INTRODUCTION}

Heart failure (HF) is a clinical syndrome characterized by the impaired cardiac pump function either with a problem of left ventricular filling or ejection. Heart Failure (HF) readmission has become a quality metric measure in $\mathrm{HF}$ research.${ }^{1}$ Readmission rates at 30 days following HF are about $25 \%$ among Medicare beneficiaries. ${ }^{2}$ This descriptive qualitative study examined the perspectives of persons who were readmitted to an academic medical center for all causes within 30 days of discharge from the initial hospitalization with HF. By understanding these perspectives, clinicians can identify effective interventional strategies for reducing HF readmission.

\section{BACKGROUND}

Currently, HF affects 6.5 million people in the United States, and the impact of HF will continue to expand with aging of the U.S. population. ${ }^{3}$ By 2030 , more than 8 million people ( 1 in 33) will be diagnosed with HF. In addition, the total annual direct medical cost for HF will increase from $\$ 21$ billion today to $\$ 53$ billion by $2030 .^{3}$ Avoiding HF patients' readmissions will reduce the financial burden on both patients and payers.

HF hospitalization has become a focal point for quality improvement, ${ }^{4,5,6}$ and reducing readmission is a key policy initiative embedded in the Patient Protection and Affordable Care Act. ${ }^{7}$ However, the causes of HF readmission are not well-understood. ${ }^{8}$ Preventing avoidable rehospitalization by implementing effective prevention strategies can be accomplished through identifying the factors that contribute to this phenomenon. Most hospitals reduce readmissions through quality improvement teams that implement evidence based practices. ${ }^{5}$

However, HF readmission is still an understudied phenomenon despite recent public attention. There is a gap in research and practice. Most HF risk prediction models based on the 
results of quantitative studies perform poorly. ${ }^{9,10}$ The research evidence on interventional strategies in reducing HF readmission is still weak. ${ }^{11}$ In evaluating why the patient is readmitted to the hospital, researchers and clinicians must collaborate and include the patients' viewpoints.

\section{Research Questions}

The following questions were addressed in this study:

1. What factors are identified by HF patients (and their caregivers) that contribute to readmission following inpatient treatment for HF?

2. What barriers and potential causes for readmission can be identified in the patients' medical records?

To answer the research questions, a qualitative study based on in-depth patient interviews and medical record review was conducted at a mid-Atlantic medical center.

\section{METHOD}

HF readmission is complicated and influenced by multiple factors. ${ }^{8}$ Few studies have directly investigated patients' experiences of readmission and living with HF. This qualitative descriptive design with phenomenological framework identified the reasons for HF readmissions from the patients' perspectives. Phenomenology can identify the essence of a phenomenon and what it means to those experiencing it. ${ }^{12,13}$

\section{Participants and Settings}

A purposive, convenience sample was recruited from the target population of patients who were readmitted to inpatient units at an academic medical center in the Mid-Atlantic. In 2014, this facility had 28,274 admissions and 58,544 emergency room visits. The average daily inpatient census of this facility was 446 and the average length of stay was 5.75. Patients discharged with a primary discharge diagnosis for HF who were readmitted for any cause within 
the subsequent 30 days were eligible for the study. Patients were excluded if they were under the age of 50 years, non-English speaking, cognitively impaired, readmitted from nursing homes, or with left ventricular assist device (LVAD), post heart transplant, trauma.

Sample size was guided by the ongoing data analysis. Data saturation was reached from 9 participant's view of their heart failure readmission. The patients' perspectives were clear and revealed patterns. No new themes were generated from interviews. ${ }^{14,15}$

Eligible patients were approached, consented, and interviewed from May through August 2014. This study was reviewed and approved by the University of Virginia Health Sciences Research Board (HSR \#17345). The study protocol was followed and no adverse effects occurred.

\section{Data Collection}

The conceptual framework developed by the principal investigator guided the interview, chart review, and analysis (see Figure 1). Donabedian's Medical Process, ${ }^{16}$ Health Belief, ${ }^{17}$ HF Trajectory, ${ }^{18}$ and the Explanatory ${ }^{19,20}$ models were integrated into the conceptual framework of Heart Failure Readmission. This framework allows clinicians to consider patients' socio-cultural perspectives in clinical encounters (e.g., inquiring about illness experience, coaching on self-care adherence, and decision-making process for service utilization behavior).

\section{Interviews}

The interview protocol was developed based on the literature review and consisted of five open-ended questions (online-only Data Supplement). The interview was conducted in the patient's room at a time chosen by the patient. The consenting participants were asked to complete a semi-structured 30 minute interview. Only on one occasion were caregivers (wife and daughter) present during the interview per the patient's request. The interview questions 
explored etiology and symptoms, decision-making for seeking care, self-care, education, treatment, and the patient's opinion for preventing readmission. The duration of the interviews ranged from 15 to 33 minutes. The interview was audiotaped with a MP3 player. Field notes were taken during or immediately after the interview in order to capture body language and facial expressions that were used to compare with transcriptions and support the interpretation during analysis.

\section{Chart Review}

The chart review guide was adapted from the STate Action on Avoidable Rehospitalizations (STAAR) initiative ${ }^{21}$ : many items were added based on the results of the literature review and the conceptual framework produced by the principal investigator (onlineonly Data Supplement). A detailed retrospective medical record review was conducted for each patient in the study to describe the characteristics of the participants (e.g., demographic, diagnostic, pre and post discharge activities). The chart review guide also served as a worksheet to collect data needed to reflect any missed opportunities for readmission: electronic medical records for both index and readmission periods were reviewed by the principal investigator.

\section{Analysis of Interviews}

The interviews were deidentified and transcribed by the principle investigator. Data collection began after the first interview and guided the future interviews. Transcripts were read line-by-line and coded to identify trends and patterns of the patient's perception and experience of HF readmission. Themes were identified and categories were placed into the themes. New concepts were identified from the data. The data analysis techniques used in this study were the Thematic Content Analysis ${ }^{22}$ method and coding methods suggested by qualitative experts. ${ }^{23}$ After the first round of descriptive coding, theoretical coding informed by the conceptual 
framework developed for this study was performed. The result affirmed the categories and themes that emerged from the initial descriptive coding. Then, in order to increase the analytic rigor, additional coding methods (e.g., value and versus coding) ${ }^{23}$ were utilized. The investigator answered this study's research questions by capturing the meaning, different perspectives on the data, and processes of the multifactorial phenomenon under investigation. As the analysis progressed, experts in heart failure served to confirm the identification of themes.

Trustworthiness of the data was ensured by maintaining a coding manual (field notes and analytic memo). Triangulation of themes was achieved between the patients' perceptions (interview analysis) and the providers' perceptions (medical record review).

\section{Analysis of Chart Review}

Data from the chart review were compared with the findings from the patient interview (e.g., outpatient and emergency visits between hospitalizations and any clinicians' remarks about reasons for readmission, care-coordination activities, etc.). The principal investigator read the notes by providers and wrote a reflected summary. The individual patient's case was reviewed by cases and phases (e.g., index, discharge, and follow-up periods) to analyze any missed opportunities to prevent readmission. ${ }^{24}$ During data analysis, the summary was revisited by the investigator to assess whether the readmission for each case was preventable.

\section{RESULTS}

The interviews consisted of 9 patients who met the criteria of the institutional review board approval: readmitted for all causes in 30 days of discharge from a mid-Atlantic medical center following an index admission for heart failure. There were 4 females and 3 African Americans; 1 was an immigrant. Days to readmission varied from 1 to 24 days. Patient ages ranged from 55 to 79 years with a mean score of 69.1. The LACE (Length of stay, Acuity, 
Charlson-co-morbid score, Emergency department visits) score ranged from 9 to 13 with a mean value of 10.7. Demographics of the participants can be found in Table 1. Participants were arranged on several transitional care interventions during their index stays: home health aide and home physical therapy, telemonitoring, and outpatient clinic-based care managed by nurse practitioners (see Table 1). On average, the participants were on at least two of the postdischarge interventions.

Several themes emerged from the preliminary analysis: inevitable or unavoidable readmission due to worsening of the disease process; optimal symptom monitoring and taking action with family and provider's support; heart failure readmission decision appreciated as a shared decision between patient, family and providers resulting from well-coordinated transitional care; appreciation of evidence based programs; and patient satisfaction regarding self-care teaching.

\section{Inevitable or Unavoidable Readmission ("I had to come back for symptom relief and further treatment.")}

When the participants were asked, "Why do you think you had to come back to the hospital?" most participants stated that the rehospitalization was inevitable or unavoidable due to the urgency of the symptoms aroused from the disease process of the heart failure or other chronic morbid condition or recurrent condition from the index hospitalization (quote 1, accompanying quotes can be found in Table 2). The most common symptoms cited by participants were palpitations, shortness of breath, and edema. One participant experienced chest pain from myocardial infarction (quote 2). All participants in this study reported that the severity of their condition, either from worsening of heart failure or other multiple comorbidities, was the primary reason for readmission. Both patients and providers perceived that readmission was 
inevitable or unavoidable due to worsening of their health status (either new or chronic disease condition).

\section{Patient Satisfaction with Education ("Coaching was good.")}

Most participants expressed satisfaction with the education provided to them and their family members by the health care providers during their index stays (quote 3). They also reported that self-care teaching continued in their homes, enhanced by home health and telemonitoring services. They felt served and secured by being continuously coached on how to monitor symptoms and take actions.

\section{Optimal Self-care Management ("I am doing my best at home")}

All participants except one reported adhering to a daily routine of monitoring and selfcare regimens recommended by providers: weight, blood pressure, oxygen saturation (by some patients), and swelling. They reported abnormal physical findings or symptoms to their providers. The majority of participants reported living on a limited income; however, they were attempting to do their best with HF self-care. All participants confirmed their priority was purchasing prescribed medications. Family members or patients loaded medication into their pill boxes. A female participant who lives alone stated that she usually ends up eating frozen, commercially-made dinners, because she had limited physical ability to move around in order to prepare food for herself (quote 4). A male immigrant from Africa, with limited English, explained how he tried to adhere to salt restriction and activity regimen even though he lives with pain in his legs (quote 5).

The majority of the participants reported doing their best to adhere to dietary restriction despite social, functional, or financial situations which limited their food selection. Most patients knew the limit and adhered to fluid restriction with support of family members. 
Seeking Care from Family and Providers ("They continued to monitor when I was back home").

All participants not only monitored their symptoms daily, but they also sought timely help when the symptoms became unmanageable at home. All of them tapped into family and providers' support to get consultation and took the actions recommended by the health care providers.

Seven out of 9 participants contacted their physician's office and followed the guidance (quote 6). All 9 participants' family members or home health aides were present at the time of symptom recognition. They all sought help from their health care providers (quote 2). Most participants believed that by following the clinicians' recommendations on self-care adherence, they could prevent coming back to the hospital (quote 9).

Satisfaction with Providers, Transitional Care, and Evidence Based Programs ("We did it together.")

The majority of the participants were supported by the evidence based HF programs. All participants expressed satisfaction toward the providers' coordinating and assisting the patients' readmission processes in order to treat the patients' conditions and provide them with symptom relief. Participants identified the continued coaching and monitoring of self-care management by their community as effective for taking action for rehospitalization (quotes 7 and 8). Patients felt that they were allowed to make decisions with family and providers as a team. Some patients conveyed their absolute belief in their providers' abilities in finding a solution to their health problems that had led them to readmission (quote 10).

Patient Suggestions for Improvement ("For future patients, I would..."). 
Participants pointed out four areas for improvement: desire to stay a little longer during index admission; learn more about the disease process; and include family members in decision making and discussions on sensitive end of life care issues.

\section{Desire to Stay Longer during Index Admission}

One third of participants opined that the readmission could have been avoidable if they stayed longer in the hospital during the index admission. The patients believed that providers could further research into other treatment options before discharging them to home (quote 11). Patients also felt that they could have learned more about the disease process if they could have stayed longer during the index hospitalization (quote 12).

\section{Desire to Learn More about the Disease Process}

Most participants in the current study were satisfied with the education offered by health care providers. However, some participants stated that they could have benefited from an explanation about their disease process during their index stay. One male participant, reporting that his liver and kidney were failing, complained that teaching and care-coordination was disjointed, and he suggested better coordination between disciplines (quote 12).

\section{Include Family Members in Decision making and Sensitive End of Life Care Issues}

Several patients recommended to include family members in the decision making process (quote 13). One female participant suggested that clinicians should be more sensitive with addressing end of life care issues. The investigator witnessed her frustrated feeling about being referred to palliative care (quote 14).

\section{Findings from Chart Review}

The Electronic Health Record review has not provided the investigator with any explicit evidence suggesting that health care providers missed any opportunities in terms of preventing 
readmission. Four patients were readmitted with recurrent conditions (recurrent fluid overload, infection, pleural effusion). Bacteremia was the main reason for readmission for an African American male who has no medical insurance.

All participants were served by the interdisciplinary discharge team to facilitate transitional care, and the majority was supported by evidence based interventions to reduce readmission. Some of the participants were seen by the heart failure navigator or by the inpatient heart failure nurse practitioner during the index stay. There was no documented evidence of using a health literacy screening tool or teach back method during the study period. Only one patient's discharge summary reported that the patient had bilateral crackles and a slight pitting lower extremity edema on the discharge day. Otherwise, clinicians' notes did not report any acute distress on the discharge date.

\section{DISCUSSION}

The purpose of this study was to explore HF patients' perspectives on why they believe they required a 30 day readmission to the mid-Atlantic medical center, and compare the patients' perspectives with the providers' perspectives through a medical record review, in order to identify any areas where patients, family members, and providers may have missed an opportunity to intervene. The study revealed that HF readmission is the interplay of many factors involving the patient, hospital, and health system. Evidence based collective interventions were highly effective in enhancing self-care management and patient experience. The trust and continuity of relationship that developed between the patients and clinicians during transitional care were translated as a positive experience for HF readmission. Further study is necessary to identify which collective intervention should be tailored to the individual patient based on their needs and perspective. 


\section{Causes of HF Readmission, Consequence of Multiple Interplays among Factors}

Both analyses of interviews and chart reviews revealed that the severity of the patient's condition, either from worsening of heart failure or other multiple comorbidities, was the primary reason for readmission. However, the root causes of HF readmission must be understood as an interplay of patient, hospital characteristics and health systems factors. Both patients and providers perceived that the readmission was inevitable or unavoidable due to worsening of their health status. This finding is consistent with previous studies. ${ }^{8,25,26}$ Half of the patients also implicated other comorbidities as directly or indirectly related to their readmission. This finding was also expected with others. ${ }^{8,25,27,28}$ Experts report that in their Commonwealth Fund analysis, safety-net hospitals are $30 \%$ more likely to have 30 -day hospital readmission rates above the national average, compared with other hospitals. ${ }^{28}$ In the current study, one male patient, whose underlying cause for repeated hospitalization could be from lack of dental treatment, exemplifies the issue of the population characteristics that an academic teaching serves.

\section{Effective Self-Care Management with Well-Coordinated Transitional Care Supports}

Symptom recognition is the hallmark of self-care management in persons with heart failure. ${ }^{30}$ Delay in seeking care is cited as reasons for rehospitalization or mortality for heart failure patients. ${ }^{25,26,31,32}$ In the current study, the participants' symptoms were optimally monitored with a group effort, and non-adherence to any medication or diet and fluid restriction was not reported as reasons for readmission. This finding is contrary to studies which have reported patients' non-adherence as the reasons for readmission. ${ }^{25,26,33}$ Self-Care coaching in relationship based technology application 
In our current study, the use of remote monitoring technology was embedded into the intervention package offered to participants: they were supported by individualized health coaches across health care settings.

An important finding in this study, reflected in a previous study, ${ }^{34}$ is that continuous monitoring and self-care coaching were key successful strategies. The participants felt safe because the coaches were connected during symptom monitoring, which led to rehospitalization. This continuous communication must be perceived as the source of patient satisfaction. Trust and continuity of relationship between the patient and clinicians must have developed, but this needs to be further researched. This investigator believes that intense human connectivity and the application of remote technology improved self-care management which led to positive patient experiences for transitional care and readmission.

\section{Patient-Centered Outcomes: Satisfaction on Evidence based Supportive Programs}

Readmission from any cause is perceived as an adverse event; however, participants in this study reported satisfaction and appreciation from support by providers, well-coordinated transitional care, and evidence based programs. Their satisfaction seemed to reflect their experience on the overall care they received across care settings. The participants in the current study were on several collective interventions. Most participants reported positive outcomes in terms of patient satisfaction and achieving health restoration. The coaching and optimization of therapies in the outpatient setting through the transitional care programs may highlight the most important aspects why the interventions were perceived as satisfactory by the participants. Another explanation for the participants' satisfaction may be the interpersonal transformation among patients and providers who had been involved in coaching (mainly telemonitoring nurse and home health aides) and continued adjustment of therapies by providers. It was a collective 
intervention approach consisting of home visiting, telemonitoring, and outpatient clinic-based care interventions. It was not surprising that this extraordinary transitional support was cited by participants as a source of satisfaction and appreciation.

The readmission trend in the current study may appear as if it is the result of wellcoordinated transitional care; this may be perplexing to the health care system and providers. However, this is consistent with previous findings where frequent monitoring of symptoms or access to providers is associated with a higher admission rate..$^{35,36,37,38,39}$

\section{Issue of collective interventions}

In the current study, the collective interventions were effective in optimizing self-care management and treatment of HF patients in the community. The interventions were successful because they not only empowered the patient with a decision making process of how to respond and react to their symptoms, but they also included family members in such decisions. ${ }^{40}$ However, all interventions may not be required for every patient. Evidence on the effectiveness of the collective interventions is still weak and inconclusive. Several studies report that collective interventions may be more effective than a single intervention in reducing readmission. . $^{5,1,41}$ Providing more services may not be the answer to decreasing rehospitalization rates in $\mathrm{HF}^{42}$

\section{Patient Recommendations for Improvement}

Similar to the findings from a previous study ${ }^{28}$ one third of participants reported that the readmission could be avoidable if the stay in the hospital was longer during index admission. They believed that the extra days enabled them to learn more about their condition, and providers could further research other treatment options. The patients' desire to learn about the disease process may differ in terms of their characteristics, role in their self-care, and comorbid conditions. Clinicians may have to provide patients with both specific and generic contents of 
symptom monitoring and an action plan, in order to cover all underlying health problems (e.g. symptoms of myocardial infarction, infection, how normal differs from abnormal), so that they can be well-prepared for future health crises. ${ }^{43}$ The comprehensive patient centered approaches may be more effective to reduce readmission than standard disease focused interventions. ${ }^{44,45}$

As a final discussion point, a 60 year old female participant focused on promoting provider sensitivity in initiating the end of life care talk with patients. She suggested that health care providers must demonstrate empathy and cultural competence in this sensitive topic and recommended to include family members in initiating the talk. Advance care planning could potentially reduce hospitalizations and improve end of life care, ${ }^{46}$ but health care providers require training on how to initiate this sensitive topic. Interprofessional education with some innovative teaching methods (e.g., role play and simulation) may be necessary for medical and nursing professionals to facilitate their comfort level in initiating this conversation.

\section{Summary}

Patients voiced satisfaction and appreciation about the care they received during index, community, and rehospitalization. Exacerbation of HF or chronic illness was the main reasons for readmission. The most important findings from this analysis are that the causes of HF readmission must be understood as an interplay of patient, hospital and health system factors. Patients' perceptions on rehospitalization were satisfactory, reflecting a positive post discharge experience from a result of well-coordinated transitional care. Both patient interviews and chart review revealed that patients' self-care management, providers' treatment, and care coordination were optimal. Patients felt empowered and appreciated with clinicians' support across health care settings. The mid-Atlantic medical center was successful in improving patients' experiences by utilizing evidence based supportive programs and bridging the gaps in communication. 
Further research is necessary to identify the cost effectiveness of these programs and tailor interventions based on patients' needs. The findings of this qualitative study suggest that the root causes for readmission may be solved only at the health system level. Readmission trends at the mid-Atlantic medical center exemplified the high quality of inpatient care and seamless transitional care.

\section{Strengths and Weaknesses of the Design}

This study utilized a conceptual framework to recognize the importance of patients' perspectives in order to better understand the complicated phenomenon of HF readmission. The chart review was conducted for triangulation of the findings from patients' interviews; however, interviews from families, providers, and observation (e.g., teaching, admission or discharge process) could have strengthened the trustworthiness of the findings.

Limitations of this study include small sample size, recruitment only within a single academic teaching hospital, and findings possibly not generalizable to other hospital settings. Another limitation is that the researcher was the sole interviewer and chart reviewer for this study, which may have led to a bias.

\section{Nursing Practice Implications: Integrating patient input into nursing process}

The findings of this qualitative study have several implications for nursing practice. The interview guide is simple and plausible for clinicians to replicate as a readmission interview instrument in order to tailor interventional strategies. The chart review may be useful for identifying whether clinicians missed any opportunities during the index stay and improving strategies to tailor interventions during the readmission period. The strengths of the interventions are including caregivers in the self-care management process, reinforcing coaching, and utilizing timely follow-up care in the community by tapping into both intensive human and technology 
applications. The identification of deteriorating conditions was ensued by continuous monitoring systems focusing on empowering interpersonal relationship. The optimization of therapy was achieved in the proactive care environment; thus, the care was perceived as satisfactory and positive by the patients.

The relevant findings of this study suggest the most important nursing practice toward a patient-centered approach: clinicians must listen to patients and their caregivers before mobilizing any evidence based interventional strategies to reduce HF readmission. Nurses are best positioned to listen to the patient's story. This study also suggests that clinicians require more practice on how to initiate conversation with patients and families for end of life care.

\section{Nursing Research Implications}

This mid-Atlantic university medical center was successful in improving patients' experiences by utilizing evidence based supportive programs and bridging the gaps in communication across care settings. It is necessary to further evaluate the cost effectiveness of collective interventions: the question of which patients, what interventions, and duration of interventions must be explored.

\section{Conclusion}

The readmission trend reflected the high risk patient population characteristics that the mid-Atlantic medical center served. The root causes for readmission can be solved at the health system level. Readmissions were perceived as an opportunity for both patients and clinicians to reflect and research into new avenues for improvement, although readmissions were not prevented. Readmission trends at the mid-Atlantic medical center did not implicate poor quality of care during the index stay. The participants' experiences exemplified the high quality of inpatient care and seamless transitional care. 


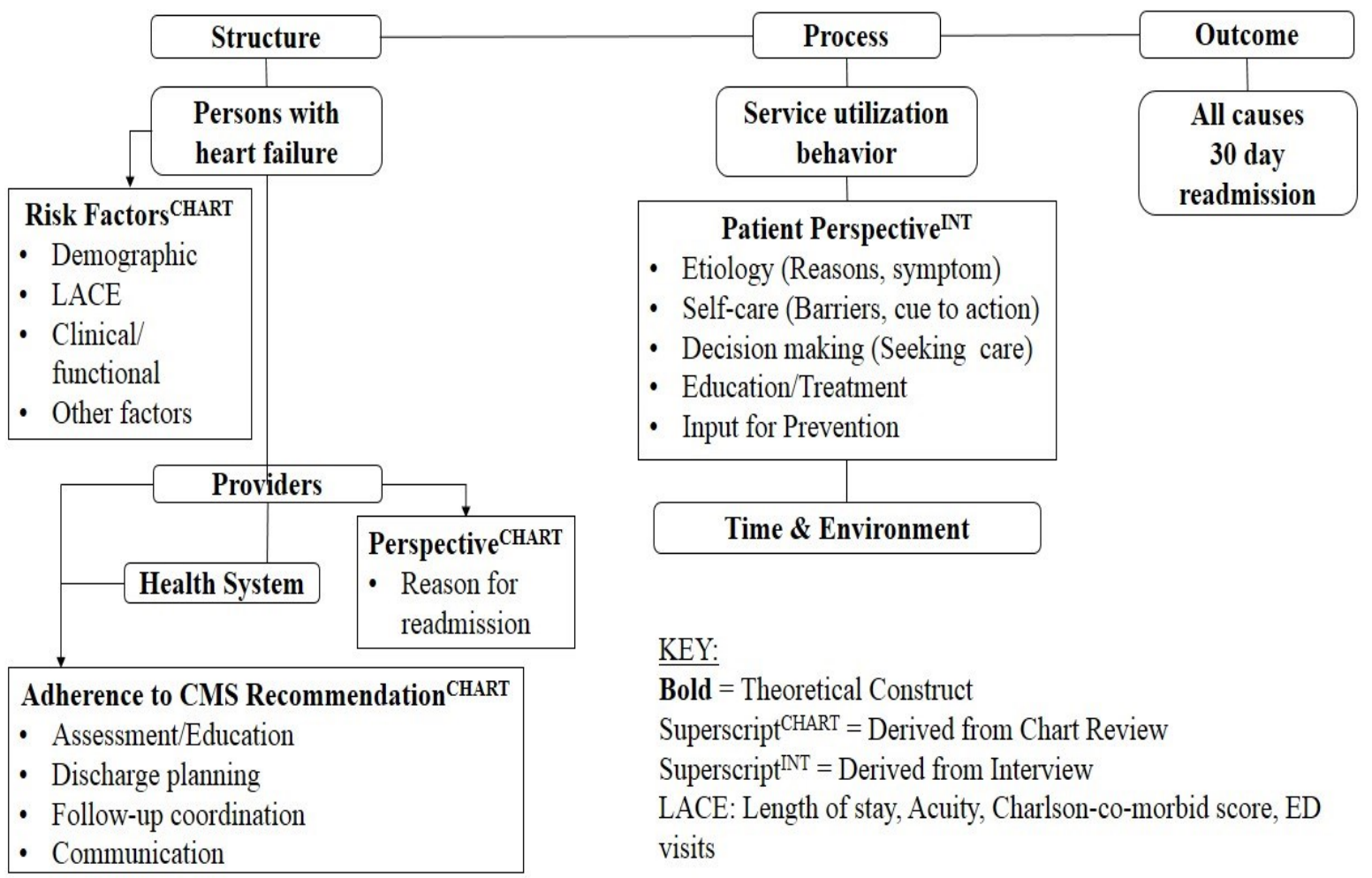

Figure 1. Conceptual model of factors influencing heart failure readmission Adapted from Donabedian, Explanatory Model, Health Belief Model, Heart Failure Trajectory Model 
$\underline{\text { Table1. Demographics and Medical Characteristics (N=9) }}$

$\begin{array}{ll}\text { Characteristics } & \text { Mean (Range) or Number (\%) } \\ \text { Age } & 69.1(55 \text { to } 79 \text { years) } \\ \text { Gender Male } & 5 \\ \quad \text { Female } & 4 \\ \text { Race White } \quad \text { African American } & 6 \\ \text { Immigrant Status } & 3 \\ \text { Days to readmission } & 1 \text { immigrant } \\ & \leq 7(\mathrm{n}=4) \\ & 8-14(\mathrm{n}=3) \\ & 15-24(\mathrm{n}=2)\end{array}$

Ejection Fraction

Reduced $(\mathrm{EF} \leq 40 \%) \quad 6$

Preserved $(\mathrm{EF}>40 \%) \quad 3$

LACE

10.7 (9 to 13$)$

Insurance

Medicare/Medicaid 7

Private 2

No Insurance 1

Programs Arranged during Index

$\mathrm{H} 2 \mathrm{H}$ (Hospital to Home) 6

3H (Heart Health at Home) 5

C3 (Care Coordination Centers) 5

PT (Physical Therapy) 3 
Table 2. Pertinent Quotes for Each Theme

\begin{tabular}{|c|c|}
\hline $\begin{array}{l}\text { Etiology: Unavoidable } \\
\text { readmission due to distressing } \\
\text { symptoms }\end{array}$ & $\begin{array}{l}\text { 1. Patient: "There just wasn't, yes...it was unforeseeable that my } \\
\text { heart would start racing... There was no way in the world to } \\
\text { prevent..." } \\
\text { 2. Patient: "...This time I had...it felt like...um...real sharp pains in } \\
\text { my chest, and I just knew I was having a heart attack..." }\end{array}$ \\
\hline Education- Patient Satisfaction & $\begin{array}{l}\text { 3. Patient: They are wonderful at explaining things to me. } \\
\text { What's happening, what could happen, what they're going to } \\
\text { do, and hopefully that it will work...They're pretty sure of } \\
\text { everything" }\end{array}$ \\
\hline $\begin{array}{l}\text { Self-care-adherence: doing their } \\
\text { best though living with limited } \\
\text { resources }\end{array}$ & $\begin{array}{l}\text { 4. Patient: "...because I can't stand up long enough to cook, so } \\
\text { I will have something in my refrigerator that I can put in a } \\
\text { microwave... I only get } \$ 52 \text { worth of food stamps a month... } \\
\text { So, I don't...it don't leave me much to try to put what the } \$ 52 \\
\text { can get things. So, I have to do what I can do. I mean, I have to } \\
\text { buy what my money can afford to buy..." } \\
\text { 5. Patient: "The nurse said I shouldn't touch salt, at all... So my } \\
\text { sister doesn't put salt on anything... I go walking around. In } \\
\text { the morning. Every morning..." }\end{array}$ \\
\hline $\begin{array}{l}\text { Seeking care-Optimal Seeking } \\
\text { Help with Family and } \\
\text { Provider's Support }\end{array}$ & $\begin{array}{l}\text { 6. Patient: "Wednesday, they discharged me. And then, } \\
\text { Thursday, I had to come back, because my heart started } \\
\text { racing... my family brought me. Well, uh, my daughter took } \\
\text { me to the heart doctor there.... I was there for a little while. } \\
\text { They did some blood work, and sent me on over here..." }\end{array}$ \\
\hline $\begin{array}{l}\text { Decision making experience- } \\
\text { Satisfaction and Appreciation } \\
\text { toward Support by Providers }\end{array}$ & $\begin{array}{l}\text { 7. Patient: "She was following me every hour on the hour to } \\
\text { watch my...vitals...and oxygen, because she was worried... } \\
\text { oxygen kept dropping lower and lower. And, we knew } \\
\text { something was wrong... she said if it dropped to a certain level, } \\
\text { call } 911 \text { and get transported..." } \\
\text { 8. Patient: "They call me about every day...If the doctor would } \\
\text { not call me, then it was the nurse who called me. I had } \\
\text { somebody call me every day" }\end{array}$ \\
\hline $\begin{array}{l}\text { Input for prevention } \\
\text { Belief in doctor }\end{array}$ & $\begin{array}{l}\text { 9. Patient: Please, listen to the doctor and their comments and } \\
\text { things. They know what they are doing. } \\
\text { 10. Patient: I always feel safer, and...so far, I know when I get } \\
\text { here, I am going to be well taken care of. And, if anything } \\
\text { crops up, they're going to fix, or help me in any way they can. } \\
\text { 11. Patient: "The doctor sent me home too early. If they had } \\
\text { not sent me home too early... I would not have had to come }\end{array}$ \\
\hline
\end{tabular}




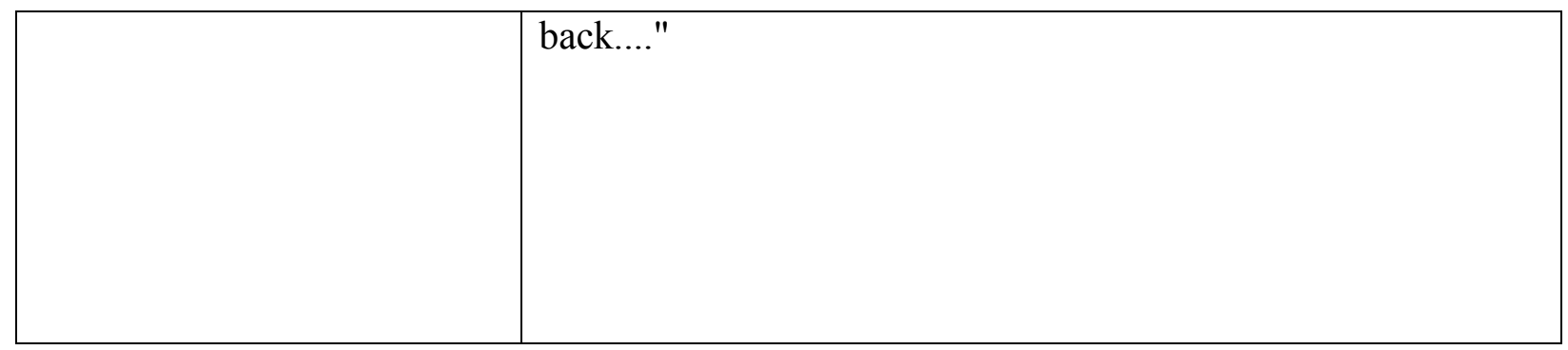

\begin{tabular}{|l|l|}
\hline $\begin{array}{l}\text { Room for Improvement } \\
\text { (continued) }\end{array}$ & $\begin{array}{l}\text { 12. Patient: "On the discharge date, well, I was optimistic; I } \\
\text { felt pretty good... I was cautiously optimistic that we were } \\
\text { moving in the right direction.... You need a better coordination } \\
\text { between the surgical team, your cardiac team, your discharge } \\
\text { team: it just gets a little disjointed...They needed to get a better } \\
\text { handle on my, um, you know, with congestive heart failure, } \\
\text { you have fluid problems, and, I have liver issues, and with that } \\
\text { you have liver problems. They just didn't get a proper handle } \\
\text { on what was going on before they sent me home" } \\
13 . \text { Patient: "I would suggest they try to make sure the family } \\
\text { is with me. That someone in my family } \\
\text { they want to talk about teaching or disease process" } \\
14 . \text { Patient: "They sent the palliative care people in here, and I } \\
\text { wasn't ready for that, too...They said that my daughter had } \\
\text { asked me, and I don't...but she had not asked me...It was a big } \\
\text { surprise. It was a shock to me. They came in. Well, } \\
\text { first of all, she put on an isolation gown, and I thought, well, } \\
\text { I'm not in isolation...And then she came in and said who she } \\
\text { was. And, I'm like, "Palliative care?" I knew what that meant, } \\
\text { you know" }\end{array}$ \\
\hline
\end{tabular}




\section{References}

1. Gheorghiade M, Vaduganathan M, Fonarow GC, Bonow RO. Rehospitalization for heart Failure Problems and perspectives. J Am Coll Cardiol. 2013;61(4):391-403.

2. Jencks SF, Williams MV, Coleman EA. Rehospitalizations among patients in the Medicare fee-for-service program. $N$ Engl J Med. 2009;360(14):1418-1428.

3. Heidenreich PA, Albert NM, Allen LA, et al. Forecasting the impact of heart failure in the united states A policy statement from the American Heart Association. Circulation: Heart Failure. 2013;6(3):606-619.

4. Boutwell AE, Johnson MB, Rutherford P, et al. An early look at a four-state initiative to reduce avoidable hospital readmissions. Health Aff. 2011;30(7):1272-1280.

5. Bradley EH, Curry L, Horwitz LI, et al. Contemporary evidence about hospital strategies for reducing 30-day Readmissions A national study. J Am Coll Cardiol. 2012;60(7):607-614. 6. Jack BW, Chetty VK, Anthony D, et al. A reengineered hospital discharge program to decrease Rehospitalization A randomized trial. Ann Intern Med. 2009;150(3):178-187. 7. Stephens C, Sackett N, Pierce R, et al. Transitional care challenges of rehospitalized veterans: Listening to patients and providers. Population health management. 2013.

8. Retrum JH, Boggs J, Hersh A, et al. Patient-identified factors related to heart failure readmissions. Circulation: Cardiovascular Quality and Outcomes. 2013;6(2):171-177. 9. Hersh AM, Masoudi FA, Allen LA. Postdischarge environment following heart failure hospitalization: Expanding the view of hospital readmission. Journal of the American Heart Association. 2013;2(2).

10. Kansagara D, Englander H, Salanitro A, et al. Risk prediction models for hospital readmission. JAMA: the journal of the American Medical Association. 2011;306(15):1688-1698. 
11. Hansen LO, Young RS, Hinami K, Leung A, Williams MV. Interventions to reduce 30-day rehospitalization: A systematic review. Ann Intern Med. 2011;155(8):520-528.

12. Creswell JW. Qualitative inquiry and research design: Choosing among five approaches. Sage; 2012.

13. Creswell JW. Research design: Qualitative, quantitative, and mixed methods approaches. Sage Publications, Incorporated; 2013.

14. Corbin J, Strauss A. Basics of qualitative research: Techniques and procedures for developing grounded theory. Sage publications; 2014.

15. Sandelowski M. Sample size in qualitative research. Res Nurs Health. 1995;18(2):179-183.

16. Donabedian A. Promoting quality through evaluating the process of patient care. Med Care. 1968;6(3):181-202.

17. Janz NK, Becker MH. The health belief model: A decade later. Health Education \& Behavior. 1984;11(1):1-47.

18. Granger BB, Sandelowski M, Tahshjain H, Swedberg K, Ekman I. A qualitative descriptive study of the work of adherence to a chronic heart failure regimen: Patient and physician perspectives. J Cardiovasc Nurs. 2009;24(4):308-315. doi: 10.1097/JCN.0b013e3181a4be30 [doi].

19. McSweeney JC, Allan JD, Mayo K. Exploring the use of explanatory models in nursing research and practice. Journal of Nursing Scholarship. 1997;29(3):243-248.

20. Kleinman A, Eisenberg L, Good B. Culture, illness, and care: Clinical lessons from anthropologic and cross-cultural research. FOCUS: The Journal of Lifelong Learning in Psychiatry. 2006;4(1):140-149. 
21. STAAR Initiative . The Diagnostic Assessment-Identifying Opportunities for Improvement. Retrieved from http://www.mhakeystonecenter.org/staar_extras/mi_staar_prework_ call_2_011011.pdf. Published February 1, 2011.Accessed July 09, 2013.

22. Green J, Thorogood N. Qualitative methods for health research. Sage; 2004.

23. Saldaña J. The coding manual for qualitative researchers. Sage; 2012.

24. Feigenbaum P, Neuwirth E, Trowbridge L, et al. Factors contributing to all-cause 30-day readmissions: A structured case series across 18 hospitals. Med Care. 2012;50(7):599-605. doi: 10.1097/MLR.0b013e318249ce72 [doi].

25. Annema C, Luttik M, Jaarsma T. Reasons for readmission in heart failure: Perspectives of patients, caregivers, cardiologists, and heart failure nurses. Heart \& Lung: The Journal of Acute and Critical Care. 2009;38(5):427-434.

26. Patel H, Shafazand M, Schaufelberger M, Ekman I. Reasons for seeking acute care in chronic heart failure. European journal of heart failure. 2007;9(6-7):702-708.

27. Islam T, O'Connell B, Lakhan P. Hospital readmission among older adults with congestive heart failure. Australian Health Review. 2013;37(3):362-368.

28. Kirk E, Prasad MK, Abdelhafiz AH. Hospital readmissions: Patient, carer and clinician views. Acute Med. 2006;5(3):104-107.

29. Berenson J, Shih A. Higher readmissions at safety-net hospitals and potential policy solutions. Issue Brief (Commonw Fund). 2012;34:1-16.

30. Riegel B, Dickson VV, Cameron J, et al. Symptom recognition in elders with heart failure. Journal of Nursing Scholarship. 2010;42(1):92-100.

31. Friedman MM, Quinn JR. Heart failure patients' time, symptoms, and actions before a hospital admission. J Cardiovasc Nurs. 2008;23(6):506-512. 
32. Jurgens CY, Hoke L, Byrnes J, Riegel B. Why do elders delay responding to heart failure symptoms? Nurs Res. 2009;58(4):274-282. doi: 10.1097/NNR.0b013e3181ac1581;

10.1097/NNR.0b013e3181ac1581.

33. Heo S, Lennie TA, Moser DK, Okoli C. Heart failure patients' perceptions on nutrition and dietary adherence. European Journal of Cardiovascular Nursing. 2009;8(5):323-328.

34. Jurgens CY, Lee CS, Reitano JM, Riegel B. Heart failure symptom monitoring and response training. Heart \& Lung: The Journal of Acute and Critical Care. 2013;42(4):273-280. doi: http://dx.doi.org/10.1016/j.hrtlng.2013.03.005.

35. Goldman LE, Sarkar U, Kessell E, et al. Support from hospital to home for elders. Ann Intern Med. 2014;161(7):472-481. doi: 10.7326/M14-0094.

36. Gorodeski EZ, Starling RC, Blackstone EH. Are all readmissions bad readmissions? N Engl J Med. 2010;363(3):297-298.

37. Herrin J, St Andre J, Kenward K, Joshi MS, Audet AJ, Hines SC. Community factors and hospital readmission rates. Health Serv Res. 2014.

38. Joynt KE, Jha AK. Who has higher readmission rates for heart failure, and why? implications for efforts to improve care using financial incentives. Circ Cardiovasc Qual Outcomes. 2011;4(1):53-59. doi: 10.1161/CIRCOUTCOMES.110.950964 [doi].

39. Kangovi S, Grande D, Meehan P, Mitra N, Shannon R, Long JA. Perceptions of readmitted patients on the transition from hospital to home. Journal of Hospital Medicine. 2012;7(9):709712.

40. Sethares KA, Sosa ME, Fisher P, Riegel B. Factors associated with delay in seeking care for acute decompensated heart failure. J Cardiovasc Nurs. 2014;29(5):429-438. doi: 10.1097/JCN.0b013e3182a37789 [doi]. 
41. Snyderman D, Salzman B, Mills G, Hersh L, Parks S. Strategies to help reduce hospital readmissions. J Fam Pract. 2014;63(8):430-438a. doi: jfp_6308e [pii].

42. Albert NM, Barnason S, Deswal A, et al. Transitions of care in heart failure: A scientific statement from the American heart association. Circ Heart Fail. 2015;8(2):384-409. doi:

10.1161/HHF.0000000000000006 [doi].

43. Slatyer S, Toye C, Popescu A, et al. Early re-presentation to hospital after discharge from an acute medical unit: Perspectives of older patients, their family caregivers and health professionals. J Clin Nurs. 2013;22(3):445-455. doi: 10.1111/jocn.12029.

44. Williams MV. A requirement to reduce readmissions: Take care of the patient, not just the disease. JAMA. 2013;309(4):394-396.

45. Scott IA, Shohag H, Ahmed M. Quality of care factors associated with unplanned readmissions of older medical patients: A case-control study. Intern Med J. 2014;44(2):161-170. doi: $10.1111 /$ imj.12334.

46. Brinkman-Stoppelenburg A, Rietjens JAC, van $\mathrm{dH}$. The effects of advance care planning on end-of-life care: A systematic review. Palliat Med. 2014;28(8):1000-1025. doi:

$10.1177 / 0269216314526272$. 